University of Louisville

ThinkIR: The University of Louisville's Institutional Repository

Electronic Theses and Dissertations

$12-2013$

\title{
The mediating effect of homework between self-regulated learning and science achievement.
}

Matthew D. Kingsley 1968-

University of Louisville

Follow this and additional works at: https://ir.library.louisville.edu/etd

\section{Recommended Citation}

Kingsley, Matthew D. 1968-, "The mediating effect of homework between self-regulated learning and science achievement." (2013). Electronic Theses and Dissertations. Paper 756.

https://doi.org/10.18297/etd/756

This Doctoral Dissertation is brought to you for free and open access by ThinkIR: The University of Louisville's Institutional Repository. It has been accepted for inclusion in Electronic Theses and Dissertations by an authorized administrator of ThinkIR: The University of Louisville's Institutional Repository. This title appears here courtesy of the author, who has retained all other copyrights. For more information, please contact thinkir@louisville.edu. 


\title{
THE MEDIATING EFFECT OF HOMEWORK BETWEEN SELF-REGULATED LEARNING AND SCIENCE ACHIEVEMENT
}

\author{
By \\ Matthew D. Kingsley \\ B.A. DePauw University, 1990 \\ B.S. Indiana University Southeast, 1996 \\ M.S. Indiana University Southeast, 2001

\begin{abstract}
A Dissertation
Submitted to the Faculty of the

College of Education and Human Development

In Partial Fulfillment of the Requirements

for the degree of
\end{abstract}

Doctor of Philosophy

Department of Leadership, Foundations and Human Resource Education University of Louisville Louisville, KY

December 2013 
Copyright 2013 by Matthew Douglas Kingsley

All rights reserved 



\title{
THE MEDIATING EFFECT OF HOMEWORK BETWEEN SELF-REGULATED LEARNING AND SCIENCE ACHIEVEMENT
}

\author{
By
}

Matthew D. Kingsley

B.A. DePauw University, 1990

B.S. Indiana University Southeast, 1996

M.S. Indiana University Southeast, 2001

\section{A Dissertation Approved on}

November 22, 2013

By the following Dissertation Committee:

Dr. Namok Choi, Dissertation Chairperson

Dr. W. Blake Haselton

Dr. Phyllis Connelly

Dr. Diane W. Kyle

Dr. Meera Alagaraja 


\title{
ABSTRACT \\ THE MEDIATING EFFECT OF HOMEWORK BETWEEN SELF-REGULATED LEARNING AND SCIENCE ACHIEVEMENT
}

\author{
Matthew D. Kingsley
}

December 19, 2013

Homework has been shown to have a significant, positive effect on student achievement and grades, particularly at the secondary level (Cooper, Robinson, \& Patall, 2006). However, homework completion and its effect on grades is controlled within the realm of the student and its success as a learning strategy depends on many things including the students' interest in the subject, their confidence, the time they have to complete it, gender and other factors within the home such as parent education level and parent involvement (Trautwein \& Ludtke, 2007; J. Xu, 2007; J. Xu, Corno, Lyn, 2006). Through the work of Eccles (2002) and Trautwein (2006), homework research has focused heavily on students' affective beliefs and their relevance. Expectancy-Value theory (Eccles, 2002) and self-efficacy theory (Bandura, 1997) identify student selfconfidence and valuation of the subject as integral components of academic motivation and Trautwein (2006) places them as antecedents to homework factors in his model of homework. However, causality among the variables has been unstudied and thus a method of analysis needed to be used that could confirm the placement of these variables in a causal sequence while at the same time demonstrate their importance to homework's relevance. 
It was the intent of this research to explore the causal relationship among the homework model factors of student positive affect towards science, student valuation of science, self-confidence in science, gender, parent education level, and self-confidence in science on science achievement in U.S. eighth-graders. With specific foci on those above variables involved indirectly in the relationship between gender, parent education level and time spent on homework, as well as the indirect effect of time spent on homework between the affective variables and achievement.

Results revealed a significant indirect effect of gender on time spent on homework, reflecting complete mediation, through the affective variables of student positive affect towards science, student valuation of science, self-confidence in science. On the other hand, the affective variables act as partial mediators between parent education level and time spent on homework as both the indirect and direct effects were significant. Indications here are that there may be other unknown variables at work that are not studied in the current research. In addition, time spent on homework was a significant mediating variable between all of the affective variables and achievement.

Conclusions and recommendations are made that homework does play a significant role in student achievement in science when the affective characteristics associated with self-regulatory learning are considered. Further research is recommended particularly involving better characterization of the homework construct. 


\section{TABLE OF CONTENTS}

PAGE

ACKNOWLEDGMENTS

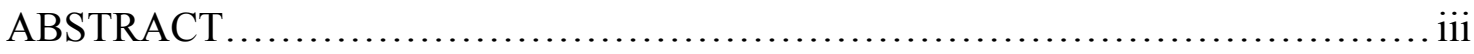

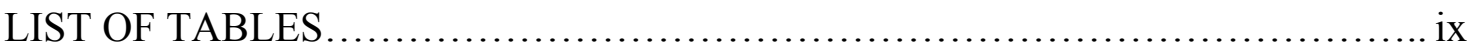

LIST OF FIGURES...........................................................

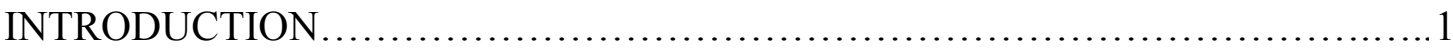

What Is Homework?...................................................... 3

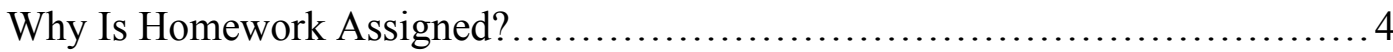

Academic Reasons....................................................4

Non-Academic Reasons................................................. 5

The Complex Nature of Homework..................................... 6

Homework Misconceptions.................................... 6

Homework Realities.................................................. 7

Previous Homework Research........................................... 9

Homework Motivation............................................. 12

Gender............................................................ 13

Parent Education Level............................................. 13

Why Science? .................................................... 14

Problem Statement...................................................... 14

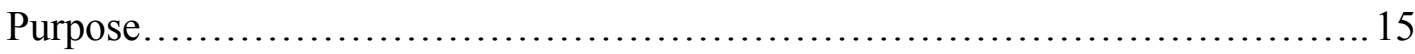

Significance....................................................... 16

Research Questions................................................. 16 
Limitations and Delimitations................................................ 17

Definitions..................................................................... 18

LITERATURE REVIEW .................................................. 20

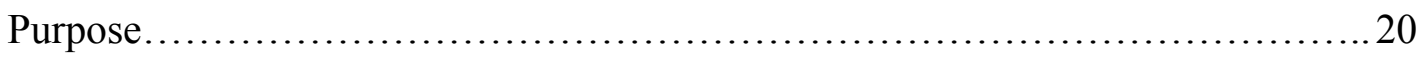

Theoretical Models..............................................................

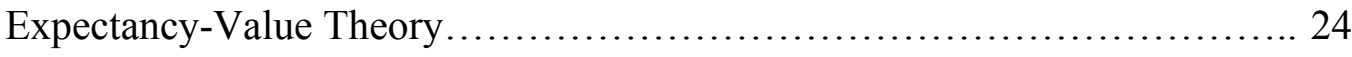

Trautwein's Homework Model........................................... 34

Self-efficacy Construct.................................................... 49

Additional Differences Between Self-Efficacy and Expectancy-Value Theories... 58

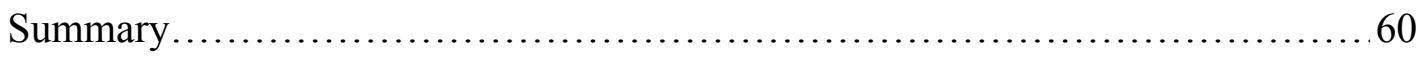

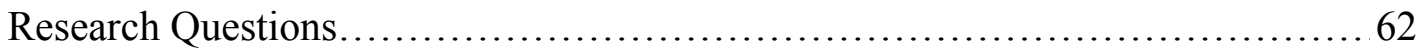

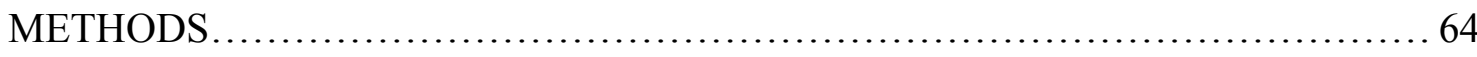

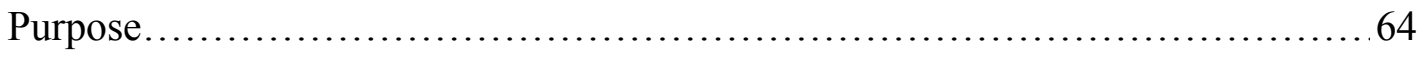

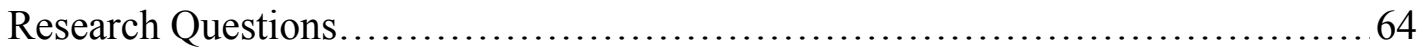

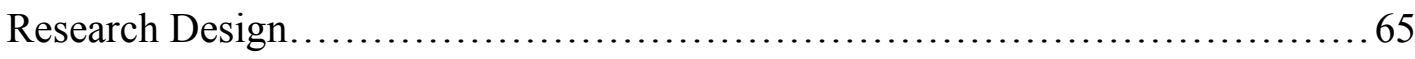

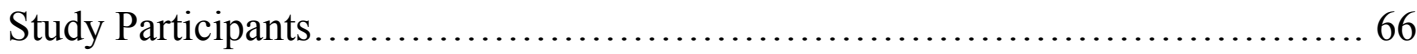

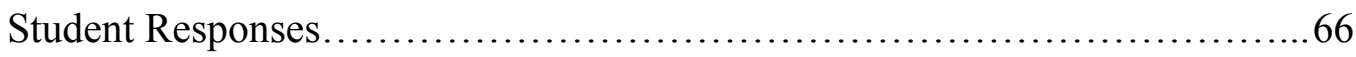

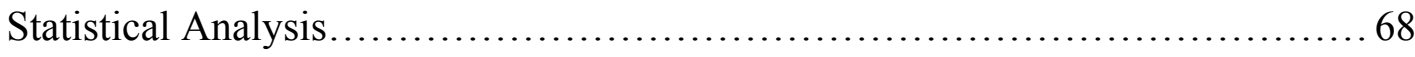

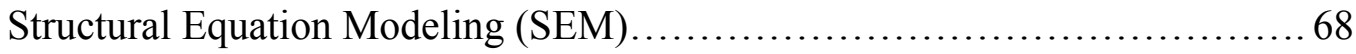

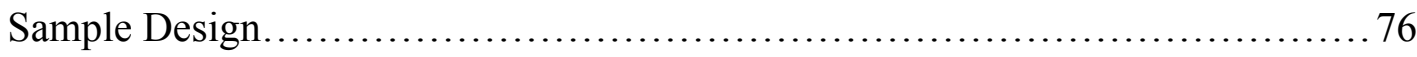

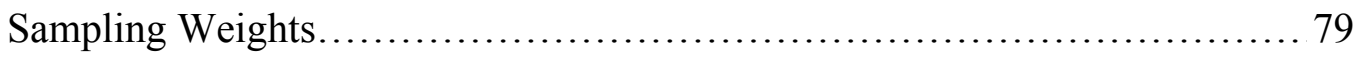

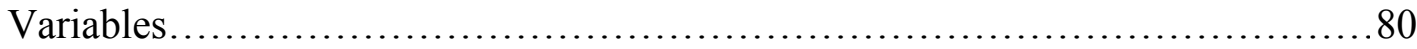

Effect (Dependent) Variable ............................................. 80

Causal (Independent) Variable ........................................... 81

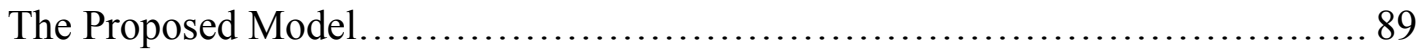

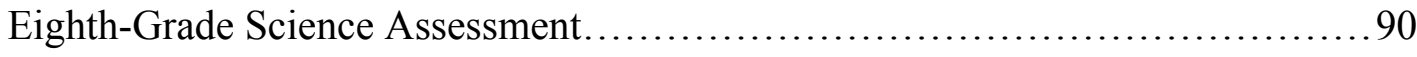

Assessment Construction.............................................. 91

Eighth-Grade Background Questionnaire .................................... 94 
Validity and Reliability .................................................. 96

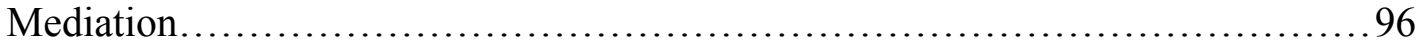

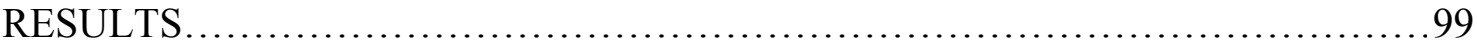

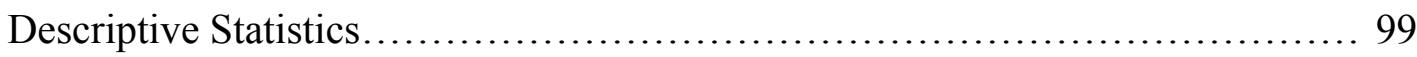

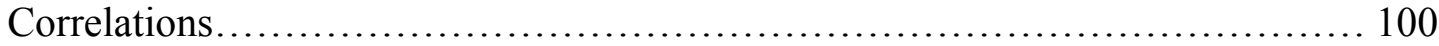

Confirmatory Factor Analysis (CFA): Measurement Model....................... 101

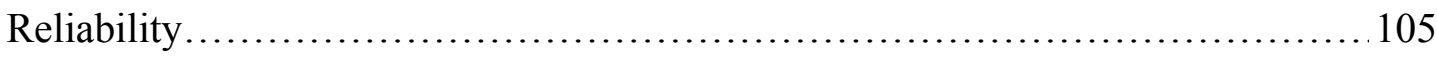

Structural Model......................................................... 108

Research Question 1................................................. 112

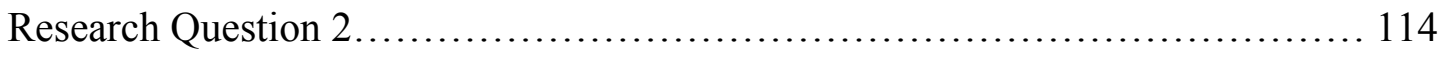

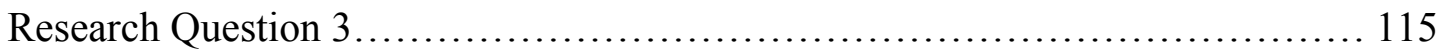

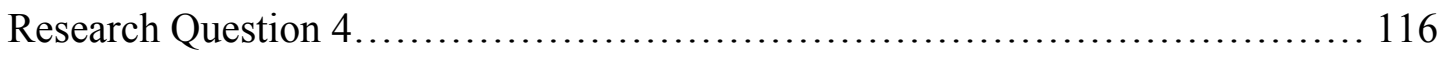

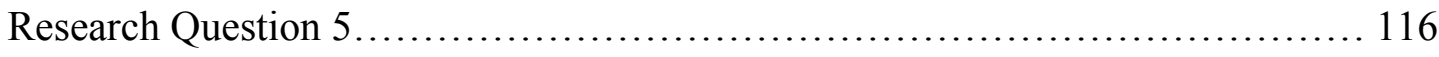

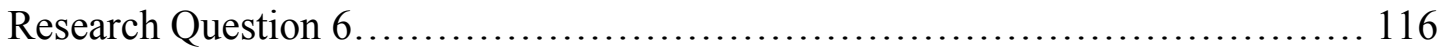

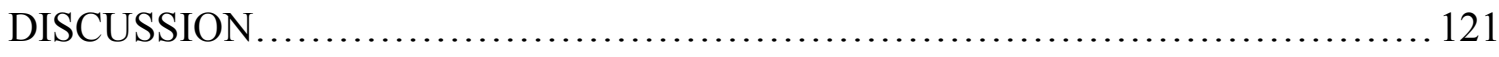

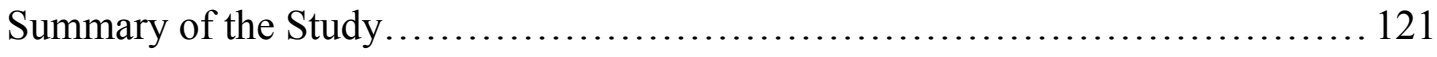

Affective Variables/Self-Regulatory Learning as Mediators......................123

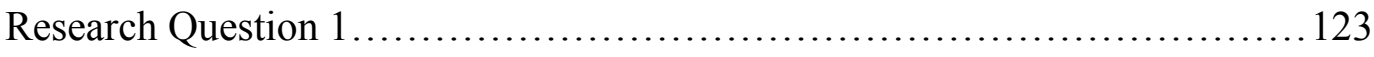

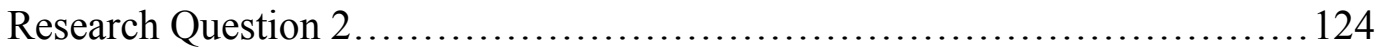

Research Question 3 ................................................ 126

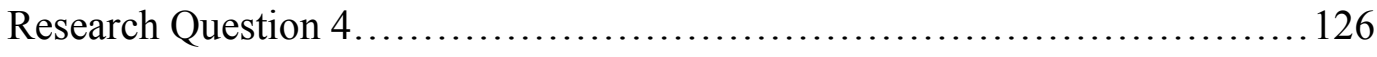

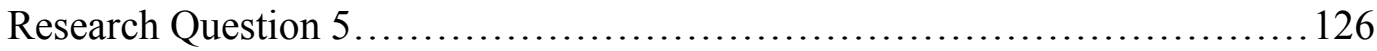

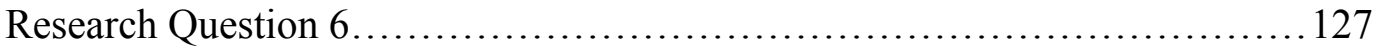

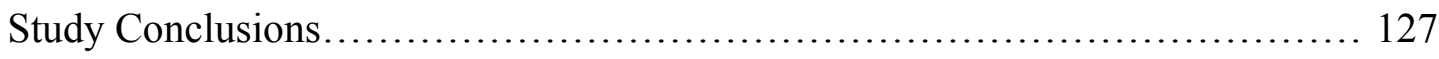

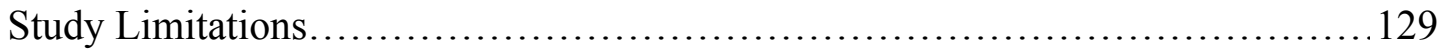

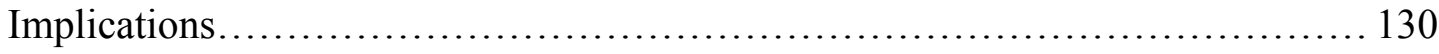

Recommendations........................................................ 131

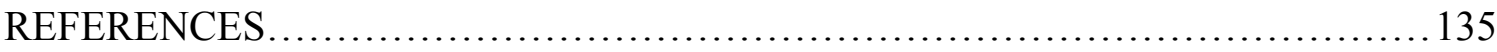




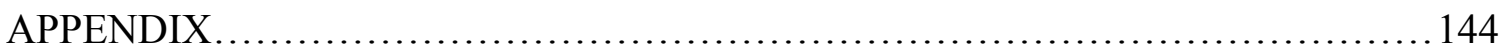

CURRICULUM VITAE........................................................ 146 


\section{LIST OF TABLES}

TABLE

PAGE

1. Summary of Evidence and Variable Relationships..........................61

2. Common SEM Terms and Their Definitions............................. 74

3. Summary Table of Variables and Rationales............................... 81

4. Pattern and Structure Coefficients, Means, and Standard Deviations for the 12 Items Loadings of Math Affective Variables................................ 86

5. Reliability of Student Attitudes Towards Math............................ 88

6. Target Percentages of the TIMSS 2007 Science Assessment Devoted to Content and Cognitive Domains in Eighth Grade.......................... 91

7. Topic Areas Included in the Science Content Domains of the TIMSS 2007 Eighth-Grade Science Assessment...................................... 92

8. Demographic Characteristics of the Exploratory and Validation Sets............ 100

9. Correlations and Significance (Two-Tailed) of the Major Variables in Validation Set.

10. Pattern and Structure Coefficients, Means, and Standard Deviations for the 12 Items. 103

11. Squared Multiple Correlations of Affective Variable Factors..................... 105

12. Values of Fit Indices for the Measurement Model............................ 107

13. Unstandardized Parameter Bootstrap Estimates with Significance Indicated..... 111

14. Phantom Model Disaggregated Indirect Effects (Unstandardized)............. 112

15. Goodness-Of-Fit Statistics for Tests of Gender Invariance on Measurement

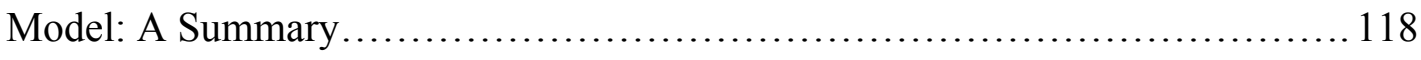

16. Summary of Full SEM Model of Gender Invariance......................... 119

17. Critical Ratios Between Parameters.................................... 120 


\section{LIST OF FIGURES}

FIGURE

PAGE

1. Basic theoretical structural model of homework's mediating effect between student affective variables and achievement................................... 21

2. Expectancy-value model of achievement motivation.......................... 25

3. Detail of expectancy-value model of achievement motivation...................27

4. Schematic depiction of the Trautwein homework model...........................35

5. Summary diagram of parent education level's connection to student affective characteristics, self-regulated learning, and homework........................60

6. Hypothesized structural and measurement models.............................73

7. Proposed model of the mediating effect of homework on achievement............89

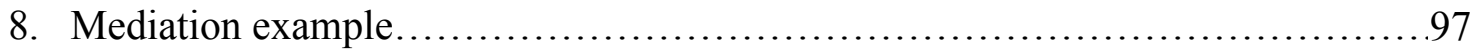

9. Finalized measurement model with standardized estimates.......................104

10. Simplified model with direct effects and significance.......................... 110

11. Phantom model construction for effects of gender on TSH.....................113

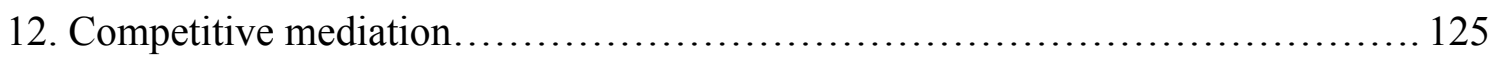




\section{CHAPTER 1}

\section{INTRODUCTION}

The history of homework in the United States is a tale of two extremes. As history and the events that mark its passing ebb and flow, so does the perceived importance of homework to the general public. Indeed, apart from standardized tests, homework, by its very public nature, is one of the most recognizable gauges of educational success or failure. Most parents, students, policy makers, and the general public believe that more homework means a better education (Gill \& Schlossman, 2003a, 2004).

Parent clashes with schools and teachers were common by 1860 (Kaestle, 1978). Parents were primarily upset with the discipline for misbehavior, but resentment was building over the academic practice of memorization and recitation which commanded larger amounts of time outside the school day (Gill \& Schlossman, 2004). However, by 1920, the progressive educational movement had taken hold in the U.S. and many school boards across the country had instituted policies to drastically reduce homework or ban it completely, especially in the lower grades, 1-8, because many parents were concerned about their children's health (Gill \& Schlossman, 2004).

The homework debate took a drastic turn in the 1950's when a strong academic excellence movement, by 1957, eventually killed the progressive movement (Gill \& Schlossman, 2004). The proponents of academic excellence called for increased rigor 
rejecting the main tenets of progressivism; experimental instruction, child-centered learning, and little or no homework. They wanted a more rigorous curriculum based on the core disciplines (Gill \& Schlossman, 2003a). These changes were paramount to combat the perceived Soviet superiority in technology and military sciences during the cold war (Gill \& Schlossman, 2004). With the launching of Sputnik in 1957, the new movement heard its clarion call. Now, Americans were driven to excel like no other time in history. The paranoid and frightening prospect of communists in space, who could watch our every move or worse, attack, was inconceivable. The National Defense Education Act of 1958 gave the federal government a bigger role in education and placed a large focus on science and math education.

The 1970's saw a sharp decline in the amount of time students spent on homework. This was due to the lessening importance of education on the national scene caused by the ascending importance of the Vietnam War and the civil rights movement (Gill \& Schlossman, 2004). But in 1983, A Nation at Risk was published in which President Ronald Reagan's National Commission on Excellence in Education used a myriad of data to declare that, “...the educational foundations of our society are presently being eroded by a rising tide of mediocrity that threatens our very future as a Nation and a people" (Harvey, 1983). This landmark report initiated a new era of school reform in which homework played a prominent role. In fact, the first statement in Recommendation C: Time, stated that students in high school should be assigned much more homework than they currently had (Harvey, 1983). Yet the overall trend in amount of time spent on homework has not changed dramatically, if at all since 1983, even with the implementation of No Child Left Behind (Gill \& Schlossman, 2004). 
Overall, the homework landscape has undergone dramatic fluctuations. During those times, the public's and experts' opinions have fueled the fires of controversy with passionate calls to either increase the amount and rigor of homework or to shut it out completely for the sake of the children's health. But, during these times, the amount of time students spent on homework did not change dramatically (Gill \& Schlossman, 2004). With the exception of the years following the launch of Sputnik, no more than $11 \%$ of high schoolers reported doing more than two hours of homework every night. This means that close to $90 \%$ of them are doing less than two hours of homework a night. These results beg the questions, What is homework? How is it used? How do you increase the time and rigor of homework? Do these need to be increased? Why do some students do homework and others not? Why is it advocated? Let us begin with what we know.

\section{What is Homework?}

In 1986, Harris Cooper performed one of the first meta-analyses of homework research from the previous 40 years. In his meta-analysis, he presented all of the variables and research methods that had been used to determine the effect of homework on student achievement up to that point. He was able to use sound meta-analytic practices to draw relevant conclusions about homework's impact on student achievement. He followed this up with another meta-analysis of homework in 2006. His findings from both of these analyses have been referenced extensively in the homework literature.

Cooper's (1989) definition of homework is widely used in the literature and is defined as all tasks assigned to students by teachers to be completed while school is not in session (1989). This excludes all distance learning activities, assignments completed in class, and work completed while in a study hall (Cooper, et al., 2006). This definition is 
restricted to those students in kindergarten through grade twelve. Naturally, this definition is broad and needs clarification. The following section describes some of the parameters of homework and its justification.

Homework is complicated (Corno, 1996). Cooper (2006) pointed out that homework is influenced by more factors than any other instructional strategy. With this in mind, it is understandable that many different instructional artifacts and practices fall under the homework title. Homework can be something as simple as reviewing vocabulary words for a test to meeting with a group of classmates to brainstorm and construct a rough outline for a major class project. A definition would not be complete, then, if the reasons for why homework is assigned were not discussed.

Why is Homework Assigned?

Homework is assigned for both academic and non-academic reasons (Cooper, et al., 2006).

Academic reasons. Lee and Pruitt (1979) were among the first to collect and categorize academic purposes for homework, and they assigned them to one of four categories. Teachers assign homework for (a) practice and (b) preparation. For practice, homework is assigned to allow students extra time to practice skills, and review concepts learned during the day. Elementary teachers indicated that they assign homework for this very reason (Becker \& Epstein, 1982). For preparation, teachers will often assign homework that prepares the student for upcoming material. Examples include a pre-lab assignment in science, or a brainstorming activity to generate ideas for a topical classroom discussion the next day. Teachers also assign homework that asks students to connect current learning to a new concept or scenario. These types of assignments are 
called (c) extension assignments and often demand a higher degree of cognitive skill than do practice or preparation assignments (Lee \& Pruitt, 1979). Teachers can also assign (d) creative homework assignments where students are asked to draw upon several skill sets in order to complete a long-term assignment that can take many days or weeks to complete. These types of assignments include book reports, research papers, and presentations.

Non-academic reasons. Epstein and VanVoorhis (2001) identified the following non-academic reasons for assigning homework. (a) Homework can be assigned to ensure everyone's participation in learning. Often, some students are reticent to actively engage during class, and homework is their chance to participate. (b) Teachers assign homework to develop students' good personal habits. They do this by creating situations where students must utilize good time management skills in order to get their work done. This is particularly true in the elementary grades as teachers are trying to prepare children for the more rigorous assignments that come later in schooling (Muhlenbruck, Cooper, Nye, \& Lindsay, 1999). (c) Teachers may assign homework to promote positive communication between parents and students. Schools strive for more parental involvement to increase student achievement (Patall, Cooper, \& Robinson, 2008). It has also been shown that homework can allow parents to show their children that they support them in their schoolwork (Balli, Demo, \& Wedman, 1998). In particular, homework becomes much more effective when parents set rules on homework time, completion, and overall achievement expectations (Fan \& Chen, 2001). It is believed that students will internalize these rules over time and achieve at higher levels (Patall, et al., 2008). (d) Homework can be used as a form of punishment. While teachers report that this is not what homework 
should be used for, it is often perceived as such when the homework is ill-conceived causing the students frustration and stress (J. Xu, Corno, L., 1998).

\section{The Complex Nature of Homework}

Homework is a multi-purpose instructional tool with no clear blueprint for how it is to be used or when. Lyn Corno (1996) was one of the first to identify homework's difficult nature. In her brief report she identified five misconceptions and five realities of homework.

Homework misconceptions. Misconceptions about homework include: (a) the best teachers give homework regularly. This, in fact, is not true. The best teachers utilize homework in a flexible fashion that best meets the educational needs of the students and the curriculum (Snyder, 1992). (b) More homework is better than less. Research shows that time on homework, alone, is not a reliable predictor of student achievement. Cooper's meta-analysis (1989) found this to be true except for secondary students. (c) Parents want their children to have homework. Corno interprets this as saying that parents want their children to be successfully educated, but not necessarily through the use of homework. If homework leads to a good education, then parents will support its use (J. $\mathrm{Xu}, 1994)$. (d) Homework supports what students learn in school. This is a huge assumption due to the great amount of variability within the ways teachers assign homework, what they assign it for and how the student completes it. Homework is supposed to enhance the learning that goes on in the classroom by allowing the students to extend their learning beyond what's given in class (Walberg, Paschal, \& Weinstein, 1985 ) and in many instances, it does not. (e) Homework fosters discipline and responsibility. Again, this is a misleading statement for it is not the homework that fosters 
the discipline and responsibility, rather it is the parent that does this by setting an environment in the home where homework time is structured and supervised ( J. Xu, 1994). Homework, while important, is a non-factor because it could be replaced by any activity such as practicing a musical instrument, playing a game, or reading.

Homework realities. Corno's (1996) realities of homework are based on empirical evidence gathered by homework researchers and paint a more realistic picture of current homework thought.

1. Homework is easily misused or abused by teachers and schools. Homework can unwittingly become an instrument of punishment. Having students write sentences as consequences for misbehavior, and reducing amount of homework assigned based on how much work is done in class are both instances where homework is used in a punitive manner to modify behaviors. This results in apathy and burn-out of all parties - students, parents and teachers (Hoy \& Woolfolk, 1993).

2. Homework can be the bane of parents' existence in the early grades. The realities of homework have led to friction between school and home (Cooper, et al., 2006). Because homework best practices are still being developed, many teachers utilize homework in ways that cause great stress on students and their parents. Public pressure to increase test scores has led to educational policy that uses increased homework time as a tool to accomplish this (Harvey, 1983). Thus, teachers assign additional amounts of unnecessary homework hoping that students will benefit. However, this additional work causes large amounts of strain on families who are already highly involved in their children's activities outside of school. 
3. A natural extension of this overburden is that homework can make some students avoid, rather than enjoy, schoolwork. All teachers going through an educational methods course learn to allow their students early successes to build confidence and motivation for future challenges. The same is true for homework. A child's perception of school can sour if he's given homework that is frivolous and thoughtless.

4. The best homework may be work done at home and brought into school. Some homework researchers argue that homework in the younger grades should be work taken to school from home and not work taken from school to home (Hill, 1994). In this light, students are making a vital link between home and school. They are realizing that these two places are linked to one another and can contribute to each other in positive ways. Students can have class discussions on conversations they have had at home. They can bring in insects or plants they collected while walking with their family through the woods. The teacher, then, incorporates these into the curriculum, showing that education can arise from the events the children experience every day.

5. Policymakers, educators, and parents can all benefit from knowing the results of homework research. Since the publication of Corno's article in 1994, homework research findings have broadened. Yet, over the years, homework practices have changed little, which makes Corno's last reality even more germane to education today. Homework researchers need to make clear their findings in such a way that policy-makers and educators alike can make informed decisions on the future role of homework in student learning and achievement. 
Considering these things, it is no wonder that homework has been described as the greatest extraneous, non-parental influence on policies and practices in the home (Goldberg, 2007). This is a profound insight that gives homework unprecedented power in the home. Policy makers routinely emphasize the increased use of homework to improve student achievement (Harvey, 1983), yet there is little consistency and virtually no best practice techniques to describe homework assignments or how it should be done (Cooper, et al., 2006). Thus, it is imperative that researchers continue to explicate the complex theory of homework and make their findings known to the public, so that teachers can make the best use of this learning tool.

\section{Previous homework research}

Early research into homework examined a few easily measurable factors such as homework frequency (how often?) and homework duration (how long?). In his metaanalysis of homework research Cooper (1989) analyzed fifty studies that correlated the amount of time a student spent on homework with academic achievement. Overall, fortythree correlations showed that students who did more homework outperformed those who did less. The other seven had negative outcomes (Cooper, 1989). Interestingly, further analysis showed that the positive correlation between homework time and achievement was significantly higher for secondary students (grades 7-12) than for elementary students (grades K-6). The mean correlation for high school students was $r=.25, p<.05$, for those in middle school, $r=.07, p<.05$, and that of elementary students was $r=0.0$ (Cooper, 1989). Cooper postulated that these significant differences in correlation could be explained by the differences in why homework is assigned at the different grade levels. An explanation he posited was that in elementary schools, homework is often assigned as 
a time management tool to allow students the practice of setting aside time for study and is not overly concerned about academic motives. At the secondary level, this scenario changes as teachers assign homework for more academic reasons that, in turn, can impact achievement (Cooper, et al., 2006).

Cooper (2006) described a need to reanalyze many studies in order to search for a causal relationship between homework and achievement. The studies described above could not demonstrate a causal relationship because of faulty analytical methods (Cooper, 1989; Cooper, et al., 2006). For example, only half of the studies used random assignment of students to conditions, where homework was assigned as an exogenous treatment or where in-class study time was provided. Exogenous treatment refers to the fact that the researchers were able to use homework as a true controlled variable or treatment - they assigned homework to some students and not to others and they determined who received the treatment. However, they did not randomly choose who received the treatment. This is problematic because oftentimes students are placed in classes with same ability peers, thus any positive effects produced from the study could not be associated with the presence or lack of homework. Any changes in achievement could have been caused by variables already inherent in the students and not by the homework itself.

The other half of the studies used neither random assignment nor did they utilize a priori matching or post hoc statistical methods to improve the similarity of the homework and non-homework groups (Cooper, et al., 2006). This was problematic because a priori matching would have increased the likelihood that the homework and non-homework groups were equivalent in quality of subjects and post hoc analyses would have helped 
determine if there were significant differences in the means of the groups. The results of the fifty studies showed that the randomized and non-randomized homework assignments produced similar, positive results in achievement, but there was no significant difference in achievement found between in-class tutoring/study and randomly-designed homework assignments (Cooper, 1989).

In his more recent study, Cooper (2006), calculated a mean effect size ( $d$ index) of $d=.60$ for students who are assigned homework. The $d$ index calculation measures the difference between two group means expressed in terms of their common standard deviation. Therefore, a $d$ index value of .25 would mean that a one-quarter standard deviation separates the two means. A value of .60 implies that, on average, students who did more homework had achievement that was .60 standard deviations higher than those students who did less. However, Cooper noted that homework is influenced by more factors than any other school activity (Cooper, et al., 2006) and he made it evident that other factors besides duration and frequency were at play in the homework model and that these factors needed to be identified.

Although measurement of frequency and duration contributed to our understanding of the nature of the relationship between homework and academic achievement in K-12 students, researchers recognized that homework's complexity was not fully explained by these simple quantitative measures due to the contradictory nature of the homework-achievement correlations. Therefore, over the past twenty-five years, researchers have been going beyond frequency and duration and questioning the influence of other variables related to homework such as parent education level ( Caprara, G. V., Fida, R., Vecchione, M., Del Bove, G., Vecchio, G. M., Barbaranelli, C., \& 
Bandura, A., 2008; Davis-Kean, 2005; Schreiber, 2002; Sirin, 2005), parental expectations (McNeil, 1999; Patall, et al., 2008), gender (J. Eccles \& et al., 1993; Harris \& Nixon, 1993; Hartlep \& Ellis; Kitsantas, Cheema, \& Ware, 2011; J. Xu, 2006; J. Xu, Corno, Lyn, 2006), student conscientiousness/attitudes towards homework (Schibeci, 1986; Singh, Granville, \& Dika, 2002) and student affective behaviors as studied through motivational theories of self-efficacy (Bandura, 1997; Kitsantas, et al., 2011; Margolis \& McCabe, 2004; Zimmerman \& Kitsantas, 2005), and expectancy-value (Trautwein \& Ludtke, 2007; Trautwein, Ludtke, Kastens, \& Koller, 2006).

Homework motivation. The most significant of these alternate homework variables are the motivational aspects. Trautwein developed a homework model that links classroom, student and home variables to homework behavior variables through expectancy and value motivational constructs (Trautwein, 2007; Trautwein, Ludtke, Kastens, et al., 2006; Trautwein, Ludtke, Schnyder, \& Niggli, 2006) through the expectancy-value theories expanded upon by Eccles (J. S. Eccles, Adler, T. F., Futterman, R., Goff, S. B., Kaczala, C. M., Meece, J. L., \& Midgley, C., 1983; J. S. Eccles \& Wigfield, 2002; J. S. Eccles, Wigfield, A., 1995). His stance is that the effect of homework time on achievement is inconclusive because studies fail to recognize the importance of student motivation to homework completion. He further states that all other homework-related variables such as socio-economic status, gender, home environment, and teacher variables are channeled through the students' senses of expectancy and value (Trautwein, Ludtke, Schnyder, et al., 2006).

Bandura's self-efficacy construct (1997) also contributes to homework motivation in the development of the self-regulated learner. Here, self-regulated learners are those 
who are able to achieve learning because they know their own strengths and limitations, and they evaluate their progress through the setting of meaningful goals. These students reflect on their progress, which provides the incentives and motivations for them to continue their pursuits (Zimmerman, 2002).

Tied to these motivational theories are student affective traits that contribute to the student's overall feelings of self-efficacy and competence in school or class. For example, self-confidence in a subject can help a student initiate a homework assignment, knowing that it will be done well and perhaps quickly. Having a positive affect towards the subject would provide motivation to complete the homework because the student finds the subject enjoyable. Valuing the subject also provides the student with motivation because the subject may play an important role in the student's future goals.

Gender. The two motivational constructs can help explain why some students complete their homework, while others do not. Yet, gender plays a role in this as well. Researchers have found that boys and girls differ in their approaches to homework primarily due to their feelings towards school (Duckworth \& Seligman, 2006; Harris \& Nixon, 1993) or the school subjects (Trautwein \& Ludtke, 2009). Some researchers postulate that girls display more of the self-regulated learner traits and this is why they tend to show greater homework effort and compliance (Harris \& Nixon, 1993; Wagner, Schober, \& Spiel, 2008).

Parent education level. Parent education level is a strong indicator of positive student achievement (Caprara, et al., 2008; Davis-Kean, 2005; Schreiber, 2002; Sirin, 2005). It has also been shown to have a significant effect on homework completion (J. Xu, 2011). Yet, its effect on achievement is not direct. Its effect is indirect as it works through 
parental expectations (Davis-Kean, 2005). These expectations can take the form of heightened parental involvement in school, homework help, and high expectations for student success (Trautwein, Ludtke, Kastens, et al., 2006).

\section{Why Science?}

TIMSS tests students for both math and science achievement. Science was chosen for two reasons. (a) Numerous studies have used math as the subject of the achievement measure and it is an intent of this study to increase the database of science related research and (b) the current push for the strengthening of STEM (Science, Technology, Engineering, and Math) curricula in all schools makes science a very pertinent topic in education at this time.

\section{Problem Statement}

Previous studies have attempted to decipher the relationship of the above variables to homework. Most notably, Trautwein has investigated the relationship of parent factors and motivation to homework behavior. In fact, his work has arguably contributed the most to our present understanding of the antecedents of homework motivation and behaviors (Dettmers et al., 2011; Trautwein, Ludtke, Kastens, et al., 2006). Trautwein's work utilized hierarchical linear modeling as the primary statistical analysis method and he strongly supports the use of this technique as homework has applications across different levels, most notably at the class and student levels. However, his studies have neither made significant use of causal structural modeling, nor have they analyzed the direct relationship between parent education level and gender, with the selfregulatory traits of self-confidence, positive affect, and valuation. 
Most others have looked at these variables in light of their effect on achievement with few using homework as a mediating variable. One that did use homework in a mediating role was Zimmerman (2005). He found, through path analysis, that homework had a significant, positive effect on student perceived self-efficacy. Again, however, the variables of parent education level and gender were not present. A survey of the research cited here uncovers many different variables used to study homework and multiple ways that the variables were analyzed. Yet none of them has taken the variables just described and placed them in a causal structural model or utilized the antecedent variables of parent education level and gender in the same model where the affective variables and homework are mediating the relationship.

\section{Purpose}

It is the intent of this research to determine if homework has a significant mediating effect between self-regulatory learning and science achievement as measured on the Trends in International Math and Science Study (TIMSS) 2007. Specifically, does homework act as a significant mediator between student affective variables towards science (self-confidence, positive affect, and positive valuation) and science achievement? Gender and parent education level, both of which are known to significantly impact these variables, will be included in the analysis.. Mediating variables will be discussed in more depth later in the methods chapter, but for now a mediating variable is one that indirectly influences, either positively or negatively, the effect of one variable on another. 


\section{Significance}

The results from this research will guide four distinct groups who have stakes in the homework research. The first group is the students. This research attempts to identify those characteristics that have the most positive effect on homework practices. Students will be able to use this research as a "how-to" when it comes to homework time and frequency, particularly in reference to the acquisition of self-regulatory learning traits. The second group consists of parents and teachers. As with the student group, teachers should be able to take away from this research those student self-regulatory learning characteristics that contribute the most to homework quality time. The same holds true for the parents. They can learn those traits that will allow their children to make the most out of their homework time and reinforce those behaviors in the environment where homework is done - the home. The third group consists of the schools and school districts. It is the hope that this research will influence the policy-makers in the school systems as to the best policies regarding homework. The fourth group is the educational researchers. They may find the results of this work important because they would be interested in the potential causal relationships among the factors.

\section{Research Questions}

These research questions will used to address the purpose of this study:

1. Do student affective variables have a mediating effect between gender and homework?

2. Do student affective variables have a mediating effect between parent education level and homework? 
3. Does homework exert a mediating effect between the student affective variables and science achievement?

\section{Limitations and Delimitations}

Several limitations and delimitations exist in this study and are explained here. First and foremost, the homework variable is only measured with time, both amount of minutes and frequency of assignments. This is problematic because there are several other factors, mentioned previously, that measure homework in a much more complete way. An example is shown in Trautwein's work where he was able to calculate the percentage of homework completed in a study of student self-confidence on homework behaviors (Trautwein, Ludtke, Kastens, et al., 2006). Second, few previous studies have made the direct connection between parent education level and homework. One methodologically sound study is presented as evidence, but the analysis would be more reliable if more studies were found that dealt with this relationship. Third, there are other factors that have been shown to influence student affective variables that aren't measured in this research. For example, student cognitive abilities and conscientiousness have been measured and shown to have both a direct effect on homework and indirectly through student affective variables (Trautwein, Ludtke, Schnyder, et al., 2006). Finally, no teacher and classroom level variables will be utilized in this study even though data will be available. The inclusion of these variables would make the model too complicated, but it allows further research to continue beyond the scope of this paper. 


\section{Definitions}

Affective Variables: Variables related to feelings. In this study, those variables related to student feelings are self-confidence, positive affect, and valuation.

Disturbance: Unspecified causes of an endogenous (effect) variable; similar to an error or residual in a prediction equation. Each endogenous variable usually has a disturbance (D. A. Kenny, 2011).

Endogenous (Effect) Variable: A variable that is caused by one or more variables in the model. This variable may also cause another endogenous variable in the model (D. A. Kenny, 2011).

Exogenous (Causal) Variable: A variable that is not caused by another variable in the model. This variable usually causes one or more variables in the model (D. A. Kenny, 2011).

Expectancy-Value: An individuals' expectancy for success in a task and the value placed on succeeding in that task determines the level of motivation (Wigfield, 1994). Homework: All tasks assigned to students, in grades K-12, by teachers to be completed while school is not in session excluding all distance learning activities, assignments done in class, and work done while in a study hall (Cooper, 1989) Latent Variable: A variable that is not measured. Also called an unmeasured or unobserved variable or factor (D. A. Kenny, 2011). Measurement Model: Schematic of the latent variables and their indicators. Also known as confirmatory factor analysis (Kline, 2011). 
Mediating variable: An indirect effect involving an intervening variable which is presumed to transmit some of the causal effects of prior variables to subsequent variables (Kline, 2011).

Self-Efficacy: Confidence in one's ability to successfully plan, execute, and complete a task (Bandura, 1997).

Structural Model: The set of structural equations. Path analysis (D. A. Kenny, 2011)

Path Diagram: The pictorial representation of a structural equation model (D. A. Kenny, 2011). 
CHAPTER II

\section{LITERATURE REVIEW}

This literature review identifies and describes theoretical and methodological issues to provide a foundation upon which to base this study. Included in this are the underlying theoretical models on which this research is based. The first section describes the purpose, gives a brief introduction to the model used and the theories underlying its arrangement. The second section provides a detailed description of the Expectancy-Value model proposed by Eccles and Wigfield (2002) and its association to Trautwein's (Trautwein, Ludtke, Schnyder, et al., 2006) homework model with a description of the variables of interest. The third section describes the details of self-efficacy theory (Bandura, 1997) and how it contributes to our understanding of self-regulated learning. Finally, the chapter concludes with a summary of the major points and the research questions that are the focus of the study.

Purpose

It is the intent of this research to further examine the relationships of parent education level and gender to student affective behaviors in regards to homework and student achievement. Specifically, does homework act as a significant mediator between student affective variables towards science (self-confidence, positive affect, and positive 
valuation) and science achievement? Gender and parent education level, both of which are known to significantly impact these variables, will be included in the analysis.

In order to examine this meditational effect of homework, a structural equation model is proposed (see Figure 1). Here, only the structural model is shown for simplicity. The other factors that define the variables have been left off so one may see the basic relationships between the variables more easily. The full model will be shown in the methods section along with explanations. The structural model is shown now so that further explanations of the theory behind the model and how those theories relate to the model are easier to visualize.

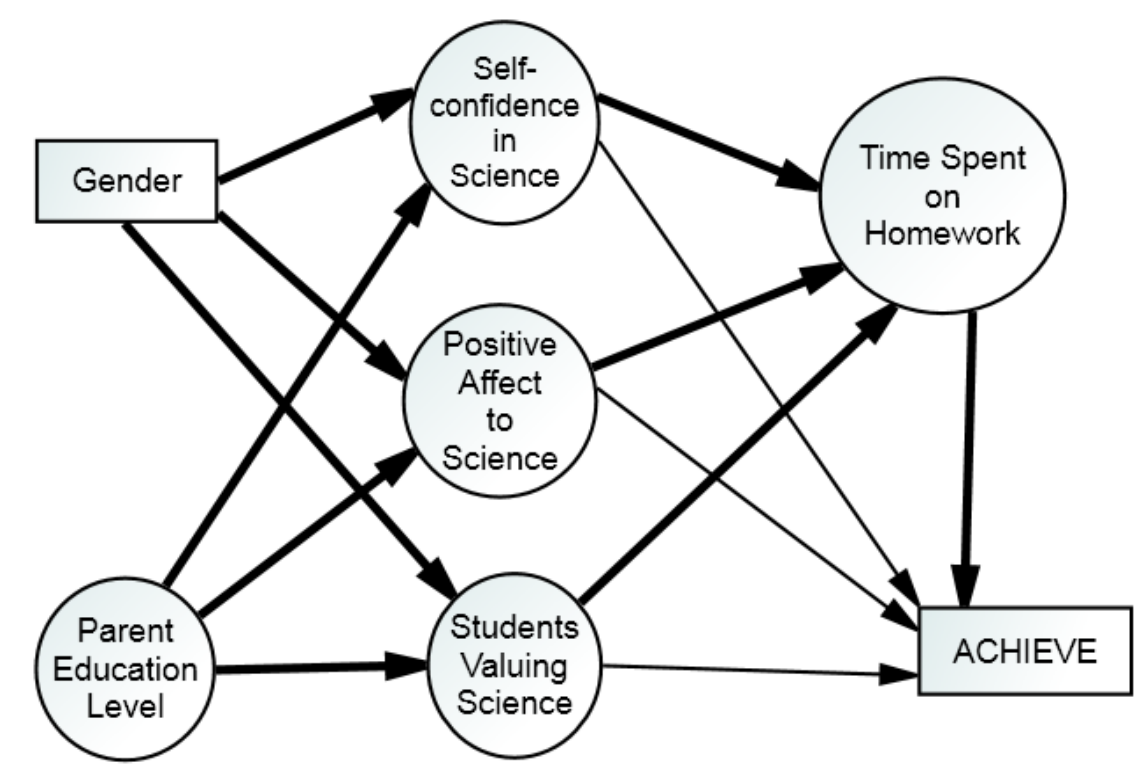

Figure 1. Basic theoretical structural model of homework's mediating effect between student affective variables and achievement.

For interpretational purposes only, Positive Affect towards Science (PATS) is used to gauge whether or not students like science. Students Valuing Science (SVS) is used as a 
measure of whether the students value science and find importance in taking it for future goals and Self-Confidence in Science (SCS) is measuring students' expectations for academic success in science class. These three components form a student motivation construct which is affected by whether they enjoy the subject, place value in the subject or believe it holds value for them in the future (Mullis, 2005). Time Spent on Homework is the homework variable, and ACHIEVE is student achievement as measured on the TIMSS 2007 test of science achievement. The arrows are given different weights simply to distinguish between paths. The heavier arrows are the hypothetically significant paths of this research and follow the course of the indirect effects of the affective variables on achievement through the mediational effect of homework. The lighter arrows indicate the direct effects of the affective variables on achievement.

It is extremely important in structural equation modeling that researchers have a solid theoretical basis for the arrangement of the variables in the proposed model. What follows are the theoretical groundwork and explanations for why the model is arranged as it is.

\section{Theoretical Models}

At its heart, homework is an instructional activity that students do, most often, alone. Thus, students rely on themselves to initiate and complete the homework. This begged the question: Why do some students do homework and others not? It is evident that some students have a positive homework outlook while others do not. Interestingly, many students that have this positive outlook possess a self-regulatory component called self-regulatory learning not present in other students who do not complete homework on a regular basis. This self-regulatory aspect of homework is an integral component of the 
current homework research and is studied through the lens of motivation theory. Students who demonstrate self-regulated learning are confident in their abilities to complete the work. Several aspects of self-regulated learning have been identified by Zimmerman (2002). He describes self-regulating learners as those who work proactively to obtain knowledge by understanding that learning will occur through their actions and is simply not an event that occurs as they sit passively in class. They are able to achieve learning because they know their own strengths and limitations, and they evaluate their progress through the setting of meaningful goals. These students reflect on their progress which provides the incentives and motivations for them to continue their pursuits (Zimmerman, 2002). Students' varying levels of motivation towards homework completion are based on external (outside of school) factors such as parental involvement, latent intellectual ability, interest in the class subject and internal factors such as success in school. These motivational factors determine the amount of effort a student puts forth in completing homework.

What follows are descriptions of Expectancy-Value theory and the Self-Efficacy construct and how they relate to Trautwein's homework model and self-regulated learning, respectively. The aim of this section is to explain the connection between these two motivational theories and the affective variables of SVS, SCS, and PATS. For Expectancy-Value, an argument will be made that SCS, and PATS are reflected in the Expectancy construct and SVS is reflected in the Value construct. For Self-Efficacy, the point will be made that SCS, SVS, and PATS are components of self-regulated learning characteristics. Lastly, an argument will be made that SCS, SVS, and PATS are significantly influenced by Gender and PEL and that it's this relationship that partly 
determines the effectiveness of homework. Expectancy-Value will be discussed first because of its importance to the homework model.

Expectancy-Value theory. The Expectancy-Value theories of motivation dominate the homework research (J. W. Atkinson, 1957; J. S. Eccles \& Wigfield, 2002; Kitsantas, et al., 2011; Margolis \& McCabe, 2004; Trautwein, Ludtke, Kastens, et al., 2006; Trautwein, Ludtke, Schnyder, et al., 2006; Zimmerman \& Kitsantas, 2005). Atkinson (1957) was the first to propose the expectancy-value model. Later it was added to and revised by several groups, particularly Eccles and Wigfield (J. S. Eccles \& Wigfield, 2002; J. S. Eccles, Wigfield, A., 1995; B. Weiner, 2010; B. Weiner, Frieze, I., Kukla, A., Reed, L., Rest, S., Rosenbaum, R. M., 1971). In the broadest sense, expectancy-value theories postulate that individuals' expectancy for success in a task and the value placed on succeeding in that task determines the level of motivation (Wigfield, 1994). This is often explained in terms of answering the question: Can I do this task? This question addresses an individual's competence and efficacy, the expectancy for success or failure, to complete a task (J. S. Eccles \& Wigfield, 2002).

Expectancy-Value Theory attempts to explain students' choice of achievement tasks, vigor (persistence) in carrying out these tasks, and their performance on them (Wigfield \& Eccles, 2000). How one chooses, persists and performs is explained by their belief in how well they will do and how they value the activity (Wigfield \& Eccles, 2000). Figure 2 shows the expectancy-value model created by Wigfield \& Eccles (2000) and shows that expectancy and values (on the far right of the model) directly influence achievement choices as well as persistence, performance, and effort (Wigfield \& Eccles, 2000). 


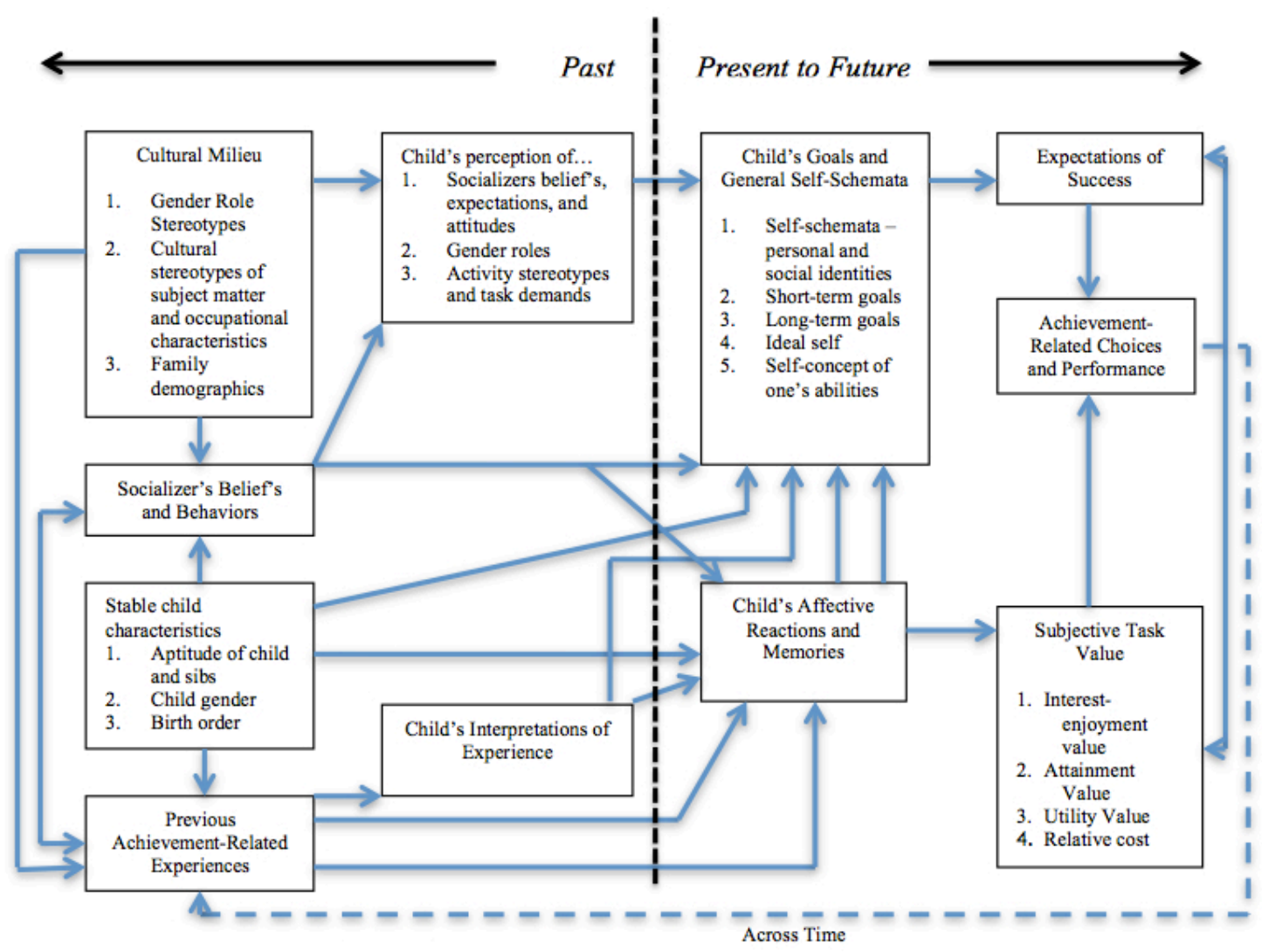

Figure 2. Expectancy-value model of achievement motivation.

From "Motivational beliefs, values, and goals", by J.S. Eccles, A. Wigfield, 2002. Annual review of psychology, 53(1), p. 119. Copyright 2002 by Annual Reviews. Used with permission of the author.

The complete model is shown in order to impress upon the reader the complexity of the events and situations that can influence expectancy and value development over an individual's lifetime. Overall, there is a temporal progression of past events on the left to more current events on the right. A dividing line (not present in the published model) shows where a temporal transition from the past to the present may occur based on textual clues in the model. Those events that happen in the past occur in the left side of the model and go back to the cultural milieu of the child (upper left portion of the model), the socializer's (parent's/guardian's) beliefs, along with aptitude and previous 
achievement experiences of the child. These past events on the left are evidenced by key words such as "child", "birth order", "previous experiences", and "socializer's beliefs and behaviors". One might assume that the left side of the model would be the "expectancy" side and the right, the "value" side since this is the expectancy-value model. But, this is not the case. Expectancy and value are both products of the person's lifetime experiences, and beliefs. Therefore, they are found on the far right side; the expectancy component in the upper right of the model and the value component in the lower right. This model does a nice job of showing the importance of background components to the formation/creation of a person's expectancy and value beliefs and, thus, the justification for showing the whole model.

The current research will focus on the right half of this model (see Figure 3). Most notably, Self-Concept of one's ability under Child's Goals and General Self-Schemata, Expectations for Success, and Child's Affective Reactions and Memories will be looked at closely as they affect Attainment and Utility value under Subjective Task Value. 


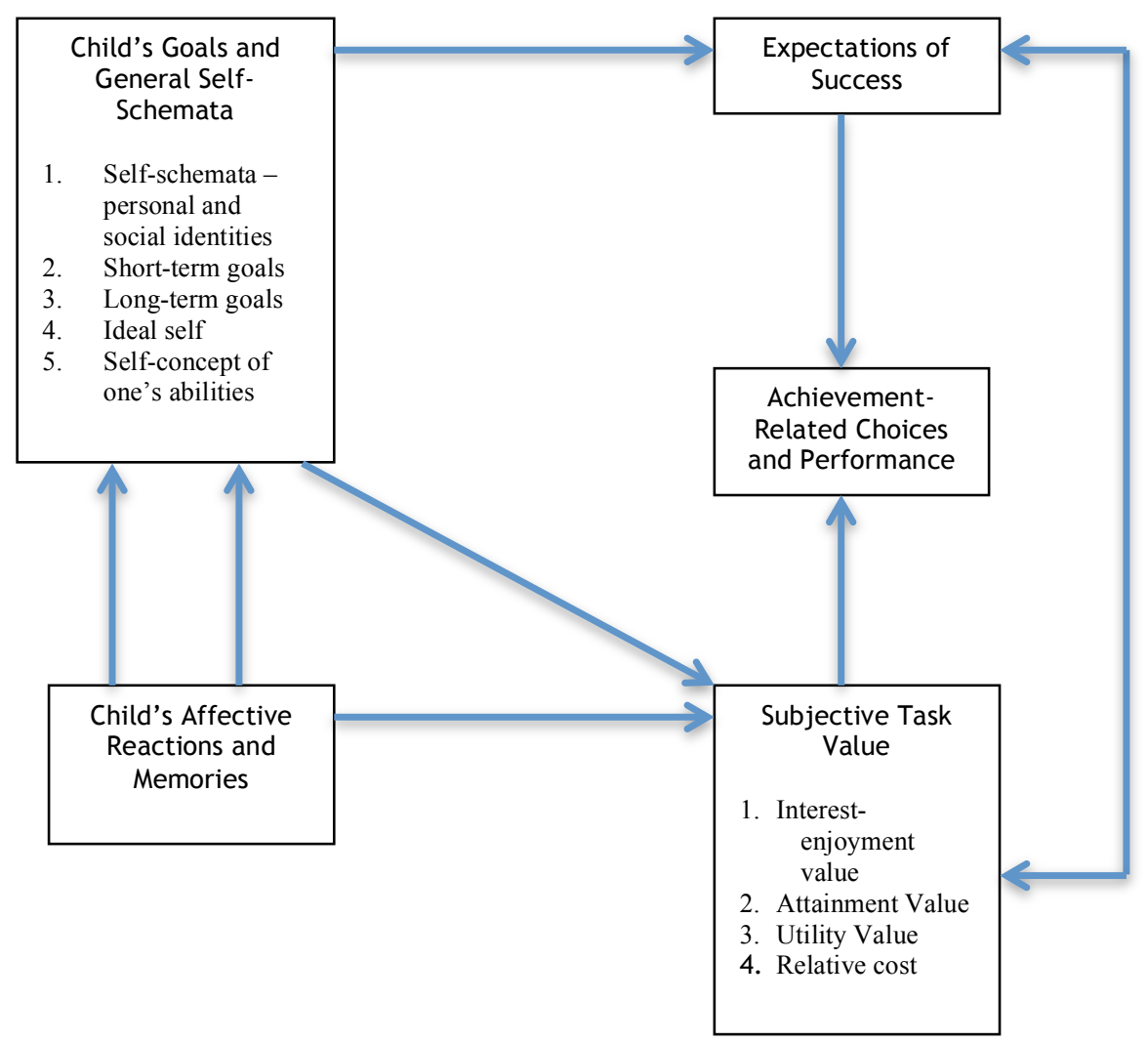

Figure 3. Detail of expectancy-value model of achievement motivation.

The reason for this focus on the value component of the model is that Eccles (1995) argued that more empirical research needs to be done on the value component of the expectancy-value theory. This is due to Atkinson's (1957) interpretation of Expectancy-Value Theory which gave little notice to the value side of the theoretical equation (Wigfield \& Eccles, 2000). Atkinson's interpretation is heavy on the "expectancy" side in explaining the causes of motivation. He believed that the incentive task value $\left(I_{s}\right)$, or the rewards one can expect to receive from doing the task, was inversely proportional to its probability of success $\left(P_{s}\right)$ (J. S. Eccles, Wigfield, A., 1995), and thus, 


$$
\text { incentive task value }\left(I_{s}\right)=1-P_{\mathrm{s}}
$$

This model implies that as the probability of success on a task increases, the incentive for doing that task decreases. Atkinson pointed out that as one gets better at a task, the probability of success on that task increases. However, he argued that the incentives for doing that task become less and less as the probability of success increases (Wigfield \& Eccles, 1992). Thus, incentive value would only be found in tasks where the probability of success is lower, a.k.a. harder tasks.

It is important to understand that Atkinson defined $P_{s}$ as the ratio of successful tasks performed over the total number of tasks performed, which means it is heavily influenced by subjective task difficulty (one's expectancy of failure at a task) (J. W. Atkinson, 1957; J.W. Atkinson, 1964; J.W. Atkinson \& Feather, 1966). It follows that $I_{s}$ would also be heavily influenced by subjective task difficulty (Wigfield \& Eccles, 1992). Therefore, this inverse proportionality effectively zeroes out task value's effect in Atkinson's interpretation of the expectancy-value theory because he gave no other value constructs besides incentives. In addition, the inverse relationship between $P_{s}$ and $I_{s}$ means that only really difficult tasks (low $P_{s}$ ) would have significant value to a person while easier tasks would have little or no value. If incentives become smaller and smaller with progressively easier tasks, then value will have no influence on the theory (Parsons, 1980). Eccles then explains that this may be the reason why task value receives such limited attention in the research (J. S. Eccles, Wigfield, A., 1995). However, researchers have recently identified alternate, and often positive relationships between expectancies and values that counter Atkinson's ideas (J. S. Eccles, Adler, T. F., Futterman, R., Goff, S. B., Kaczala, C. M., Meece, J. L., \& Midgley, C., 1983; J. S. Eccles, Wigfield, A., 1995; 
Feather, 1982). For example, Eccles et. al. (1983) found that people tend to value most those tasks they are good at in order to maintain a high self esteem. Additionally, as affective memories and actions affect task value, there should be positive ramifications to self-perceptions of expectancy (J. S. Eccles, Wigfield, A., 1995). In other words, past experiences and emotions of satisfaction and elation upon the completion of difficult tasks will draw one to complete more of these tasks.

Knowing this positive relationship did indeed exist between incentive value and task success, Eccles (1995) expanded on Atkinson's theory by broadening the scope of task value beyond incentives while maintaining that task value is directly related to objective difficulty. She stated that Atkinson's approach to task value was very narrow and not given the importance that it deserves. Eccles believes that expectancy and value both contribute to the expectancies an individual has for success in upcoming tasks. While incentives for difficult tasks can be easily seen, values other than incentives that can motivate people when the tasks are very easy include broader human values, affective experiences with the task, and sex roles (Wigfield \& Eccles, 1992). Also, it has been noted that in children and adolescents, there are strong motivations for easy tasks due to their desire to maintain a positive self-esteem (J. S. Eccles, Wigfield,

\footnotetext{
Child's Goals and General Self-Schemata

1. Self-schematapersonal and social identities

2. Short-term goals

3. Long-term goals

4. Ideal self

5. Self-concept of one's abilities
}

$$
\text { A., 1995). }
$$

Self-Schemata and student characteristics are an integral component of the Expectancy-Value model in that they contribute to the development of both the Expectations for Success construct and the Subjective Task Value construct. Wigfield and Eccles (1992) identified the importance of Self-Schemata and Goals to Expectations of Success and 
Task Value. Children's self-schemata (first on the list) is their beliefs and ideas they have about themselves (Self-Schema, 2012). Children learn to develop self-schemata very early through the teachings of their parents and other influential persons. Eventually, people develop a schema of themselves that become a self-perpetuating manifestation as they partake in activities that reinforce their personal schema. As it pertains to the Expectancy-Value model, self-schemata describes those components of children's psyche they have developed over the course of their lifetime that dictates their belief in their capabilities (Wigfield \& Eccles, 1992). For example, children who have developed a musical schema, believe themselves to be good at music, while perhaps not good in sports. Therefore, their expectations for success in gym class may be significantly lower than in a music theory class. The concept of self-schema also ties in with the quality of ideal self (fourth on the list) and short and long-term goals (second and third on the list). Here, as children develop their self-schemata, they anticipate what their ideal self would be given the full development of their self-schemata. This is done through the anticipation of short and long-term goals which are made in order to better reach the ideal self (Wigfield \& Eccles, 1992). The fifth construct, self-concept of one's abilities, refers to ability beliefs. Ability beliefs are an individual's perception of his/her competencies on an activity at a given time.

Under Subjective Task Value, Eccles (1995) describes four major components. The first is interest-enjoyment or the inherent enjoyment one receives doing certain activities. The second is Attainment Value, which is the importance of doing well on a task when one takes into account self-schemata and core personal value (J. S. Eccles, Wigfield, A., 1995). Utility Value is the third and refers to the activity's worth in its 
contribution to obtaining future goals. For example, college biology majors might find no intrinsic value in taking calculus, but the class' utility value is high because it will allow them to obtain a degree in science. The final component is Relative Cost. This is a gauging effort needed to accomplish a task including the emotional costs

Subjective Task Value

1. Interestenjoyment value 2. Attainment Value

3. Utility Value 4. Relative cost (Wigfield \& Eccles, 2000). Or simply, what an individual gives up or suffers as a result of undertaking a task (J. S. Eccles, Wigfield, A., 1995). Eccles essentially argues that Subjective Task Value is determined by the task itself and that it's judged through the "values" lens of the individual. Individuals look at a task and ask themselves: Will I succeed or fail? Will completing this task further my ambitions? Do I believe in the inherent value of the task? These questions, in combination with the individual's ability and effort, determine the final motivation towards a task.

Expectations for Success are a person's expectancy beliefs or their confidence in accomplishing certain tasks in the future. Expectancy beliefs are temporally different from ability beliefs in that ability beliefs refer to a person's ability at the present time and expectancy beliefs refer to abilities in the future (Wigfield \& Eccles, 2000). For example, a young man may join a swim team to improve his swimming ability. He may see his ability as quite low presently, but his expectations are that he will improve over time. If he does improve later, then his ability beliefs at that future time will be higher. Conversely, if he does not improve, then his ability beliefs will remain stagnant or lessen. Given this scenario, his motivation to continue will be low. Naturally, ability beliefs and expectancy beliefs, while measured separately, are highly related to one another (Wigfield \& Eccles, 2000). 
Child's Affective Reactions And Memories are a part of the value side of the model and are the most difficult to measure. One could say that this is the "catch-all" for the affective components of value decisions the students make when judging whether or not to perform a task. A student's affect (e.g. happiness, physical well-being) is their emotion or subjectively experienced feeling. These emotional states affect their task choices in both conscious and unconscious ways. For example, past experiences with bad teachers, being bullied in a particular class, or having multiple friends in class can influence how that student perceives a class regardless of their anticipated success or value. This category is a way for Eccles to acknowledge that not all motivational decisions are based on rational processes (J. S. Eccles \& Wigfield, 2002). In other words, Eccles is using the inclusion of this construct to acknowledge that there are irrational, unconscious factors that go into a person's choice decision. This category directly affects task value in that it describes a student's base emotional predisposition towards making value judgments separate from the higher order psychological components of self-schema.

Results of studies testing aspects of Eccles' expectancy-value model (J. S. Eccles \& Wigfield, 2002; J. S. Eccles, Wigfield, A., 1995; Wigfield, 1994; Wigfield \& Eccles, 2000) have addressed two major questions with results that have lent credibility to the model; (a) How do children's expectancy for success, ability beliefs and subjective values change as they progress through school? And (b) how do these beliefs/values relate to children's performance and activity choice? The results are interesting and strengthen the position to use this component in the study of homework and science achievement. Wigfield and Eccles' model identifies a student's ability, expectation for success and task value as separate components. To confirm this arrangement, some of 
their studies involved young children where they wanted to determine if these components were, indeed, separate. They found that even in early childhood $\left(1^{\text {st }}\right.$ grade $)$ students have the ability to distinguish between their ability and expectancy beliefs in different achievement domains, i.e., math, reading, music, and sports (Wigfield \& Eccles, 2000). In other words, they could identify what they were good at and what they valued in each of the areas (Wigfield \& Eccles, 2000). This helps confirm the existence of three separate domains in her model: Children's Goals/General self-schemata, Subjective Task Value and Expectations for Success (Wigfield \& Eccles, 2000).

Wigfield and Eccles (2000) also performed an analysis of the mean change in children's achievement beliefs and subjective values. They found that ability-related beliefs steadily declined throughout schooling with a particularly sharp dip occurring right after the transition into middle school ( $6^{\text {th }}$ grade). They explained that this phenomenon might occur for two reasons.

First, children become much better at understanding and interpreting the evaluative feedback they receive and engage in more social comparisons with their peers. This contributes to more accurate self-assessments which results in a lowering of beliefs over time (Wigfield \& Eccles, 2000). One can say that children become more self-aware of their abilities as they age. Students are very aware of who the strong academic students are in their classes as they progress through the grade levels. A "pecking order", so to speak, is formed when the students begin to realize who the successful students are. This realization of their place in the order tends to lower secondary students' achievement beliefs when compared to elementary students. 
Secondly, the school environment changes in ways that make evaluation more salient and competition between students more likely which lowers achievement beliefs (Wigfield \& Eccles, 2000). In this instance, students become more aware of the value placed on assessments and thus, place more value on them as well. This importance fosters competition between students for academic recognition. In competition, there are winners and losers, therefore, in this scenario, an overall lowering of achievement beliefs could occur as students recognize their place along the achievement spectrum of their class.

Furthermore, additional analysis showed that older children's ability and expectancy beliefs affected their achievement more so than did their achievement values (Wigfield \& Eccles, 2000). In other words, children's future performance is determined more strongly through their current ability and expectancy beliefs than through their valuing of the subject. This argument seems plausible considering teen-agers tendency to focus on the present and thus, their current feelings regarding their ability and expectations. This would take precedence over their value beliefs that tend to be about future goals and are thus not immediate concerns.

Trautwein's homework model. Given these findings, as reported in the literature, homework research needs to include components of the expectancy-value model if the goal of a study is to determine the impact of homework on science achievement. This is a logical conclusion because homework is done outside the classroom and its completion is totally dependent upon the student who needs to have the motivation to successfully complete it on a regular basis. Therefore, through this motivational model, one can gauge the effectiveness of homework on an individual student's science achievement. 
Trautwein has completed numerous studies involving homework and motivation (Trautwein, 2007; Trautwein \& Koller, 2003; Trautwein \& Ludtke, 2007, 2009;

Trautwein, Ludtke, Kastens, et al., 2006; Trautwein, Ludtke, Schnyder, et al., 2006;

Trautwein, Niggli, Schnyder, \& Ludtke, 2009) and he used expectancy-value theory as the model for his homework motivational studies. Thus, he created a model of homework (see Figure 4) that utilizes the major components of expectancy-value theory as a link between the environmental, teacher, student, and parent characteristics on the left and the homework behaviors on the right.

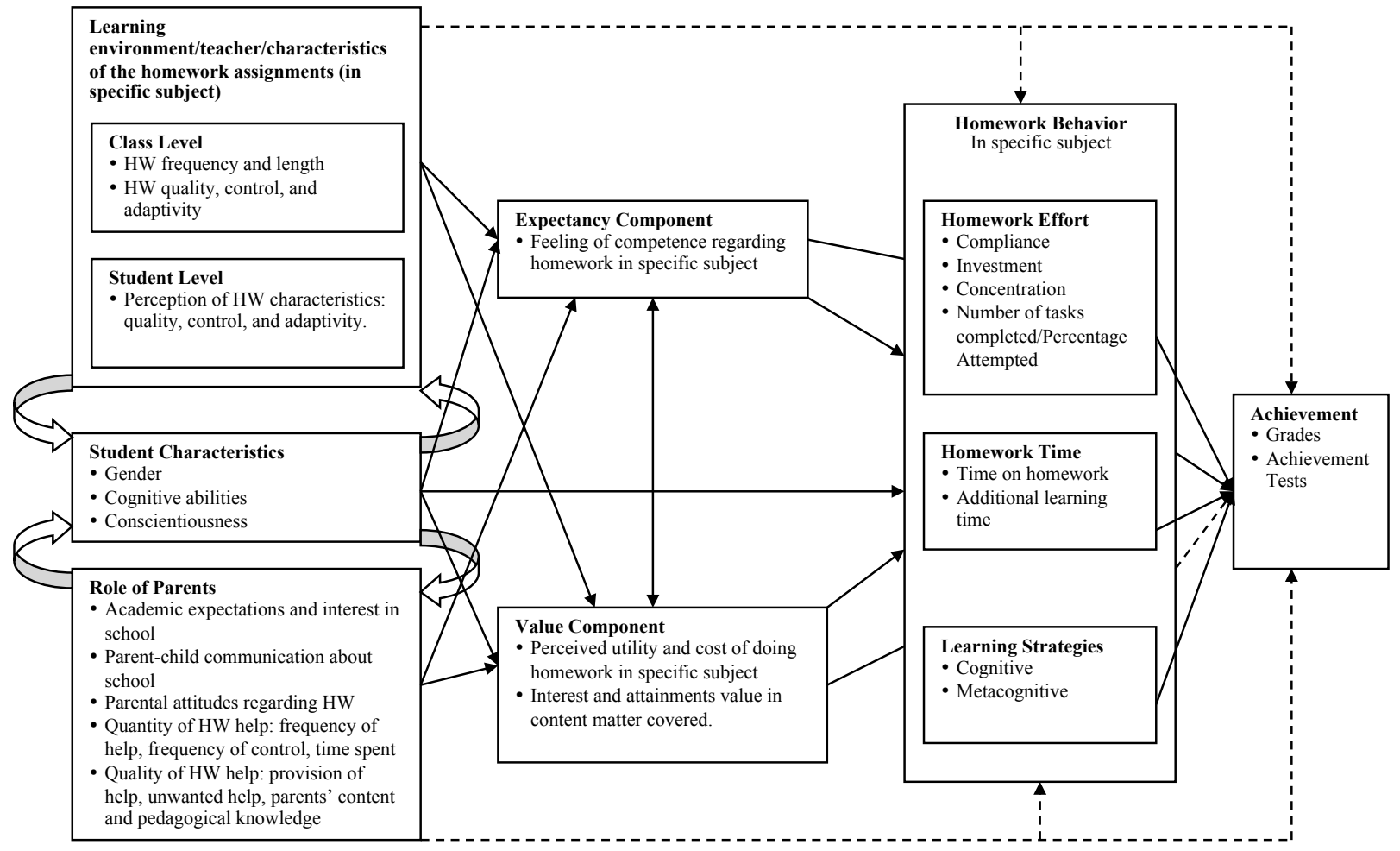

Figure 4. Schematic depiction of the Trautwein et al. homework model.

From “ Predicting Homework Effort: Support for a Domain-Specific, Multilevel Homework Model,” by U.

Trautwein, O. Lüdtke, I. Schnyder, and A Niggli, 2006, Journal of Educational Psychology, 98(2), p. 440.

Copyright 2006 by the American Psychological Association. Used with permission of the author. 
Before proceeding, one needs to understand that Eccles' model and Trautwein's model look similar but are not the same. Eccles' model is a model of the expectancyvalue motivational process and its component factors. Trautwein's model is a model of homework within which Eccles' model plays an important role. Trautwein demonstrates in his research that motivation plays a pivotal role in homework completion. His findings further reveal that these motivational factors coincide very strongly with those components of expectancy-value as suggested by Eccles and others.

Overall, the model demonstrates three major categories represented by vertical columns. The column to the left represents what Trautwein has found to be the three major antecedents of homework's success; (a) the learning environment which is divided into classroom and student variables, (b) the student-specific variables such as gender, intellectual ability and desire to do well (conscientiousness), and (c) the role of the parents.

The middle column is the motivational component of homework utilizing the expectancy-value model very similar to the one just described. This affective/cognitive component of the diagram signifies the importance of student motivational factors to the homework model (Trautwein, Ludtke, Schnyder, et al., 2006). The two components in this column are expectancy and value. The expectancy component is related to how well the students believe they will do on the homework. Included in this component would be the Child's Goals and General Self-Schemata and Expectations of Success constructs described above in Eccles' model. The value component is a reflection of the student's judgment about the value of the homework; Is the homework worth doing? Is it a waste of time or will it help me master the material? 
The right column represents student specific behaviors outside the normal school day. These consist of homework effort, homework time and learning strategies the student uses to complete or attempt the homework assigned. The final component, achievement, is the dependent variable in most of the research.

The key concept of this model is the connection expectancy and value make between the learning environment and home environment constructs on the left and the homework behavior construct on the right. In fact, Trautwein, himself (2006), said that all other homework variables such as socio-economic status, gender, home environment, and teacher variables are channeled through the students' senses of expectancy and value. This, then, can theoretically determine the students' homework behavior.

An important characteristic at the student level is gender. One notices that the homework model shows gender can directly effect homework behavior and indirectly affect it through the expectancy and value components. There is

Student Characteristics

- Gender

- Cognitive abilities

- Conscientiousness good evidence that this could be due to self-regulated learning traits (Harris \& Nixon, 1993; Hong \& Milgram, 1999; Trautwein \& Ludtke, 2009; Wagner, et al., 2008; J. Xu, Corno, Lyn, 2006). This multifaceted impact has its roots in the psychological differences between boys and girls. In her qualitative study of 57 rural middle schools in England, Harris (1993) noted that there were differences in the community's attitudes between the genders with males making a clear distinction between home life and work life. The time they spent away from work was meant to be a time of relaxation and to be cared for by the women (Harris \& Nixon, 1993). Women, on the other hand, were seen as the organizers and as the liaisons with the outside world (Harris \& Nixon, 1993). Their role 
was to take care of the men when they were not working and to hold down both homemaker's duties and an outside job. This attitude was reflected in the homework attitudes as well. Boys separated their school life from home life and did not place a lot of effort and importance on homework. Whereas girls, in their role as organizers, felt comfortable working on homework at home and would oftentimes use this as a topic of discussion when among girlfriends (Harris \& Nixon, 1993). This research might suggest that girls' more positive outlook on homework could stem from their superior organizational habits pointed out in Harris' work. Analogously, Hong and Milgram (1999) found a similar propensity in girls to organize when they compared approximately 400 U.S. and Korean seventh-graders and noted that girls in both countries tended to organize their homework by topic and perform the work in brightly lit rooms.

In another study, Xu (2006) found similar results. In his study of 426 U.S. high school students in grades 9-12, he ran a series of MANOVA's with follow-up univariate tests to compare the effects of the independent variables on the dependent variables. Overall, he found that girls showed a significant effect in six homework related characteristics: (a) arranging the environment $(F[1,392]=10.56, p=.001)$, (b) managing time $(F[1,392]=9.66, p=.002),(\mathrm{c})$ monitoring and controlling emotions $(F[1,392]=$ $47.12, p<.001),(\mathrm{d})$ time spent on homework $(F[1,417]=6.74, p=.01)$, (e) frequency of homework completion $(F[1,417]=11.77, p=.001)$, and (f) how interesting the homework was to the student $(F[1,407]=16.00, p<.001)(\mathrm{J} . \mathrm{Xu}, 2006)$. The effect sizes for all of these were small (range of partial $\eta^{2}=.02$ to .04 ), indicating that $2-4 \%$ of the variance in these facets of homework was explained by gender. However, his findings demonstrate that girls have a more positive outlook on homework; they take time to 
prepare their mind and environment to do it and they spend significantly more time on homework, which allows them to successfully complete it more frequently.

Wagner (2008) came to the same conclusions for girls and their homework attitudes. In one of her studies, 234 Viennese $10^{\text {th }}$ grade students completed diary entries on homework time and found that girls spent significantly more time on homework than boys $(t(234)=3.27, p=0.001)$. In an additional study, Wagner tested the correlation between the amount of time spent on homework and achievement with gender used as a mediating variable. A two-sample confirmatory factor analysis (CFA) with a Bonferroni adjustment was used to analyze the data. He found that the association of high achievement and high amount of time spent on homework was significantly tied to girls $\left(\chi^{2}=12.26, p<0.012\right)$, and that the low achievement and low amount of time spent on homework association was not $\left(\chi^{2}=1.15, p=0.284\right)$ (Wagner, et al., 2008). While this does not explain whether an increase in homework effort would increase boys' achievement, it does demonstrate that girls tend to view homework in a more favorable manner in that they make time to do it, which pays off with higher achievement. Wagner's final conclusion was that gender was a significant moderating variable between homework time and achievement (Wagner, et al., 2008).

Results from other researchers indicate that girls' positive attitudes and compliance with homework are domain specific (only occur in certain subjects) (Trautwein \& Ludtke, 2009). Trautwein, et al. (2009) studied the homework motivation and effort in 511 German eighth and ninth graders in Biology, Physics, English, Math, German, and History. Homework motivation was measured by expectancy and value components. Students who scored high on this scale have an optimistic outlook on their 
ability to do the work even if it's complicated. And they value the work as worthwhile and a good use of their time (Trautwein \& Ludtke, 2009). The effort scale was measured using the students compliance with doing the work and the percentage of work attempted (Trautwein \& Ludtke, 2009). Their study found that males had higher homework expectancy beliefs than females in all subjects and significantly higher scores in classes that are traditionally male; Math $(\beta=.49, p<.001)$, Physics $(\beta=.52, p<.001)$, and History $(\beta=.34, p<.001)$ even though history tends to be seen as a female subject (Trautwein \& Ludtke, 2009). Interestingly, male compliance with homework was lower in all subjects except for History and Physics and significantly lower than females in subjects typically seen as female; Biology $(\beta=-.12, p<.05)$, German $(\beta=-.22, p<.001)$, and English $(\beta=-.28, p<.001)$ (Trautwein \& Ludtke, 2009). Males also had lower value beliefs in four of the six tested subjects except Math and Physics. Their value beliefs were significantly higher in Physics $(\beta=.14, p<.05)$, and significantly lower in English $(\beta=-.26, p<.001)$. One can see that males have high self-confidence in their ability to do the work even though they tend not to place a lot of value in it or make the time to complete it. Conversely, girls have a lower confidence in completing the homework yet make greater efforts to complete the assignments.

All of these examples illustrate that girls show a propensity for self-regulated learning traits and that it is intimately connected to homework attitude. Self-regulated learning will be discussed further in the section on self-efficacy. 
Role of Parents

- Academic expectations and interest in school

- Parent-child communication about school

- Parental attitudes regarding HW

- Quantity of HW help: frequency of help, frequency of control, time spent

- Quality of HW help: provision of help, unwanted help, parents' content and pedagogical knowledge
A very important set of contributing factors to a student's outlook on homework, in the Trautwein model, are related to parents. Parents can have a positive role on their children's homework completion and their attitudes towards it by the way

they influence their children's perception of the work. Trautwein (2006) identifies some parental factors in his model; academic expectations, interest in school, parent-child communication about school, parental attitudes regarding homework, and the quantity and quality of homework help given to their child. Unfortunately, there are few studies where homework has been analyzed in light of parent education level. However, one study did examine how parent education level affected homework completion. $\mathrm{Xu}$ (2011) used hierarchical linear modeling to introduce several student level indicators and a few classroom level indicators to decipher their effects on homework completion. Student level variables included parent education level, gender, free/reduced lunch status, selfreported grade (academic achievement), reasons for doing homework, homework management, family help, teacher feedback, and homework interest. Classroom level variables included grade level, parent education level as an aggregate of the whole class, teacher feedback and student interest (as a class) (J. Xu, 2011). The results showed that parent education level, at the classroom level, had a positive, significant impact on homework completion $(b=.22, p<.01)$. Xu states that his unstandardized betas can be interpreted as standardized betas due to his standardization of all the continuous variables prior to analysis (J. Xu, 2011). This means that for every standard deviation increase in parent education level, the homework completion rate went up .22 standard deviations. 
Interestingly, parent education level at the student level had no such effect. Yet, the researcher hypothesized that this lack of significance might have been due to the mediating effect of academic achievement between parent education level and homework completion (J. Xu, 2011). One needs to understand that academic achievement, measured at the student level, was significantly related to homework completion $(b=.26, p<.01)$. However, academic achievement, itself, could likely be effected by parent education level (J. Xu, 2011). For that reason, he re-analyzed his model leaving academic achievement out of the analysis and found that parent education level, at the student level, was positively associated with homework completion (no statistics given).

Trautwein's homework model links parent factors to achievement through student motivation and homework. Parent education level can act indirectly on achievement through student attitudes, values, and confidence. This is because students who are from highly educated families enjoy other benefits besides increased achievement. High educational attainment within the family has been linked to increased social mobility, a higher degree of cultural capital within the home (access to books, encyclopedias, computers, etc.), better social capital outside the home such as parent-school relationships that promote the sharing of societal norms and values (Sirin, 2005), and increased parental expectations of student achievement (Davis-Kean, 2005; McNeil, 1999; Sirin, 2005; Trusty, 1998).

The important links between parent educational level and student attitudes, valuation, and confidence in academics show themselves as well. It is logical that well educated parents would have children who have healthy, positive attitudes for school, value an education, and are confident in their abilities because the parents are more 
involved in their schooling (Caprara, et al., 2008; Sirin, 2005). The parents are willing and capable of organizing school clubs, events, running the parent-teacher organization, and tutoring. One could also assume that highly educated parents place a high value on education. This positive bent towards academia should transfer to their children in the form of positive attitudes and high confidence in school. In fact, family socio-economic status is one of the strongest correlates of academic performance because it directly influences the quality of the relationship between school personnel and parents (Sirin, 2005). Conversely, parents who have little educational experience might foster home environments that convey lower expectations for their children (Hanson, 1994) while at the same time, see school as a threatening place in which they found little success. On the other hand, these same parents may have high expectations but have few capital resources which prevents them from providing the books, computers and transportation needed to be an active participant in their child's education (Sirin, 2005). Parental support in poorer schools and school districts is eroded partly because of these conditions. It would follow that children of less educated parents might have a reticence towards school due to their being raised in environments where trust in school was weak or non-existent (Davis-Kean, 2005).

The parent education level-student academic attitude connection was further clarified by Schreiber (2002), who found in an HLM study of TIMSS 1999 data that student level variables: attitude $(\gamma=-9.90, p<.05$, reverse coded $)$, parent education level $(\gamma=-90.34, p<.05)$, and gender $(\gamma=-20.58, \mathrm{p}<.05)$ were significantly related to math achievement. In other words, students with poor attitudes, parents with lower educational levels and girls did worse on advanced math achievement tests, than students who were 
male, had good attitudes towards math, and had parents who attained higher academic levels (Schreiber, 2002). He also ran level 2 analyses where he took the three students level variables and ran them as models at the school level. Interestingly, attitude had a significant level 2 effect on math achievement, meaning that average parent education level (an aggregate value at the school level) explained part of the variability in attitude $(\gamma=3.61, p<.05)$. Thus, student attitudes toward math have a stronger relationship with advanced math achievement in schools with higher mean parent education levels (Schreiber, 2002). Conversely, student attitudes towards math had less of an impact on achievement in schools with lower levels of parental education level. This is interesting because it means that all students can have good attitudes towards math, but for some unknown reason, students whose parents are more educated can make better use of that attitude and translate that into higher achievement. Perhaps this unknown factor is selfregulated learning, which Schreiber did not include in his study. It is apparent that parent education level is related to student attitudes toward school and homework.

Parent education level can also have a significant, seemingly direct impact on achievement. Research has found that students from families whose parents have earned higher degrees achieve at higher levels than students whose parents did not go to college or did not finish (Lau et al., 2002; McNeil, 1999; Mikk, 2007; Sabah \& Hammouri, 2010; Schibeci, 1986; M. Xu, Kushner Benson, Susan N., Mudrey-Camino, Renee, Steiner, Richard P., 2010). Lau (2002) performed a hierarchical regression analysis on a sample of 491 high school students in northern California and found that considering student demographic data only, parental education level accounted for $26 \%$ of the variability in student science test scores $\left(R^{2}=.26, p<.01\right)$, and $22 \%$ of the variability in students' second 
semester grades $\left(R^{2}=.22, p<.05\right)$. However, when Lau introduced motivational factors (efficacy-related beliefs and task values), the significance of parent education dropped to non-significance in science test scores $\left(R^{2}=.06, \mathrm{p}>.05\right)$ and science second semester grades $\left(R^{2}=.02, \mathrm{p}>.05\right)$. Yet, the same pattern of diminishing significance happens to other demographic variables that were significant as well, i.e. gender, and race. Lau noted that this showed that the psychological processes were more potent predictors of student achievement than the demographic data. While this demonstrates the importance of student motivation to science achievement, it also shows that parent education level is an important underlying demographic for achievement. Lau does not draw this conclusion, but parent education level could have a direct influence on motivational factors that act as a mediating variable to achievement that could explain the disappearance of significance he observed in his statistics.

Additionally, parent education level was significantly and directly related to student achievement in TIMSS 2007 results in Jordan for science and math (Sabah \& Hammouri, 2010). In this study, the researchers used hierarchical linear modeling (HLM) to estimate the relationship of multiple variables to both science and math achievement. Controlling for student attitudes towards the subject matter, parent education level was significantly associated with student science achievement $(\gamma=1.45, p=0.00)$ and mathematics achievement $(\gamma=1.32, p=0.00)$. Gamma, $\gamma$, represents the slope between the dependent variable and a level 1 predictor in HLM. In this case, achievement was the dependent variable and parent education level was a Level 1 predictor. The gamma values indicate that for every one unit increase in parent education level, student achievement scores increased 1.45 points in science and 1.32 points in math. 
Similar results were obtained on the TIMSS 1999 for American students in advanced math classes (Schreiber, 2002). Schreiber used a two-level HLM with student variables on the first level and school variables on the second level. Mainly, he looked for interactions: student level interactions to achievement and school-level interactions to achievement as well as cross-level interaction effects, i.e. school-level effects influencing student-level effects. He found that average parent education level significantly impacted student achievement at the school level at both Level 1 and Level 2 factors $(\gamma=-90.34, p$ $<.05$ and $\gamma=-22.62, p<.05$, respectively). The gammas in this example are negative because the coding of the parent education level was reversed; higher education levels were assigned lower numbers. However, for the Level 2 factors, he also found that this varied significantly from one school to the next. Thus, in some schools, this was not a significant association.

Further evidence of the beneficial influence of parent education level on achievement is found in Schibeci and Riley's (1986) study that used structural equation modeling to gauge the causal effect of several factors, including parent education level, on student achievement. The structural equation model examined the relationship of five independent variables on three latent variables, (a) student's perception of science instruction, (b) students' attitudes toward science instruction, (c) and science achievement. The fit of the model was calculated using Chi square statistics. For the model chosen, the chi-square was $\chi_{56}^{2}=64.02(p=0.21)$ which indicates that the model is a good fit. In this model parent education level had a significant effect on student science achievement, $\beta$ $=.22$ (no $p$ value given). 
A student's expectancy beliefs, and perceived efficacy towards a task play a significant role in that student's achievement. This is probably true for science as well. Students who demonstrate healthy expectancy beliefs and value the knowledge gained from taking science will be motivated to do well. Self-confidence, valuation, and positive affect are important components when considering a homework model. One can notice that these affective variables relate to the middle section of Trautwein's model that deals with expectancy and value. The student's value belief in science (SVS) belongs in the value component of the model. The expectancy component of the model is reflected in the self-confidence (SCS) and the positive affect (PATS) the students have towards science.

Homework time and frequency have been studied extensively (Cooper, 1989; Cooper, et al., 2006; Dettmers, Trautwein, \& Ludtke, 2009; Mikk, 2006; Trautwein, 2007; Trautwein, et al., 2009). Previous studies on homework time have shown mixed results. Some researchers have found an increase in homework time increases student achievement in secondary students (Cooper, 1989). Others have found negligible or no

Homework Time

- Time on homework

- Additional learning time

effect of homework time on student achievement (Trautwein \& Ludtke, 2007). Never the less, major assessments of student achievement such as TIMMS-2007 still ask students of their time spent on homework. The TIMSS 2007 contextual questionnaire gauged student input on science homework time and frequency through two questions that became indicators for the latent variable, Index of Time on Science Homework (TSH). More specific information is covered in the Methods chapter. 
Admittedly, measuring homework through time and frequency is not ideal. Many other researchers have concluded that better measures of homework give a more comprehensive picture of homework (Corno, 1996; Dettmers, et al., 2009; Trautwein \& Ludtke, 2007). For example, Trautwein's model identifies a whole column of homework behavior where homework time is but one of three components. The other two components are homework effort and learning strategies. Homework effort includes compliance, investment, concentration, and percentage of tasks completed and attempted. This is important because homework time, in itself, cannot indicate the quality of the effort a student puts forth. High amounts of time on homework do not equal high amounts of quality. Additionally, students who are having trouble with the classwork may spend more time on the homework and still not achieve at high levels even if the homework is of high quality. This is problematic in that it may lead researchers to a false conclusion on the time and achievement relationship.

Wagner's research (2008) supports this well. He found that low achieving students, on average, spend more time on homework than higher achieving students $(r=$ $0.15, p=.022)$. But he also found large, but not significant, variability in the amount of time high achieving students spend on homework - some spent a lot of time, and others not (Wagner, et al., 2008). This seems illogical if one assumes more time on homework would equal better grades. Therefore, simple measures of time do not give one a complete picture of the homework environment and effort exerted by the student.

Learning strategies address the question of quality homework time as well and tap into self-regulated learning characteristics. Students who make use of good learning strategies and organizational skills are giving themselves a better chance of making their 
homework time a quality experience over those students who do not possess the selfregulated learning skills.

Self-efficacy construct. Self-efficacy's importance to this research lies in its contribution to the development of self-regulated learning. Here, and in the sections that follow, self-efficacy will be described along with how its tenets contribute to the idea of self-regulated learning. Self-regulated learning is an important skill needed for successful completion of homework and its pertinence to this discussion is that the affective constructs in the model of this study are used as indicators of self-regulated learning characteristics. These characteristics are hypothesized to positively affect time spent on homework, which should be followed by an increase in science achievement for those students who display the self-regulated learning characteristics. An explanation of how parent education level is connected to self-regulated learning follows an initial description of self-efficacy.

A closely related motivational construct that has pertinence in this literature review is Self-Efficacy. Bandura (1997) developed this social-cognitive model and defines efficacy as a key component of human generative behavior (Bandura, 1997). Efficacy influences how humans react when facing everyday phenomenon. Self-efficacy, in particular, is confidence in one's ability to successfully plan, execute, and complete a task (Bandura, 1997). His definition includes multiple dimensions in strength, generality, and level (J. S. Eccles, Wigfield, A., 1995). This means that some individuals have a strong sense of self-efficacy while others do not (strength). Some people may only feel efficacious at easy tasks, others at hard tasks (level). Additionally, some may feel 
efficacious at a wide range of tasks, whereas others at only a narrow range of tasks (generality) (J. S. Eccles \& Wigfield, 2002).

An issue that is very important to self-efficacy constructs is that typically, selfefficacy researchers ask task-specific questions in regard to efficacy beliefs. It has been shown that context and task-specific self-efficacy questions need to be utilized when measuring specific efficacy constructs in order to obtain accurate and reliable data $(\mathrm{N}$. Choi, 2005). More general efficacy measures such as a general self-efficacy and academic self-efficacy are much less predictive of self-efficacy beliefs because their generality may be tapping into other more specific self-efficacy constructs (N. Choi, 2005). Furthermore, self-efficacy measures tend to be criterion-referenced as they ask respondents to evaluate themselves against their own past performance (N. Choi, 2005; Wigfield \& Eccles, 2000). For example, a self-efficacy questionnaire would ask a student to rate their agreement to the following statement, "I usually do well taking science tests." The question is specific in the task - test taking in science and the statement refers to the student's ability, not others. On the other hand, expectancy-value theorists tend to ask more domain-specific, general questions that are norm-referenced as they ask respondents to assess their abilities compared to others (N. Choi, 2005; Wigfield \& Eccles, 2000). An example would be, "Science is more difficult for me than for many of my classmates." Here, the topic is science in general and the student is being asked to compare themselves to other peers.

Self-efficacy makes some very meaningful contributions to educational contexts. Perceived efficacy, or one's belief about what one can do with given skills under different sets of conditions, plays a major role in the degree to which cognitive 
development can be initiated and sustained. Many factors contribute to cognitive development and eventual perceived academic efficacy. One of the more prominent of which is the social milieu of the child. Bandura (1997) notes that children's intellectual development cannot be separated from the social relations and interpersonal experiences they encounter every day; "Cognitive development and functioning are embedded in social relations" (p.228). At very young ages, students begin to discover their academic strengths and weaknesses through their interactions with their teachers and parents. Teachers, parents, and other influential adults, consciously and unconsciously, give children evaluative cues and signals on their academic abilities that children sense and internalize. Over time, children's interests evolve based in large part on the social molding that adults have done for them. Supporting this is research that demonstrates students' appraisal of their own academic capabilities are closely related to their teacher's judgments of them (Bandura, 1997).

Eventually, as the students move through school, whole classes of peers are well aware of the relative cognitive abilities of their classmates. There are those who are "smart", "dumb", "nerds", "jocks", and so on. The last two examples refer not only to the student's interests (science and sports), but also to their intellectual ability (smart and "less-smart"). In the teen years, peers hold a significant influence over a student's perceived academic self-efficacy. Bandura (1997) noted that a student's self-appraisal of his academic abilities is closely tied to those appraisals held by his peers. To this end, he said that students learn more from watching their peers demonstrate good cognitive learning skills than they do from adults demonstrating the same (Bandura, 1997). This holds true even when peers demonstrate under-developed cognitive skills. Bandura cites 
research where underachieving students were shown videos of peers using cognitive skills and strategies as they perform academic tasks. This peer modeling raises the students' beliefs in their efficacy for learning and their academic achievement. Bandura speculates that students see peer models as more like themselves, and therefore, believe they are capable of accomplishing the same tasks. In contrast, when observing adults, students see skills at a masterly level and cannot identify. They see adult behaviors as outside of their realm of capabilities (Bandura, 1997).

Bandura characterizes a student's maturation process in cognitive development where self-regulated learning is the culminating skill (Bandura, 1997). Moreover, he believes that the ultimate goal of any educational institution is to produce "life-long learners" whose primary quality is an inherent sense of learning for its own sake. In selfregulated learning, a student's well-developed sense of efficacy allows her to go beyond what is taught in class. She has interests that have cultivated her self-efficacy to a point where she can identify a desire, set goals, and maintain sustained effort to achieve the desire.

A key component of self-regulated learning is self-motivation. Two major aspects of self-motivation are perceived efficacy and intrinsic interest (Zimmerman, 2002). Bandura (1997) reflects this belief and identifies three components to motivation: (a) selection: the goal or object for which the person is motivated, (b) activation: the initiation of actions a person takes to achieve the selection and, (c) sustained direction of behavior towards the goal. Bandura states that attempts to explain motivation must include identification of the determinants and intervening mechanisms that control those three features (Bandura, 1997). In a sense, these two constructs form a feedback loop 
where the motivational qualities of Bandura are strengthened by the characteristics of Zimmerman's self-regulatory learning which themselves will turn around and strengthen Bandura's motivational qualities. More specifically, in order to be rightfully motivated, one needs to set goals, be self-aware of one's limitations and strengths, be able to control one's environment, so that learning can take place, and to reflect on progress to gauge future leaning activities. These mechanisms motivate the self-efficacious students to further learning pursuits as well as strengthen their own feelings of efficacy. As for intrinsic interest, Bandura (1997) argues that intrinsic interest manifests itself in tasks where perceived efficacy becomes greater - perceived efficacy determines interest. Expectancy-value theorists see intrinsic interest a little differently. They see intrinsic interest as a value that students can consciously choose to have for tasks whether they are efficacious at them or not. For them, the value of a goal provides motivation. Thus, a student need not be particularly efficacious at a task to be motivated by their valuation of the task. Zimmerman does not make clear his stance on this, but it is apparent that selfregulated learners must have a high sense of perceived efficacy as well as interest in what they are pursuing so that they can be successful.

Where homework is concerned, Zimmerman and Kitsantas (2005) used selfefficacy for learning, and perceived responsibility as mediating observed variables between student reports on homework practices and academic achievement (GPA). This study utilized path analysis which is a structural model for observed variables, (symbolized by rectangles) where a structural model represents hypotheses about cause and effect relationships (Kline, 2011). Traditionally, casual variables are shown to the left side of the diagram, and their effects are shown to the right. A single-headed arrow that 
represents the direct effect connects the observed cause and effect variables. The statistical analyses of these direct effects are called the path coefficients and can be interpreted as regression coefficients in multiple regression (Kline, 2011). Further, a mediational variable is one that is positioned between a causal variable and an effect variable and is theorized to transfer some of the variance from the causal variable to the effect variable in an indirect path. In Zimmerman and Kitsantas' study, aspects of selfregulated learning (finding good places to study, goal setting, studying every day, and completion of assignments) characterized homework quality. They found that prior achievement, as measured by the National Education Development Test, had a small, but significant, direct effect on GPA, $(\beta=.18, p<.05)$. This means that for every standard deviation increase in prior achievement, a student's achievement will increase .18 GPA points. Interestingly, when mediated by quality of homework, self-efficacy for learning, and perceived responsibility, prior achievements indirect effect more than doubled, $(\beta$ $=.39, p<.05)$. This would indicate that most of the variance in prior achievement was mediated through homework variables representing self-regulated learning strategies, and high senses of self-efficacy and perceived responsibility (Zimmerman \& Kitsantas, 2005). More importantly, the direct effect of quality of homework on GPA, was zero, $\beta=0.00$, whereas the indirect effect was significant $(\beta=.45, p<.05)$. This means that quality of homework's effect on GPA was completely mediated by self-efficacy and perceived responsibility beliefs. In other words, without the influence of self-efficacy for learning and perceived responsibility, the quality of homework would have not have influenced the students' GPA. Thus, it is vitally important to include affective/motivational components to a model that studies the interaction of homework and achievement. 
The argument that follows will attempt to show that the affective constructs of self-confidence, positive valuation, and positive affect reflect the same characteristics of self-regulated learning.

It has been made clear that parental education level significantly impacts student attitudes, confidence, and valuation. Thus, it would follow that self-regulated learning is influenced indirectly by parent education level as well because attitude and self-regulated learning are key components of each other. As mentioned previously, self-regulated learners are those who work proactively to obtain knowledge by understanding that learning will occur through their actions and is simply not an event that occurs as they passively sit in the classroom. Several researchers have shown the intimate interaction of parental education level (expectations), student attitudes, emotion and self-regulated learning (Dettmers, et al., 2011; Pekrun, 2002; J. Xu, 2010). Typical behaviors/attitudes that must be present in students who demonstrate self-regulated learning are heightened feelings of self-efficacy, motivation, and confidence in one's ability to do the work and creation of an environment conducive to completing the work, including management of time to facilitate completion of homework.

$\mathrm{Xu}$ (2010) measured the influence of parent education level on homework time management in secondary students and found, in a multi-level model, that parent educational level had a significant effect on homework time management (a selfregulated learning trait) at the class level $(\beta=.16, p<.05)$. For every one standard deviation increase in parent education level, the student's time management of homework went up .16 standard deviations. This is important because it demonstrates that some function of parent education level has a positive effect on an aspect of self-regulated 
learning and that well educated parents have some way of instilling in their children the characteristics that predispose them to learning the qualities of self-regulated learning. The subsequent acquisition of self-regulated learning contributes greatly to achievement.

Parent education level has also been shown to slow down the loss of self-efficacy beliefs in students as they get older (Caprara, et al., 2008). Caprara et al. (2008) performed a longitudinal study of 412 students from the time they were twelve until they were twenty-two. Through SEM, they measured the meditational effects of perceived efficacy for self-regulated learning on socio-economic status (as measured by parent education level and occupation) and achievement. Their results showed that socioeconomic status slowed down the loss of perceived self-efficacy that students normally go through during this age period. In other words, students typically lose some degree of perceived self-efficacy as they age. In this study it was found that those students from higher socioeconomic backgrounds lost less over time than those who came from lower socioeconomic backgrounds with total indirect effects being, $\beta=.11, t=3.93$ for males and $\beta=.12, t=3.93$ for females (all $t$ values above 1.65 are significantly different from zero) (Caprara, et al., 2008). These results are growth curve parameters and indicate that the higher the parents socio-economic status, the greater their child's retention of selfregulated learning traits.

It is important to tie the ideas of self-efficacy theory to Trautwein's expectancyvalue influenced homework model, so one can tie together expectancy value theory and self-efficacy and realize the similarity and importance of these two theories to this research. In reference to Trautwein's homework model, the left side containing the learning components; student characteristics and roles of the parents, can be seen as the 
social milieu of the child as described by Bandura. These components could include previous knowledge at the student level. At the parent level this can be socioeconomic factors such as parent education, income, occupation, and social and economic resources that provide educational advantages.

The middle of the model contains the expectancy and value components. The expectancy component can be directly related to perceived efficacy. In fact, its description of a "feeling of competence regarding homework in a specific subject" (Trautwein, Ludtke, Schnyder, et al., 2006) could be interpreted as a feeling of competence in any given task which is very similar to Bandura's definition of perceived efficacy (Bandura, 1997). Two statements, one of which is "Interest and attainments value in content matter covered", describe the value component. This is describing the inherent interest a student has for the subject as well as their interest in the content as a means to further their endeavors.

The right column, describing homework effort, homework time and learning strategies, is an iteration of the self-regulatory qualities Zimmerman (2002) clarified in his research. Trautwein's model descriptors under homework effort are compliance, investment, concentration, and number of tasks completed/percentage attempted. Under homework time the descriptors are time on homework and additional learning time. Under learning strategies are cognitive, and metacognitive strategies. Conscientious, selfregulated learners display all of these traits Trautwein mentions; they are compliant of the homework responsibilities given them. They invest in time, resources, and construct a favorable working environment in order to complete their homework. They are selfaware of their cognitive abilities and take steps to augment or adapt what they can do 
through metacognitive practices that will enable them to succeed. In support of this, Zimmerman (2005) found that stronger self-regulated learning/homework behaviors will strengthen perceived efficacy/expectancy. He placed self-efficacy and perceived responsibility after homework in his path model and found the significance described earlier. Conversely, he found that making perceived responsibility and self-efficacy for learning the causal variables of homework's effect on GPA, resulted in an ill-fitting model, $\chi^{2}(2)=101.24, p<.001$ (Zimmerman \& Kitsantas, 2005). Thus, Zimmerman demonstrated that homework beliefs, in effect, caused the efficacy and responsibility beliefs of the students and not the reverse. This is the opposite of what Trautwein modeled. There, expectancy-value is placed before homework with the assumption that expectancy beliefs and the inherent value a student has for the subject will positively influence homework effort and, eventually, achievement. Conflicting evidence begs the need for further research in this causal loop.

Additional Differences Between Self-efficacy and Expectancy-Value

Compared to expectancy-value theory, Bandura's theory relies heavily on the expectancy side of the expectancy-value equation. His theory distinguishes itself between two types of expectancy beliefs: outcome expectations and efficacy expectations. Bandura defines outcome expectations as beliefs that certain actions can result in certain outcomes, while efficacy expectations are the beliefs that one can actually perform the behaviors required by the task (J. S. Eccles, Wigfield, A., 1995). An example would be an employer believing that an employee will get better at a task given more practice (outcome expectation), but also understanding that the employee will never perform the task as it was intended due to the employee's lack of skills (efficacy expectation). 
Achievement related choices and performance are directly influenced by a person's expectancy of success and the values that person has for the choice. These, in turn, are influenced by task-specific beliefs such as the assessment of one's ability for the task, the perceived difficulty of the task, the person's goals and self-schema, as well as the person's previous success or failure at similar tasks. These factors themselves are influenced by individual's perception of other people's attitudes towards the tasks and of themselves (J. S. Eccles \& Wigfield, 2002). Therefore, it is important to look at variables that describe these factors when analyzing student achievement in light of homework.

Finally, self-efficacy explains the development of self-regulated learning and selfregulated learning is significantly related to parent education level through the expectations of the parents. A high degree of self-regulated learning is the ultimate achievement of the fully self-efficacious student. This is an important concept as it relates to homework because this learning activity takes place outside of the structured classroom environment where a teacher is not present to keep the student on task. A connection had to be made between parent education level and the student affective characteristics of valuation, positive affect, and self-confidence. This is accomplished primarily through parental expectations as can be seen in Figure 5. 


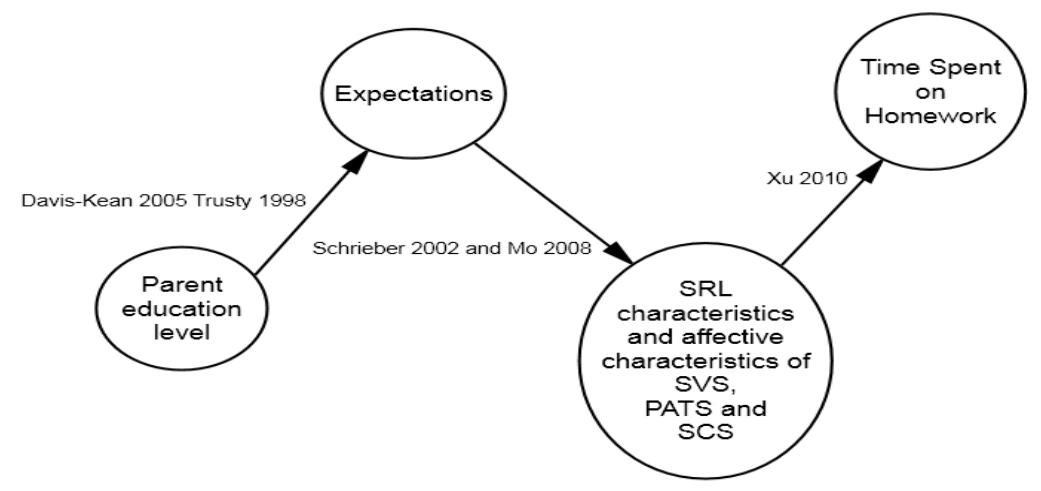

Figure 5. Summary diagram of parent education level's connection to student affective characteristics, self-regulated learning, and homework.

\section{Summary}

A review of the literature on homework reveals an immensely complex educational practice whose utility is influenced by a multitude of potential variables. While the qualities of homework duration and frequency have been fairly well documented, researchers have recently uncovered many other aspects of homework that can not only explain how it works best, but how it can be altered to work even better.

Motivational aspects of student homework behavior have come to the front of current research and help explain a lot of the success and failures of homework as an instructional tool. Trautwein and his colleagues (Trautwein, 2007; Trautwein, Koller, Schmitz, \& Baumert, 2002; Trautwein \& Ludtke, 2007, 2009; Trautwein, et al., 2009) have elucidated the motivational aspects of homework quite elegantly. Their homework model, which incorporates aspects of Eccles and Wigfield (2002) expectancy-value model, creates a framework on which further research could continue to establish relationships between homework, motivation and antecedent factors such as parent education level and gender. 
Table 1 shows a summary of major studies relevant to this study. Of all of the research cited in this literature review, none address a relationship where parent education level, gender, attitudinal variables, and homework have been brought together in a structural equation model that could attempt to examine a causal relationship among these variables.

\section{Table 1}

$\underline{\text { Summary of Evidence and Variable Relationships }}$

\begin{tabular}{l} 
Relationship \\
\hline Parent education level \\
Parent education level to \\
affective variables
\end{tabular}

Self-regulated learning as student affective variables

Expectations to affective variables/self-regulated learning

Gender to affective variables/self-regulated learning

Affective variables/selfregulated learning to homework

Homework to achievement

\section{Evidence}

- Parent education level is a good indicator of SES (Sirin, 2005)

- Parent education was used as the sole indicator of SES or was one of two indicators used (Caprara, et al., 2008; Schreiber, 2002)

- Higher educated parents tend to be more involved in child's schooling (Caprara, et al., 2008; Sirin, 2005)

- Directly influences the quality of the relationship between school personnel and parents (Sirin, 2005)

- Parent education level (at the school level) explained part of the variance in student attitude (Schreiber, 2002)

- Somewhat inconclusive, yet self-motivation and self-regulated learning influence each other where self-motivation is composed of perceived efficacy (confidence) and intrinsic interest (Zimmerman, 2002)

- Explanations of motivation must include the determinants and mechanisms that control motivational processes. These mechanisms include perceived efficacy (confidence) (Bandura, 1997)

- Parental expectations positively affected student cognitive engagement that includes self-regulated learning (Mo \& Singh, 2008)

- Gender can indirectly effect homework behavior, through the demonstration of self-regulated learning /affective traits (Harris \& Nixon, 1993; Hong \& Milgram, 1999; Trautwein \& Ludtke, 2009; Wagner, et al., 2008; J. Xu, Corno, Lyn, 2006)

- Motivational factors heavily influence homework behavior (Trautwein, 2007; Trautwein \& Koller, 2003; Trautwein \& Ludtke, 2007; Trautwein, Ludtke, Kastens, et al., 2006; Trautwein, Ludtke, Schnyder, et al., 2006; Trautwein, et al., 2009)

- Increasing amounts of homework may lead to higher achievement (Cooper, et al., 2006; Dettmers, et al., 2009; Dettmers, Trautwein, Ludtke, Kunter, \& Baumert, 2010) 


\section{Research Questions}

This study will decipher the relationship between the variables in the proposed model by answering the following research questions:

1. Does gender have an indirect effect on time spent on homework through the affective variables associated with self-regulatory learning (self-confidence in science, positive affect towards science, and students valuing science)?

2. Does parent education level have an indirect effect on time spent on homework through the affective variables associated with self-regulatory learning (self-confidence in science, positive affect towards science, and students valuing science)?

3. Does time spent on homework have a significant mediating effect between self-confidence in science and science achievement?

4. Does time spent on homework have a significant mediating effect between positive affect toward science and science achievement?

5. Does time spent on homework have a significant mediating effect between students valuing science and science achievement?

6. Is there gender invariance in the model?

The questions have been modified from those presented in the Introduction because the Literature review illuminated a meaningful difference in the effects of the individual affective variables on homework. Therefore, the third research question in the introduction has been split into three questions (\#3-\#5). The sixth question is being asked at the request of the Dissertation chair. Question six is an excellent addition because it is 
important to identify any gender discrepencies within the model if it is used again in later research. 


\section{CHAPTER III}

\section{METHOD}

This chapter describes the design of the study, the instrumentation used, and statistical analysis used to answer the research questions.

\section{Purpose}

This is a multipurpose study to determine if homework has a significant mediating effect between student affective variables associated with self regulated learning and science achievement as measured on the Trends in International Math and Science Study (TIMSS) 2007. Specifically, does homework act as a significant mediator between student affective variables towards science (student self-confidence in science, positive affect toward science, and student valuation of science) and science achievement? Gender and parent education level, both of which are known to significantly impact these variables, will be included in the analysis.

Research Questions

This study's research questions are asked to illuminate and clarify the meditational effect of homework between student affective variables and science achievement as depicted in this study's theoretical model.

1. Does gender have an indirect effect on time spent on homework through the affective variables associated with self-regulatory learning (self-confidence in science, positive affect towards science, and students valuing science)? 
2. Does parent education level have an indirect effect on time spent on homework through the affective variables associated with self-regulatory learning (self-confidence in science, positive affect towards science, and students valuing science)?

3. Does time spent on homework have a significant mediating effect between self-confidence in science and science achievement?

4. Does time spent on homework have a significant mediating effect between positive affect toward science and science achievement?

5. Does time spent on homework have a significant mediating effect between students valuing science and science achievement?

6. Is there gender invariance in the model?

\section{Research Design}

This study employs the quantitative method of Structural Equation Modeling (SEM) to identify causal relationships among parent education level, affective student traits, homework, gender, and science achievement among a population of United States eighth graders. The data were obtained from the 2007 administration of the Trends in International Math and Science Study (TIMSS). Specifically, SEM will be used to analyze the covariance patterns among the identified variables that will be arranged in an a priori manner in order to identify causal relationship among the variables (Kline, 2011). The results from the data analysis will determine if the data fits the proposed model. If the fit is poor, then the model will be modified in order to improve its fit to the data. 


\section{Study Participants}

The complete study encompassed 425,000 students worldwide in both fourth and eighth grade. This report deals only with the population of eighth graders living in the United States. These students were chosen because this study was primarily designed to examine the relationship between homework and science achievement in the United States. Eighth graders were chosen over fourth graders because Cooper's research (1986) showed that homework was ineffective in the primary grades, but became effective beginning in the middle school years. The sample included a randomly selected group of both public and private school students who were at the end of their eighth grade year. 239 schools encompassing 7,377 American eighth graders were administered the survey. $51 \%$ of the students were female and $49 \%$ were male. Ethnic groups represented included White, Black, Hispanic, Asian, and Multiracial.

A 2-fold cross-validation method will be used in this research in order to lend credibility to the analysis (Cross-validation (statistics)). The total sample of United States eighth graders will be randomly assigned to two groups. One group will be designated the exploratory set which will be used to test the proposed model for goodness of fit where possible changes to the model can be made including the addition/deletion of paths. The other set will be designated the validation set. The validation set will be run on the finished model developed by the exploratory set allowing the model to be run on a completely on two different sets of data (Keith, Diamond-Hallam, \& Fine, 2004).

Student Responses. This study makes use of student level data, which are of major importance because students are the key to the effectiveness of homework as a tool in the classroom. Homework is created and utilized in the classroom by the teachers, but its 
instructional capability is only achieved if the students do it. If they did not complete the homework, then its utility is gone. Teacher plans for reviewing the homework are useless if the homework is not complete because homework review relies upon the students being in a certain frame of mind to accept and incorporate the information from the homework. Xu (2011) found that $94.34 \%$ of the variance in homework completion occurs at the student level.

Moreover, the psychological components are aspects of the student responses. The homework expectancy component, which deals with a student's belief that they can successfully complete a homework assignment, and the value component, which measures a student's willingness to do the assignment, are both psychological components from the student (Dettmers, et al., 2010). These two components, together, describe student motivation for completing assignments (Trautwein \& Ludtke, 2009). This is a crucial aspect of the homework model.

Further evidence in support of using student responses comes from researchers who have analyzed homework data collected from differing sources; teachers, students, schools, administrators, etc. They say it is interesting to note from whom one collects it. Collecting data from different sources is advantageous because Cooper (2006) identified an inconsistency in student vs. teacher homework reporting. He hypothesized that this was due to the students and teachers being on different parts of the homework spectrum. Teachers are centered in the classroom and are unaware of the environment in the home. Students migrate between school and home environments and are aware of both scenarios. Because of this, some researchers believe that students are the best source of homework 
data (Dettmers, et al., 2010). Thus, it would be advantageous to obtain data from the student to give a more accurate representation of homework variables.

Homework time and frequency variables are significant for students. In fact, Dettmers, Trautwein, et. al. (2010) argue that student ratings on these variables may be more reliable than teacher or third party observer ratings. They point out that professional observers can be costly and labor intensive while teachers can be victims of pride in that their responses can be biased towards the positive to make them look better. Students, on the other hand, are experts in their own right. They have years of experience in different teachers' classrooms. They know when a teacher is effective and when they are not. The teacher dictates their motivations and interest in the classes. In addition, the student is an integrated part of the mechanisms of the classroom and their homework behavior and attitudes towards it are colored by the influences of the classroom. Objective observers would not have this and teachers can often be unaware of student level dynamics (Dettmers, et al., 2010).

\section{Statistical Analysis}

Structural equation modeling (SEM). Structural equation modeling (SEM) will be used to analyze the mediating effect of homework between student affective variables (self-regulated learning) and science achievement.

SEM is a type of non-experimental statistical method for determining the causal relationships among variables of interest (Keith, et al., 2004). An important aspect of this is the causal relationship developed by the researcher that reflects his theory of how the variables are related to each other (Keith, et al., 2004). Thus, it is very important that the researcher provide solid evidence for the arrangement of the variables in the model. If the 
model approaches the causal relationships in the real world, then the model is considered a good fit (Keith, et al., 2004).

The basic statistic of SEM is the covariance which is the product of the standard deviations of two observed, continuous variables and their Pearson correlation (Kline, 2011). The covariance represents the strength of the relationship between the two variables and their variances. Thus, the aim of SEM is twofold; (a) to decipher the relationships between covariances of observed variables, and (b) explain as much of the relationship with the researcher's model as possible (Kline, 2011).

SEM accomplishes the second goal by using an iterative estimation process known as maximum likelihood (ML). ML derives parameter estimates that maximize the likelihood that the data were drawn from the population (Kline, 2011). To analyze the data in SEM, the researcher enters the specifications of the model along with the data into the SEM software. The data set can take the form of a pre-made covariance matrix or raw data (here, the software would create the covariance matrix on its own). Once the parameters have been set and the data entered, the job of the software is to compare the entered covariance matrix with the covariance matrix estimated by the researchers model. The software attempts to minimize the differences between the two models with the final result being the "goodness-of-fit" indicators as described below.

Kline (2011) outlines the procedural steps of performing an SEM analysis and this will be the same process used in this research. First, an a priori model, or a model that was developed prior to analysis, is specified by arranging the variables in such a manner as is dictated by the theoretical arguments presented in the literature review. The specification makes use of standard shapes that signify different variables (square shapes 
vs. circles) and relationships (single vs. double-headed arrows). The combination of these shapes and arrows define the model's parameters and relationships between the variables (Kline, 2011). This step is the most important as it determines both the correctness of the model and the results of subsequent steps (Kline, 2011). Second, the model is identified. In other words, the computer must be able to theoretically derive a unique estimate for every parameter of the model. If the model is not identified, then it must be respecified (as in step 1) or it cannot be analyzed (Kline, 2011). Non-identification assumes that there was a specification error which means that a causal effect was left out or a connection needs to be deleted. Third, the data will be prepared and screened for problems. Fourth, the model will be estimated. This involves three events; (a) the model fit will be evaluated, which determines how well the model explains the data (Kline, 2011). When fit is bad, then the researcher needs to go back to step one and respecify. (b) If model fit is satisfactory, then the parameter estimates need to be interpreted. In this case the researcher needs to go back and review the details of the metrics of the interactions to ensure that they make sense in light of the theoretical underpinnings of the model. (c) The researcher needs to consider equivalent models. Oftentimes, there are models that fit the data just as well as the researcher's model, but have minor changes in their structure that could allow alternate, significant interpretations of the relationships in the model (Kline, 2011).

Once a model is specified and identified, the goodness of fit, along with parameter estimates, will determine whether or not the researcher keeps the model or respecifies it. Determination of model fit is a two-step process that involves running a chisquare test on the model and then running various "goodness of fit" indices. A non- 
significant chi-square result indicates an acceptable model fit. However, the chi-square test alone leaves too many factors unanalyzed that could indicate problems, such as large covariance residuals or many small ones (Kline, 2011). Additionally, chi-square tests are not good for large sample sizes such as the one used in this study. Therefore, several approximate fit indices can be used to support the conclusions of the chi-squared test. In this study Root Mean Square Error Approximation (RMSEA), Comparative Fit Index (CFI), and Standard Root Mean Residual (SRMR) will be used. RMSEA reflects the degree of poor fit of the model, and the value ranges between zero and one, where zero is the best fit. This index is important because it is a parsimony-adjusted index (indices that penalize more complex models) that does not make use of a chi-square distribution (Kline, 2011). CFI is an incremental fit index that demonstrates the improvement of the model fit compared to a default model (a null model that assumes a zero relationship between variables). CFI adds a penalty for increasing model complexity. Their range is zero to one with the better fitting models having values close to one (Kline, 2011). SRMR is a measure of the overall difference between the observed and predicted correlations. No difference is indicated as a value of zero, which would indicate a perfect match between the correlations of the default model and the correlations of the tested model. So, values closer to zero are preferred with values $\leq .08$ indicating an adequate fit and values $\leq .06$ being a good fit

There are four reasons why SEM is preferred: (a) It allows complex phenomena to be statistically modeled and tested. (b) SEM takes measurement error into account in its analysis. Many other techniques separate the error from the statistical analyses. (c) SEM modeling and analysis have advanced greatly since its inception. Currently, multi- 
level modeling, and multi-group modeling can now be reliably analyzed using SEM. (d) SEM software programs are now extremely user friendly. SEM inputs have gone from researchers having to enter Greek and matrix notations to using Windows-types pull down menus (Schumaker, 2010). In that regard, the SEM software used in this analysis is IBM AMOS 20.

This research uses a type of basic SEM called a hybrid model. Hybrid models are a combination of a structural model and a measurement model. The structural portion of the model allows for the testing of hypothetical direct and indirect causalities. However, unlike path analyses, the structural component of SR models allows for latent variables because there is a measurement component that represents observed variables as indicators of factors (Kline, 2011). Figure 6 below indicates the hypothesized structural and measurement models of the present research. 


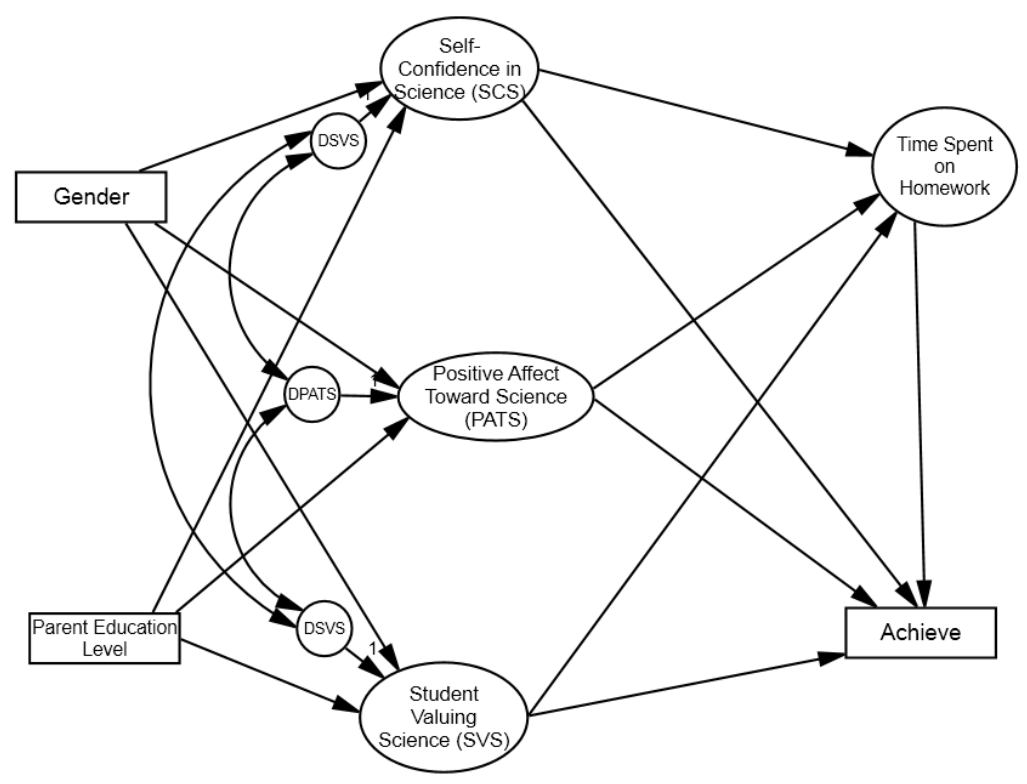

(a) Structural model

(b) measurement model

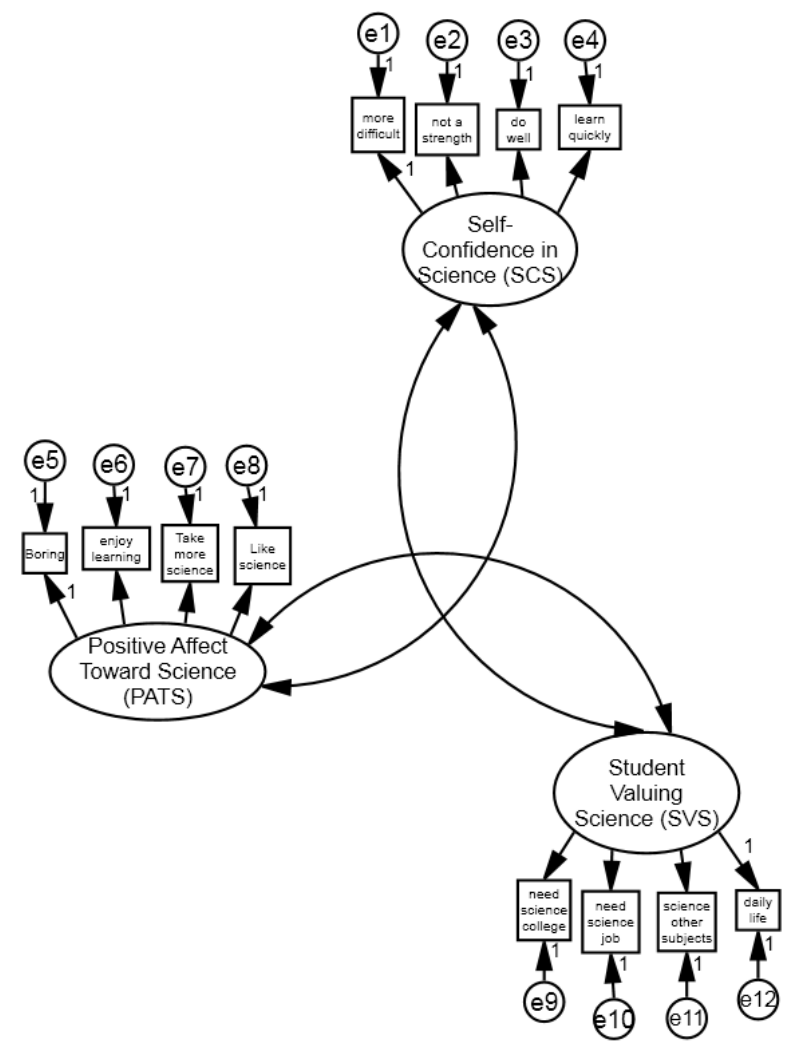

Figure 6. Hypothesized structural and measurement models. 
Structural equation modeling makes use of several terms to identify the variables and relationships present in the model. Table 2 lists pertinent terms and their definitions.

Table 2

Common SEM Terms and Their Definitions

\begin{tabular}{ll}
\hline Term & Definition \\
\hline Latent Variable & $\begin{array}{l}\text { A variable that is not measured. Also called an unmeasured or unobserved } \\
\text { variable or factor. }\end{array}$ \\
$\begin{array}{l}\text { Exogenous (Causal) } \\
\text { Variable }\end{array}$ & $\begin{array}{l}\text { A variable that is not caused by another variable in the model. This variable } \\
\text { usually causes one or more variables in the model. }\end{array}$ \\
$\begin{array}{l}\text { Endogenous (Effect) } \\
\text { Variable }\end{array}$ & $\begin{array}{l}\text { A variable that is caused by one or more variables in the model. This variable } \\
\text { may also cause another endogenous variable in the model. }\end{array}$ \\
Disturbance & $\begin{array}{l}\text { Unspecified causes of an endogenous (effect) variable. Similar to an error or } \\
\text { residual in a prediction equation. Each endogenous variable usually has a } \\
\text { disturbance. }\end{array}$ \\
The set of structural equations. Path analysis. \\
Path Diagram
\end{tabular}

Source: Kenny, D. A. (2011). Terminology and basics of SEM. Available at: http://davidakenny.net/cm/basics.htm

The use of maximum liklihood (ML) as the estimation method used in SEM supposes certain assumptions that must be met in order for the results to have meaning. These are (a) independence of observations, (b) multivariate normality of the endogenous variables (because ML is a normal theory method and the endogenous variables are assumed to be normally distributed in the population), (c) independence of exogenous variables and disturbances, (d) structural model assumes exogenous variables are measured without error, (e) correct specification of the model (nothing has been left out that could account for variability), and (f) ML assumes that all variables are unstandardized and there are no missing data (Kline, 2011). Arguably, the most important 
assumption is "e". Here, it's important to understand that ML makes use of the entire, model-implied covariance matrix ( a.k.a full-information method) and one specification error could have a domino effect throughout the model leaving the researcher with an illfitting model when in fact, it may fit well had that one parameter been included. Identification of a structural equation model can take one of three forms: (a) Under-identified describes a situation where one or more parameters are not identified due to lack of information in the covariance matrix. (b) Just-identified models have all of the parameters uniquely identified due to just the right amount of information in the covariance matrix. (c) Over-identified models have more than one diagrammatic solution to the information in the covariance matrix (Schumaker, 2010). In terms of measurement and structural models, the rules for identification are simple. Measurement models are identified if the confirmatory factor analysis (CFA) model (the same as the measurement model) has greater than two factors and each factor has more than two indicators. Figure $6 \mathrm{~b}$ shows the measurement model and there are 3 factors with 4 indicators each, thus the model is identified. Once the measurement model is identified, then the structural model can be as well. For structural models, if the model is recursive, then the model is identified. Yet, if the model is non-recursive then certain parameters must be met for it to be identified. A non-recursive model has feedback loops between variables and correlations between the disturbances of endogenous (effect) variables that have direct effects between them (Kline, 2011). Figure 6a, then, shows a recursive structural model where the disturbances are correlated, yet, there is no direct effect between them. In other words, there are no arrows going between the latent variables of Positive Affect Towards Science, Students Valuing Science, and Self-Confidence in Science. 


\section{Sample Design}

This study utilizes the 2007 Trends in International Mathematics and Science Study (TIMSS) that was administered in the U.S.A between April and June of 2007. The TIMMS is an international, longitudinal survey of science and mathematics achievement that has been administered every four years since 1995. TIMSS is developed and administered by the International Association for the Evaluation of Educational Achievement (IEA) that has its U.S. base at Boston University. TIMSS measurements of math and science achievement, as well as its collection of contextual information on a global scale, allow it to supply a wealth of reliable and pertinent data for education professionals worldwide.

In 2007 TIMSS was administered in 67 countries and involved 425,000 students in grades four and eight. Ensuring a random sample that would accurately reflect the population was of utmost importance. Therefore, a National Research Coordinator (NRC) was assigned to each country and was in charge of administering the sampling design devised by IEA. A national desired target population was defined for each country based upon the United Nations Educational, Scientific, and Cultural Organization's (UNESCO) International Standard Classification of Education (ISCED). These desired target student populations were of two levels: (a) Children who had completed four years of formal schooling from the first year of ISCED level 1 (fourth grade) and whose age did not severely deviate from average age of 9.5 years. And (b) children who had completed eight years of formal schooling from the first year of ISCED level 1 (eighth grade) and whose age did not severely deviate from average age of 13.5 years. Countries could choose to test either grade level or both. Countries that had tested previously were asked 
to test the same populations. Students in each tested country identified all of the students who fit these criteria. This became the country's desired target population. However, not all students met these criteria.

Stringent rules were created to ensure that schools and students were selected in such a way that exclusion from the study was difficult. Exclusion rules were at two levels: school-level exclusions and within-school exclusions. At the school-level, schools could only be excluded if (a) schools were geographically remote, (b) schools had very few students, (c) the curriculum or structure of the school was fundamentally different than the typical schools in the educational system, and (d) schools created specifically for students with special needs. At the within-school level, the criteria for exclusion included: (a) students with intellectual disabilities, (b) students with functional disabilities and (c) non-native language speakers. Taken together, the final list of students who were tested became the national defined population. If the national defined population was less than $95 \%$ of the national desired target population, this was annotated in the results. For United States eighth graders, $100 \%$ of the target population was covered. There were no school-level exclusions and an overall within-school exclusion rate of $7.9 \%$.

Due to the hierarchical nature of the units, sampling was done in stages. A twostage stratified cluster sample design was used. The first sampling stage involved schools. National Research Coordinators (NRCs) were required to provide four pieces of information on each school within their country where fourth and eighth graders could be tested in order to ensure that the selected schools were representative of the student populations (Joncas, 2008). These four pieces of information were, 
1. Measure of Size: number of students, number of students per class, number of classrooms at grade level.

2. Minimum Cluster Size: the expected number of sampled students per class if the number of classrooms in the target grade could not be provided.

3. Variables: any variables that describe characteristics of the school such as type of school, sex of students served by school.

4. School Sampling Probability and status: was the school already participating in another study where control was shared with another international study?

Once above information was complete and known to the selection committee, schools and classes were chosen in a systematic, random sampling utilizing a two-stage probability proportional to size (PPS) technique. Here, schools are chosen first and then the classes within those schools are chosen second (Joncas, 2008). The researchers believed that this was an excellent technique given the hierarchical nature of the sampling units (Joncas, 2008). At the root of this sampling technique is the probability for selection based on size. For example, if school A is twice as large as school B, then school A had twice the chance (probability) of being selected over school B.

School stratification was used to complete the process of selection. This step places the schools into smaller samples, according to the initial information obtained by the NRCs, in order to improve the efficiency of the sampling technique or ensure the presence of the desired groups of interest in the sample (Joncas, 2008). Stratification can be either explicit or implicit. In explicit stratification, smaller sampling frames are created when the usual proportional allocation may not result in adequate representation of target groups. For instance, the schools could be purposely divided into private and public 
schools in order to ensure a sampling of private school students if the number of public schools is overwhelmingly large. In implicit stratification, schools sampling is sorted according to a previously defined variable(s) prior to sampling. Examples of implicit strata in the TIMMS data are rural vs. urban and private vs. public. The United States sample used only implicit stratification. The implicit stratification used was by school type (public, private), geographic location (northeast, southeast, mid-west, west), location indicator relative to populous areas ( 8 categories), and minority status (above/below 15\% minority), for a total of 128 implicit strata (Joncas, 2008).

Once the schools were chosen, the second stage sampled classes. In this stage, the countries had only to supply the researchers with all the fourth and eighth grade classes, in addition to class sizes, from the schools that had been chosen through the first stage of the selection process. This included both regular education and special education classes along with a listing of all the students in the classes. If a class was chosen, then all students within that class were sampled except for those students who met the student exclusion criteria (intellectual or functional disabilities, and non-native language speakers) (Joncas, 2008). In the United States, two classrooms per school were sampled. Sampling weights. A statistical correction of sampling weights were used in TIMSS 2007 in order to compensate for the over or under-representation of certain student populations in the sample design. An overall student sampling weight was assigned to each student and was comprised of three sub-weights; school, classroom, and student.

The basic school weights were calculated as the inverse of the probability of the school being sampled in the first stage. In order to prevent very large schools from being 
oversampled, they were given weights equal to the sampling interval so that all of them had equal probability of being sampled. The same is true for very small schools. They were assigned a constant in order to ensure equal probabilities of being selected. These methods were done outside the normal explicit stratifications. Additionally, the basic school weights were adjusted through a multiplier for non-participation (Joncas, 2008).

The classroom weight functioned in the same fashion as the school weights. A basic classroom weight was derived as the inverse of the probability that a classroom within a target school would be selected. One to three classrooms were chosen per school, therefore, the probability of selection was determined as the total number of classrooms over 1, 2, or 3. A multiplier for non-participation adjusted the basic weight. Classes that had less than 50\% participation were considered non-participants (Joncas, 2008).

Student weights were equivalently set to 1.0 for all students in a selected classroom since all students were chosen if a specific classroom was picked. Nonparticipation adjustments were made at this level as well (Joncas, 2008).

Student weights were the product of the three final weights, after nonparticipation adjustments. In this weighting strategy, typically sampled schools (not very large or small) had school and classroom weights that varied, but students in the same classroom would have equal weighting (Joncas, 2008)

\section{Variables}

Effect (dependent) variable. For this study, science achievement is the final effect variable and is represented by five plausible scores obtained on the TIMSS 2007 science assessment. The scores range from a low of 200 to a high of 800 . The test covers all the major science topics; biology, chemistry, physics, and earth science. The student science 
achievement scores are reported as five plausible values (discussed later) as determined through IRT scaling and multiple imputation. All five of these scores will be used as the effect variable.

Causal (independent) variables. A review of the TIMMS contextual questionnaire found twenty-one questions dealing with the students' home life, family background, classroom practices, and activities both outside and inside of the classroom. The following independent variables, from the background questions, were used in this study and will be discussed in detail here after: parent education level (PEL), student's value of science (SVS), student's positive affect towards science (PATS), student's selfconfidence in science (SCS), homework frequency and homework time (TSH), and gender.

Table 3

$\underline{\text { Summary Table of Variables and Rationales }}$

\begin{tabular}{lll}
\hline Variable & Latent Variable Indicators & Rationale \\
\hline 1. Science Achievement: Dependent Variable & \\
N/A (observed variable) & - \\
\hline
\end{tabular}

2. Index of Student Time Spent on Science Homework (TSH)

- Homework time

- Homework frequency
Students who spend more time on homework may achieve at higher levels than those who do not.
3. Parent Education Level

$$
\text { N/A (observed variable) }
$$

Evidence shows that students from families whose parents are more educated achieve at higher levels than those students from homes of less educated parents (Davis-Kean, 2005; Sirin, 2005; J. $\mathrm{Xu}, 2010)$. 
Table 3 (cont.)

Summary Table of Variables and Rationales

\begin{tabular}{|c|c|c|c|}
\hline \multicolumn{2}{|c|}{ Variable } & \multirow{2}{*}{$\begin{array}{l}\text { Latent Variable Indicators } \\
\text { Attitudes Toward Science }\end{array}$} & \multirow[t]{2}{*}{ Rationale } \\
\hline 4. & Indices of Studer & & \\
\hline a) & $\begin{array}{l}\text { Positive Affect } \\
\text { Toward Science } \\
\text { (PATS) }\end{array}$ & $\begin{array}{l}\text { - I enjoy learning science. } \\
\text { - Science is boring (reversed). } \\
\text { - I like science. } \\
\text { - I would like to take more } \\
\text { science in school. }\end{array}$ & $\begin{array}{l}\text { Shown to be an important aspect in } \\
\text { science achievement (House, 2009); } \\
\text { (Trautwein, Ludtke, Schnyder, et al., } \\
\text { 2006). }\end{array}$ \\
\hline b) & $\begin{array}{l}\text { Student Valuing } \\
\text { Science (SVS) }\end{array}$ & $\begin{array}{l}\text { - I think learning science will } \\
\text { help me in my daily life. } \\
\text { - I need science to learn other } \\
\text { school subjects. } \\
\text { - I need to do well in science to } \\
\text { get into the university of my } \\
\text { choice. } \\
\text { - I need to do well in science to } \\
\text { get the job I want. }\end{array}$ & $\begin{array}{l}\text { Valuing homework becomes more } \\
\text { important in older students as a } \\
\text { motivational tool (Trautwein, Ludtke, } \\
\text { Kastens, et al., 2006; Wigfield \& Eccles, } \\
2000 \text { ). }\end{array}$ \\
\hline c) & $\begin{array}{l}\text { Self- } \\
\text { Confidence in } \\
\text { Science (SCS) }\end{array}$ & $\begin{array}{l}\text { - I usually do well in science. } \\
\text { - Science is more difficult for me } \\
\text { than for many of my classmates } \\
\text { (reversed). } \\
\text { - Science is not one of my } \\
\text { strengths (reversed). } \\
\text { - I learn things quickly in } \\
\text { science. }\end{array}$ & $\begin{array}{l}\text { Homework expectancy beliefs and } \\
\text { homework emotions (a.k.a., self- } \\
\text { confidence) significantly predict math } \\
\text { achievement (Dettmers, et al., 2011; } \\
\text { Pekrun, 2002). }\end{array}$ \\
\hline
\end{tabular}

5. Gender

N/A (observed variable) Gender is seen as a significant contributor to the relationship between homework and achievement (Wagner, et al., 2008; J. Xu, 2007; J. Xu, Corno, Lyn, 2006).

Important Note: TIMSS created composite indices (Index Variables) for some select background variables (including the ones used in this research) in order to combine multiple item indicators into one indicator with three levels. These being: (a) Low responses expected to characterize the least supportive learning environment. (b) High responses expected to characterize the most supportive environment. (c) Medium somewhere in between High and Low. The indices attempt to describe factors that are 
found to enhance science and math education and are stated in such a way as to leave little room for interpretation. All derived background indices had component variables that are inter-correlated so together they form a reliable scale. Additionally, the TIMSS researchers created the classification cut off points and combination of responses for high, medium, or low classifications, with achievement in mind. Those combinations and scales that were high were considered to have the highest correlation to math and science achievement. Those that were low were considered the least likely to produce achievement. These correlated relationships were judged to be high, medium, and low by the researchers according to relevant literature and were not determined through research of their own. (Martin, 2008). However, these composite indices will not be used in this study as they are categorical and SEM endogenous variables need to be continuous. Therefore, each background question will be utilized as an independent source. Specifically, the students were asked to respond to the following questions. 1) How often does your teacher give you homework in science? The responses with values are, (a) Every day $=1$; (b) 3 or 4 times per week $=2$; (c) 1 or 2 times per week $=3$; (d) Less than once a week $=4$; (e) Never $=5.2)$ When your teacher gives you science homework, about how many minutes do you usually spend on your homework? The responses with values are, (a) Zero minutes $=1$; (b) 1-15 minutes $=2$; (c) 16-30 minutes $=$ 3; (d) 31-60 minutes $=4$; (e) 61-90 minutes $=5$; (f) more than 90 minutes $=6$. This data was considered missing if question 1 was missing or if question 2 was missing and the response to question 1 was "Never" (Martin, 2008).

TIMSS created a parent's highest education level variable from the responses to these questions, "What is the highest education level completed by your mother (or 
stepmother or female guardian)?" and "What is the highest education level completed by your father (or stepfather or male guardian)?" Students could answer "Less than middle school or none" $=1$, "Completed middle school" =2, "Completed some High School" = 3, "Completed High School" = 4, "Completed some post-secondary school, but not a Bachelor's degree" $=5$, "Completed a University degree" $=6$, "Went beyond first degree" $=7$, and "I don't know" $=8$. The highest parent education level of either parent was the recorded value. If the father's education level was missing, then the mother's education level was used. If the mother's education level was missing, then the father's was used. The response values were reassigned so that the higher education values were allotted lower numbers and the total number of categories was reduced to six. $1=$ University Degree $=$ Responded "University degree or "Beyond University degree", $2=$ Completed Post-secondary Education but Not University = Responded "Completed High School" or "Completed some post-secondary school, but not a Bachelor's degree". 3 = Completed Upper-secondary School = Responded "Completed some High School" 4 = Completed Lower-secondary School $=$ Responded "Completed middle school". $5=$ Less Than Lower-secondary School $=$ Responded "Less than middle school or none". $6=$ Do Not Know = Responded "I don't know". The datum was considered missing if the student did not respond to both questions.

As was mentioned in the literature review, student attitudes have significant effects on achievement given the results of research in Expectancy-Value theory and Self-Efficacy Theory. In Trautwein's Expectancy-Value model of homework expectancy and value play prominent roles in the level of student achievement (Trautwein, Ludtke, Schnyder, et al., 2006). In fact, Trautwein, et al. (2006), said that all other homework- 
influencing variables such as socio-economic status, gender, home environment, and teacher variables are channeled through the students' senses of expectancy and value. This, then, can theoretically determine the students' homework behavior.

The TIMSS developers used eleven of twelve science attitude items to create a three-factor solution consisting of three items for Positive Attitude Towards Science (PATS), and four items each for Student Valuing of Science (SVS), and Self-Confidence in Science (SCS). However, researchers have been inconsistent in their application of the twelve items and the three factors in the research (N. Choi, Bush, S., English-Hunter, A., and Truitt, T., 2011). Therefore, Choi et al. ran a principal component analysis with oblique rotation on the twelve items in order to generate a psychometrically sound solution to research inconsistencies. The results are shown in Table 5. Although Choi et al. factor analyzed the 12 items measuring attitude towards math, the factor structure of the 12 science items will be likely very similar to the one reported by the authors. The twelve items loaded on three factors whose names remained consistent to the names developed by TIMSS. The twelve items were rated on a 4-point scale and the means are shown for each with the SD. 


\section{Table 4}

Pattern and Structure Coefficients, Means, and Standard Deviations for the 12 Items Loadings of Math Affective Variables

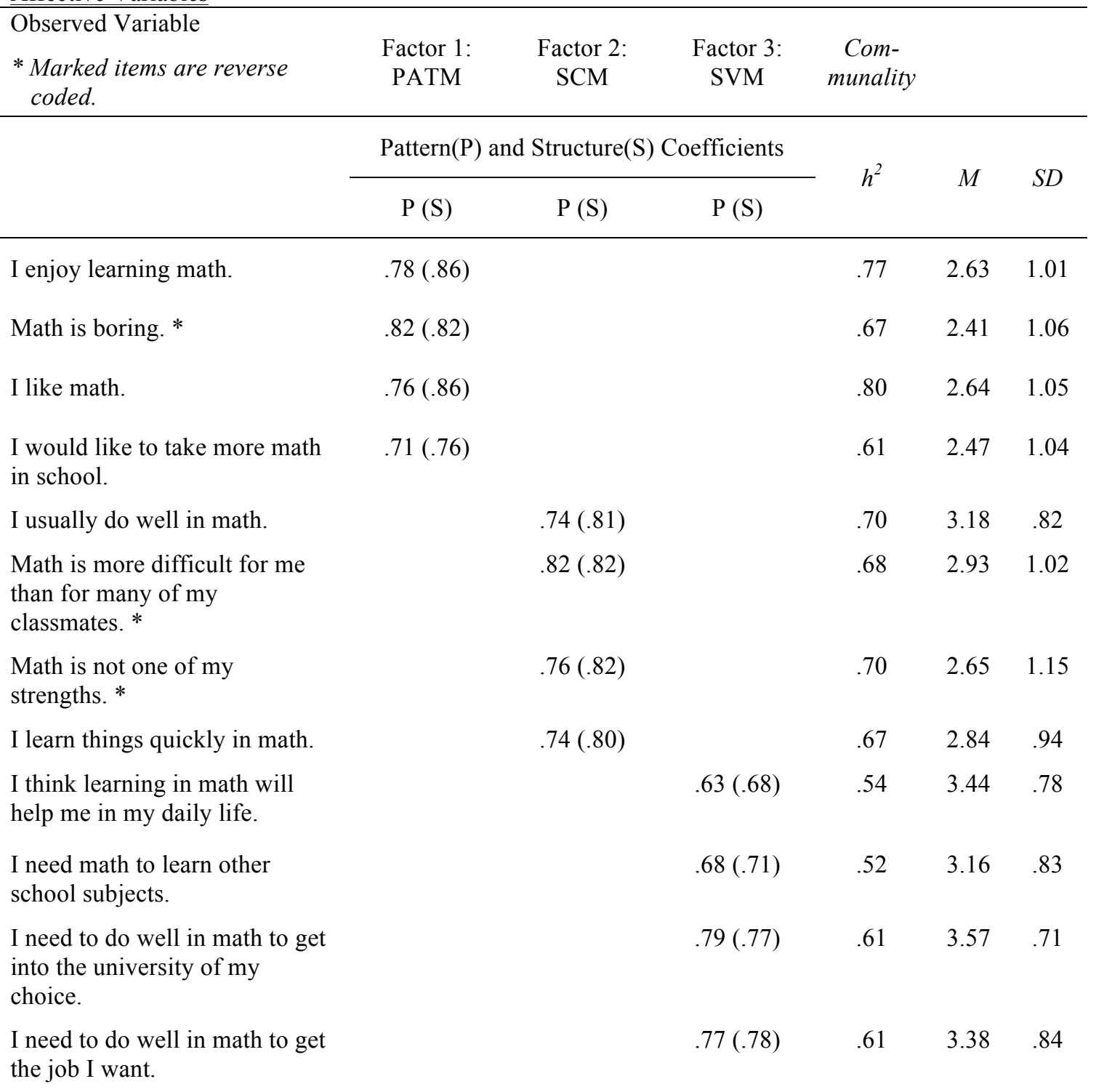

Source: Choi, N., Bush, S., English-Hunter, A., \& Truitt, T. (2011). Factorial validity of the scores from the TIMSS 2007 mathematics attitude scale. Paper presented at the American Educational Research Association Annual Conference, New Orleans, LA. Used with permission of the author.

Communalities ranged from .52 to .80 and these indicate the proportion of a variable's total variance that is accounted for by the factor solution (Hancock, 2010). 
For Positive Affect Towards Science, students were asked to respond to the following question: "How much do you agree with these statements about learning science? (a) I enjoy learning science (b) Science is boring (reverse coded) (c) I like science (d) I would like to take more science in school". The response options were: Agree a lot $=1 ;$ Agree a little $=2$; Disagree a little $=3$; Disagree a lot $=4$.

For Students Valuing Science, students were asked to respond to the following question: " How much do you agree with these statements about learning science? (a) I think learning science will help me in my daily life (b) I need science to learn other school subjects (c) I need to do well in science to get into the $<$ university $>$ of my choice (d) I need to do well in science to get the job I want". The response options were: Agree a lot $=1$; Agree a little $=2$; Disagree a little $=3$; Disagree a lot $=4$.

For Self-Confidence in Science, students were asked to respond to the following question: "How much do you agree with these statements about learning science? (a) I usually do well in science (b) Science is more difficult for me than for my classmates (reverse coded) (c) Science is not one of my strengths (reverse coded) (d) I learn things quickly in science". The response options were: Agree a lot $=1 ;$ Agree a little $=2$; Disagree a little $=3$; Disagree a lot $=4$.

The questions and statements used to determine the three affective domains in TIMSS were developed in previous versions of the test. Each year the questions are reviewed by a Questionnaire Item Review Committee which sends their revision recommendations on to the NRCs (Martin, 2008). The NRCs review the recommendations and make final revisions which are sent to the TIMSSS and PIRLS International Study Center (Martin, 2008). From this point, reliability is tested through 
field test questionnaires developed and deployed to the participating countries to check whether the questionnaires are appropriate for the measurements for which they are designed (Martin, 2008).

With regard to reliability of the scores generated from these items, Table 5 shows the Cronbach's alpha values for the student attitudes towards math scales (Choi et al., 2011).

Table 5

$\underline{\text { Reliability of Student Attitudes Towards Math }}$

\begin{tabular}{|c|c|c|c|}
\hline Aspect: & Positive Affect & Self-Confidence & Valuing the Subject \\
\hline Index: & PATM & SCM & SVM \\
\hline $\begin{array}{r}\text { Reliability } \\
(\text { Cronbach's } \propto) \text { : }\end{array}$ & 0.86 & 0.74 & 0.84 \\
\hline
\end{tabular}

One can see that the internal reliability of the questions' pertinence to the indices were all very good with all alpha coefficients being above 0.70 (Nunnaly, 1978), which suggests that student responses to those items were consistent.

Girls and boys have a long history of performing differently in science and in their outlooks on ability to succeed in the sciences (Martin, 2008). Thus, it was very important to determine if these same attitudinal differences affected homework and it's subsequent effect on science achievement. The TIMMS 2007 background questionnaire asked if the subject was a girl or a boy, with 1 indicating a girl and 2 indicating a boy. 


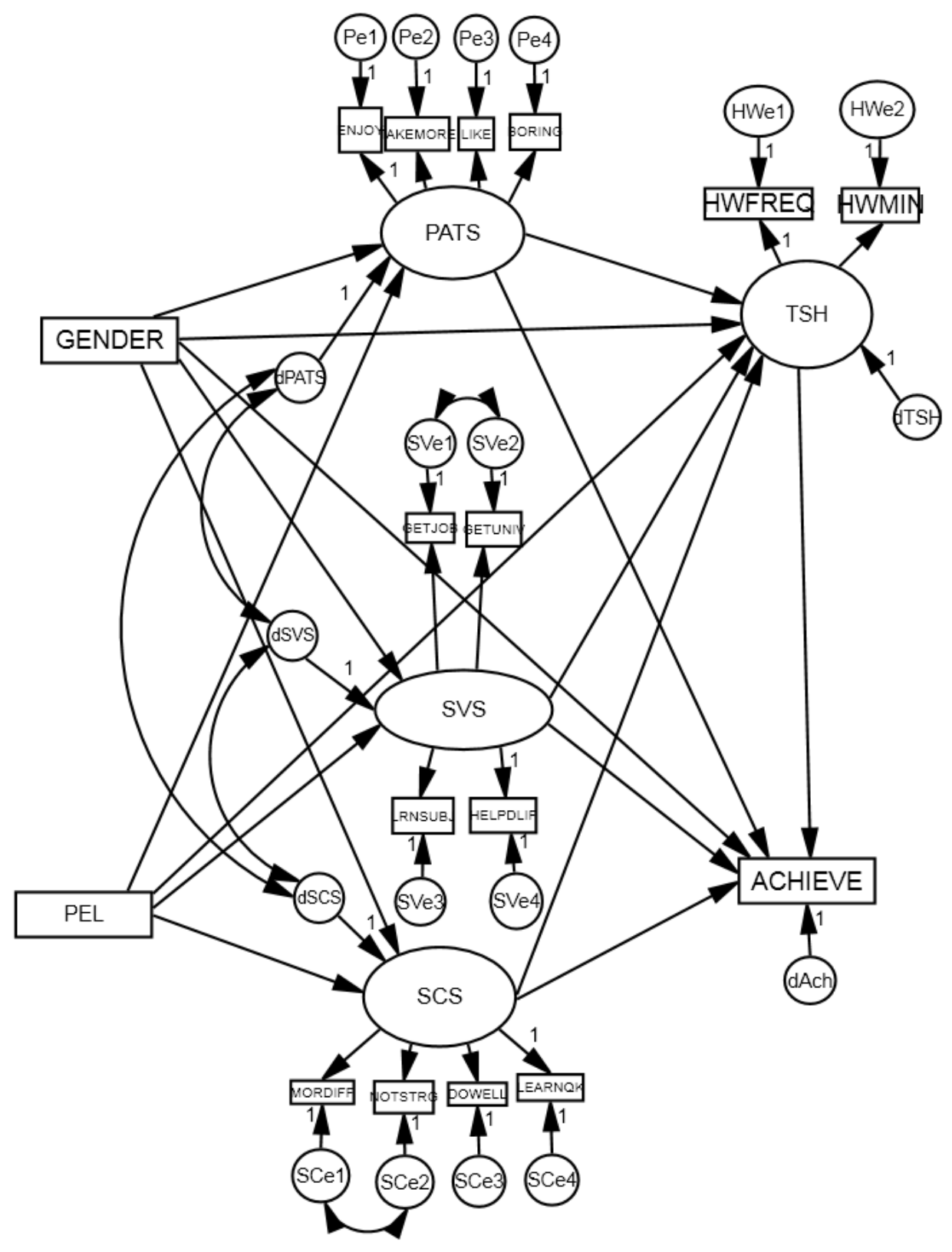

Figure 7. Proposed model of the mediating effect of homework on achievement.

The proposed model (Fig.7) has three major observed variables shown in rectangles; parent education level, and Gender, which are exogenous variables, and science achievement (Achieve), which is an endogenous variable. There are four latent, 
endogenous variables; PATS, SVS, SCS, and TSH. Each of these has observed indicator variables with an attached error variance symbolized by "e". Each endogenous latent variable also has a disturbance (dSVS, etc.) that represents all of the variance not attributable to its indicators. It is predicted that parent education level and gender will have an effect on student attitudinal variables that in turn will affect homework.

\section{Eighth-Grade Science Assessment}

Since science achievement will be measured using the overall science score earned by U.S. eighth graders, it is important to describe the nature and structure of the assessment used to determine science achievement.

The eighth-grade science assessment framework was divided into two domains, cognitive and content. While these domain configurations have no bearing on this research, it is important to inform the reader of the nature of the eighth grade science assessment. The cognitive domain dealt with thinking processes and included three areas with approximate percentage of total questions in parentheses; Knowing (30\%), Applying (35\%), and Reasoning (35\%). The content domain was divided into four areas with approximate percentage of total questions in parentheses, Biology (35\%), Chemistry (20\%), Physics (25\%), and Earth Science (20\%). Table 6 outlines this organization. In addition, each content area dealt with specific topics outlined in Table 7. 
Table 6

Target Percentages of the TIMSS 2007 Science Assessment Devoted to Content and Cognitive Domains in Eighth Grade

\begin{tabular}{lc}
\hline Eighth Grade Cognitive Domains & Percentage \\
\hline Knowing & $30 \%$ \\
Applying & $35 \%$ \\
Reasoning & $35 \%$ \\
\hline Eighth Grade Content Domains & Percentage \\
\hline Biology & $35 \%$ \\
Chemistry & $20 \%$ \\
Physics & $25 \%$ \\
Earth Science & $20 \%$ \\
\hline
\end{tabular}

Assessment construction. A total of 429 eighth grade math and science questions were created and chosen to be included in the administration of TIMSS-2007. These questions were divided into 14 blocks each of math and science questions for a total of 28 blocks. Seven of the blocks in each subject contained trend items (items that can be used to analyze trends in data) from the 2003 administration of the test. These were included in the 2007 study so that countries that participated in the 2003 administration could examine longitudinal trends between their results. The other seven blocks were newly constructed items for 2007. A total of fourteen test booklets were created from these blocks of questions. The test booklets contained two parts made up of two blocks of math and science questions. Each test booklet alternated between having the math or science part placed at the beginning. The booklets were designed so that each block of questions appeared in two booklets. The eighth grade participants were allowed ninety minutes to complete the test. 
Table 7

Topic Areas Included in the Science Content Domains of the TIMSS 2007 Eighth- Grade Science Assessment

\begin{tabular}{|c|c|}
\hline Content Domains & Topic Areas \\
\hline Biology & $\begin{array}{l}\text { - Characteristics, classification, and life processes of organisms } \\
\text { - Cells and their functions } \\
\text { - Life cycles, reproduction, and heredity } \\
\text { - Diversity, adaptation, and natural selection } \\
\text { - Ecosystems } \\
\text { - Human health }\end{array}$ \\
\hline Chemistry & $\begin{array}{l}\text { - Classification and composition of matter } \\
\text { - Properties of matter } \\
\text { - Chemical change }\end{array}$ \\
\hline Physics & $\begin{array}{l}\text { - Physical states and changes in matter } \\
\text { - Energy transformations, heat, and temperature } \\
\text { - Light } \\
\text { - Sound } \\
\text { - Electricity and magnetism } \\
\text { - Forces and motion }\end{array}$ \\
\hline Earth Science & $\begin{array}{l}\text { - Earth's structure and physical features } \\
\text { - Earth's processes, cycles, and history } \\
\text { - Earth's resources, their use, and conservation } \\
\text { - Earth in the solar system and the universe }\end{array}$ \\
\hline
\end{tabular}

Each block of questions was assembled so that a balance was maintained between cognitive and content domains as well as item format (multiple-choice or constructed response). The number of science items in an eighth grade question block contained 
between 14 and 18 items depending upon the number of constructed response or multiple-choice items.

Since it was impossible to assess the eighth graders on all $\sim 215$ science questions, TIMSS used a complicated psychometric scaling technique called IRT scaling with conditioning and multiple imputation to estimate student responses. This technique makes use of the student's responses to given items in the science assessment and the background questionnaire to create a basis for "imputing" values into the other assessment items they did not take (Foy, 2008). This technique comes with obvious error, therefore, this process creates a series of five plausible value ranges for the over all content assessment and the separate domains for each student. The plausible values were standardized to a mean score of 500 and a standard deviation of 100 (Foy, 2008)

Test developers needed to make sure that the scores would be free from random measurement error. Thus, steps were taken to make the test as reliable as possible. A series of statistics were run on all items in the assessment. These statistics included the number of students that responded, the difficulty level of the question (as measured by the number of correct responses divided by the total number of responses), and a discrimination index (the point-biserial correlation between success on an item and a total score) (Olson, 2008). In constructing a discrimination index for both multiple-choice questions and constructed response, point-biserial correlations were calculated comparing a student's success on an item and the total score, which was the total number of correctly answered. This allowed the assessment developers to determine if the question was a good indicator of a student's success on the assessment. In other words, students who do well on the assessment overall should do well on the multiple-choice questions. 
In addition, a positive correlation on the correct answer and negative correlations on the distractors in a multiple-choice question would indicate that the question and answer are reliable (Olson, 2008). Examples of the point-biserial correlations were given in the technical manual, for a section of math. However, none of the other statistics were shown. It should be noted that it was explained that if any of the correlations were significantly different than expected, special note was made of these so that changes could be made (Olson, 2008).

For constructed response items, detailed scoring guides that included examples of acceptable responses and extensive training in the application of these guides were provided to ensure that all student responses were scored consistently. In addition, the developers utilized inter-rater reliability measures. A random sample of no less than 200 student responses to each constructed response item were selected and scored independently by two scorers and their agreement was measured. If inter-rater reliability agreement was below $85 \%$, then graders had to be re-trained. In the U.S., the Correctness Score Agreement on the science constructed response items was 93\% (range was 73\%$100 \%$ ), which is considered good (Stemler, 2004).

The overall reliability (Cronbach's Alpha) of the test questions across the 14 test booklets was $\propto=.86$. This value is considered very good (Kline, 2011). Values above .90 are considered excellent, and those above .70, adequate (Kline, 2011).

\section{Eighth-Grade Background Questionnaire}

The TIMMS background survey instrument collected a large amount of background information including demographics, teacher preparation, professional development, the school environment, teaching, curriculum, pedagogy, computers, 
homework, assessment, student expectancy, time spent on homework, how often homework is assigned, and parent education level.

Four types of background questionnaires were developed; curriculum, school, teacher, and student. These were organized around the TIMSS curriculum model that had three aspects; the intended curriculum (what is supposed to be taught), the implemented curriculum (what is actually taught), and the attained curriculum (what the students actually learned from the curriculum). The curriculum questionnaire asked about the structure and content of the intended curriculum in math and science. The school, teacher, and student questionnaires asked about the implemented curriculum, the instructional approaches used, the organization and resources of the schools and classrooms, the preparation of the teachers, and the experiences and attitudes of both teachers and students related to math and science.

In the development of the 2007 questionnaire, revisions to the 2003 background questions were made and additional components were added including school demographics. A section on social climate in the school's environment was added, as was a section on technology support and equipment use in schools. Thus, the questionnaire included items from the 2003 administration and new items added for 2007. A final edit was conducted to streamline the questionnaire and reduce the response burden.

The student questionnaire, in particular, asked about student's demographics, home background and resources for learning, attitude toward science and experiences in learning science. Two versions of the eighth grade background questionnaire were created depending upon whether science was taught as an integrated course or as separate courses (biology, chemistry, earth science, and physics). U.S. eighth graders were given 
the integrated version. Eighth graders were given 30 minutes to complete the background questionnaire.

Validity and reliability. Validity of the questionnaire was strengthened through the process used to create it. Creation of the final background questionnaire was a collaborative effort between the TIMSS International Study Center, the NRC's, a Questionnaire Item Review Committee, and the IEA Data Processing and Research Center. Reliability was obtained through a process that had forty-five countries field test a draft of the eighth grade questionnaire. This was then analyzed and revised. After completion of the field tests, the responses to the background questions were compared to average student achievement on the science test in order to classify background qualities

as being highly correlated to a supportive learning environment or being highly correlated to a least supportive learning environment.

\section{Mediation}

This analysis will include the significance of mediators between a causal variable and an outcome variable. For example, it will be determined whether the causal variable, Gender, has an indirect effect on TSH through the affective, mediating variables, PATS, SVS, and SCS. Mediating variables indirectly influence, either positively or negatively, the effect of one variable on another. For example, in figure $8, \mathrm{X}$ has both a direct effect on variable $\mathrm{Y}$ through path c' and an indirect effect on $\mathrm{Y}$ through the mediating variable $\mathrm{M}$ indicated by paths $\mathrm{a}$ and $\mathrm{b}$. 


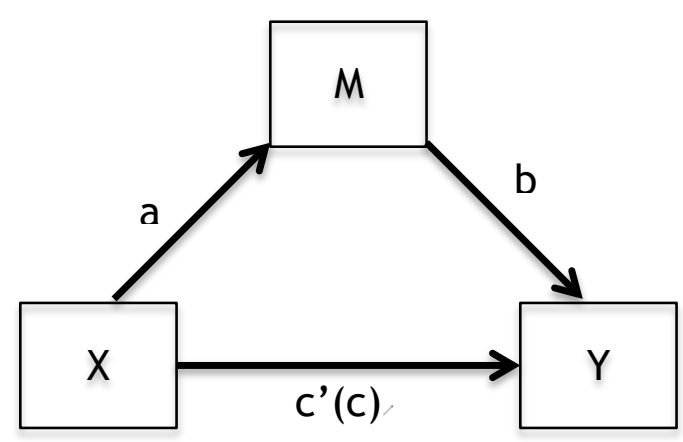

Figure 8. Mediation example

In this example, the effect of $\mathrm{X}$ on $\mathrm{Y}$ through $\mathrm{M}$ is called the indirect effect (the product of paths $\mathrm{a}$ and $\mathrm{b}$ or $\mathrm{ab}$ ). The effect of $\mathrm{X}$ on $\mathrm{Y}$ controlling for $\mathrm{M}$ is called the direct effect (path c'), and the effect of $\mathrm{X}$ on $\mathrm{Y}$ through all paths is called the total effect (c). Generally speaking, the total effect (c), is equal to the sum of the indirect effect (ab) and the direct effect (c'):

$$
\mathrm{c}=\mathrm{ab}+\mathrm{c}^{\prime}
$$

The important factors in this analysis will be the presence and significance of the indirect effects between the variables outlined in the research questions.

Bootstrapping will be used in the analysis of the model as well. Bootstrapping has been shown to be the recommended method for determining the significance of indirect paths in an SEM (Byrne, 2009). Bootstrapping is a method used in samples with nonnormal distributions where numerous subsamples (500-2000) are drawn from the main sample with substitution (Byrne, 2009). An indirect effect is calculated from each sampling, which allows the generation of a mean of an indirect effect with a sampling distribution, a confidence interval, a $p$ value, and a standard error (Kenny, 2013). If a zero 
is not present in the confidence interval, then it can be assumed that the indirect effect is different from zero (Kenny, 2013). 


\section{CHAPTER IV}

\section{RESULTS}

This chapter begins with the descriptive statistics of the exploratory and validation sets along with the correlations of the major variables within the validation set. Then the results of a confirmatory factor analysis of the latent variables for science affective variables and the indicators that describe them are presented. The result being the final iteration of the measurement model used for this analysis. Afterward, the results of the structural equation model are presented in a manner that answers the six research questions individually.

\section{Descriptive Statistics}

Table 9 details the descriptive statistics of the exploratory and validation sets. The exploratory and validation sets reflect the same statistics across the major variables. Parent Education Level was consistent between boys and girls across the two groups. Boys showed a higher average in all categories except for Time Spent on Homework that is consistent with the literature that has girls spending more time on homework on average than boys. Boys having a higher achievement average than girls is also consistent with the literature that places science as a more masculine subject in which boys consistently out perform girls (Trautwein, Ludtke, Schnyder, et al., 2006) 
Table 8

Demographic Characteristics of the Exploratory and Validation Sets

\begin{tabular}{ccccc}
\hline & \multicolumn{2}{c}{$\begin{array}{c}\text { Exploratory Set } \\
\mathrm{n}=3,632(49 \%)\end{array}$} & \multicolumn{2}{c}{$\begin{array}{c}\text { Validation Set } \\
\mathrm{n}=3,733(51 \%)\end{array}$} \\
\cline { 2 - 5 }$(\mathrm{N}=7,365)$ & Male & Female & Male & Female \\
\cline { 2 - 5 } & $49.1 \%$ & $50.9 \%$ & $49.7 \%$ & $50.3 \%$ \\
\hline Variables & Mean (SD) & Mean (SD) & Mean (SD) & Mean (SD) \\
\hline PEL & $2.84(2.077)$ & $2.76(1.935)$ & $2.79(2.030)$ & $2.78(1.957)$ \\
TSH & $2.41(.631)$ & $2.42(.654)$ & $2.40(.656)$ & $2.42(.650)$ \\
Achieve & $525.35(80.87)$ & $516.44(74.76)$ & $526.39(81.57)$ & $512.06(76.63)$ \\
PATS & $11.35(3.54)$ & $10.92(3.54)$ & $11.43(3.50)$ & $10.90(3.59)$ \\
SVS & $11.58(3.12)$ & $11.53(5.06)$ & $11.59(3.17)$ & $11.47(3.08)$ \\
SCS & $10.61(1.98)$ & $10.26(1.99)$ & $10.56(1.95)$ & $10.27(2.01)$ \\
\hline
\end{tabular}

\section{Correlations}

Correlation table 9, below, shows some interesting data. Parent Education Level $(P E L)$ was negatively and significantly correlated with all of the affective variables that characterize self-regulated learning; Positive Affect Towards Science(PATS), Students Valuing Science(SVS), and Self-Confidence in Science(SCS). Time Spent on Homework(TSH) had only one significant correlation with Self-Confidence in Science between both males and females. Science Achievement(Achieve) was significantly and positively correlated with all of the affective variables indicating that these variables have a positive relationship with achievement as has been theorized in the literature. SelfConfidence in Science was the only major variable that was significantly and positively correlated with all the other major variables. Additionally, there were no discrepancies between males and females in what variables were significant. 
Table 9

Correlations and Significance (Two-Tailed) of the Major Variables in Validation Set

\begin{tabular}{|c|c|c|c|c|c|c|c|}
\hline Gender & & & & Male & & & \\
\hline \multirow{7}{*}{ Female } & & PEL & $\mathrm{TSH}$ & Achieve & PATS & SVS & SCS \\
\hline & PEL & 1 & -.021 & $-.202 * *$ & $-.055^{*}$ & $-.088 * *$ & $-.088 * *$ \\
\hline & $\mathrm{TSH}$ & -.026 & 1 & .041 & .013 & -.021 & $.063 * *$ \\
\hline & Achieve & $-.296 * *$ & .046 & 1 & $.222 * *$ & $.202 * *$ & $.332 * *$ \\
\hline & PATS & $-.076 * *$ & .028 & $.195 * *$ & 1 & $.537 * *$ & $.488 * *$ \\
\hline & SVS & $-.077 * *$ & -.027 & $.163 * *$ & $.507 * *$ & 1 & $.258 * *$ \\
\hline & SCS & $-.080 * *$ & $.140 * *$ & $.257 * *$ & $.524 * *$ & $.225 * *$ & 1 \\
\hline
\end{tabular}

Note: ${ }^{*}$ Correlation is significant at the $p<.05$ level. ${ }^{* *}$ Correlation is significant at the $p<.01$ level.

It is also interesting to note the high correlations between the affective variables for both boys and girls. These values ranged from a low of .225 between Self-Confidence in Science and Students Valuing Science in girls to a high of .537 between Positive Affect Towards Science and Students Valuing Science in the boys. These correlations are reflected in the measurement model presented in figure 9.

Confirmatory Factor Analysis (CFA): Measurement Model

The results of a CFA for the attitudinal variables in math portion of the TIMSS 2007 SBQ were presented in the methods chapter. However, results for the science questions, although similar, needed to be clarified. Martin and Preuschoff (2008) and others (Choi et al., 2011) have confirmed the presence of 3 factors representing the 12 attitudinal variables for math, while TIMSS confirmed the presence of the three factors in science. A second confirmation of the TIMSS results was warranted to confirm the presence of the 3 factors for this study. 
A principal component analysis (PCA) was conducted on the 12 affective items with oblique rotation (delta $=-5$, least correlated). The Kaiser-Meyer-Olkin measure verified the sampling adequacy for the analysis, $\mathrm{KMO}=.902$, which is an excellent reading (Field, 2009). Barlett's test of sphericity, $\chi^{2}(66)=44868.765, p<.001$, indicates that the correlation matrix of these factors is significantly different from an identity matrix and that the correlations are sufficiently large enough for a PCA. Initially, 2 factors with eigenvalues greater than 1 were extracted that accounted for $61.48 \%$ of the total variance. But, previous studies (Choi et al., 2011: Martin, 2008) have shown that the math and science items reduce to three factors. Therefore, SPSS was directed to reduce the components to three factors. Again, two of the three factors had values greater than 1 (5.598 and 1.779) with the third having a value just under 1 at .961. The three factors combined, explained $69.49 \%$ of the variance. A scree plot demonstrates that the point of inflexion occurs at the third factor. Thus, due to the third factors proximity to an eigenvalue of 1 and its position to the left of the point of inflexion, it was retained.

These three factors were given the same names as the factors from previous studies due to similarity of the results. The first factor was named positive affect towards science (PATS), the second factor was named students valuing science (SVS) and the third factor was named self-confidence in science (SCS). All of the factors consisted of four items whose pattern coefficients were greater then .40 (See Table 10).

The findings from this analysis verified the presence of 3 factors consisting of 4 items each. Each item had significant factor structure and pattern coefficients whose range was $.650-.858$. The four items that loaded on PATS were I enjoy learning science, I like science, Science is boring, and I would like to take more science. These items 
Table 10

Pattern and Structure Coefficients, Means, and Standard Deviations for the 12 Items Loadings of Science Affective Variables

\begin{tabular}{|c|c|c|c|c|c|c|}
\hline \multirow[t]{3}{*}{ Item } & \multicolumn{3}{|c|}{ Factor 1: PATS Factor 2: SVS Factor 3: SCS } & \multicolumn{3}{|c|}{$\begin{array}{l}\text { Com- } \\
\text { munality }\end{array}$} \\
\hline & \multicolumn{3}{|c|}{ Pattern(P) and Structure(S) Coefficients } & \multirow{2}{*}{$h^{2}$} & \multirow{2}{*}{$M$} & \multirow{2}{*}{$S D$} \\
\hline & $\mathrm{P}(\mathrm{S})$ & $\mathrm{P}(\mathrm{S})$ & $\mathrm{P}(\mathrm{S})$ & & & \\
\hline I enjoy learning science. & $.81(.89)$ & $.12(.38)$ & $.11(.42)$ & .81 & 2.91 & .99 \\
\hline I like science. & $.80(.89)$ & $.11(.37)$ & $.15(.45)$ & .82 & 2.89 & 1.03 \\
\hline Science is boring. & $.77(.78)$ & $-.06(.18)$ & $.10(-.36)$ & .62 & 2.70 & 1.07 \\
\hline $\begin{array}{l}\text { I would like to take more } \\
\text { science. }\end{array}$ & $.70(.80)$ & $.24(.46)$ & $.09(.37)$ & .70 & 2.66 & 1.05 \\
\hline $\begin{array}{l}\text { I need science to get the job I } \\
\text { want. }\end{array}$ & $.00(.27)$ & $.83(.84)$ & $.07(.18)$ & .71 & 2.82 & 1.06 \\
\hline $\begin{array}{l}\text { I need science to get into } \\
\text { college. }\end{array}$ & $-.05(.24)$ & $.82(.83)$ & $.14(.23)$ & .70 & 3.16 & .93 \\
\hline $\begin{array}{l}\text { I need science to learn other } \\
\text { school subjects. }\end{array}$ & $.18(.38)$ & $.72(.77)$ & $-.06(.10)$ & .62 & 2.64 & .94 \\
\hline $\begin{array}{l}\text { Learning science will help me } \\
\text { in my daily life. }\end{array}$ & $.31(.49)$ & $.66(.75)$ & $-.05(.15)$ & .64 & 2.93 & .91 \\
\hline $\begin{array}{l}\text { Science is more difficult for me } \\
\text { than my classmates. }\end{array}$ & $-.01(.28)$ & $-.03(.08)$ & $.86(.85)$ & .72 & 3.00 & .96 \\
\hline $\begin{array}{l}\text { Science is not one of my } \\
\text { strengths. }\end{array}$ & $.15(.42)$ & $.01(.16)$ & $.76(.82)$ & .69 & 2.74 & 1.06 \\
\hline I usually do well in science. & $.25(.52)$ & $.14(.30)$ & $.65(.76)$ & .67 & 1.80 & .83 \\
\hline $\begin{array}{l}\text { I learn things quickly in } \\
\text { science. }\end{array}$ & $.29(.55)$ & $.15(.32)$ & $.60(.72)$ & .64 & 2.88 & 1.03 \\
\hline Eigenvalue Post-rotation \% & $46.65 \%$ & $14.83 \%$ & $8.01 \%$ & & & \\
\hline
\end{tabular}

Bold numbers indicate coefficients significantly large to load onto a factor. 
reflect the student's experiential feelings for science. SVS gauges the "cost-benefit" a student gives science and the things which could come from the learning of it and this is reflected in the items that loaded onto this factor; I need science to get the job I want, I need science to get into college, I need science to learn other school subjects, and Science will help me in my daily life. Finally, SCS attempts to measure a student's ability beliefs in science. The items that loaded onto SCS were Science is more difficult for me than my classmates, Science is not one of my strengths, I usually do well in science, and I learn things quickly in science.

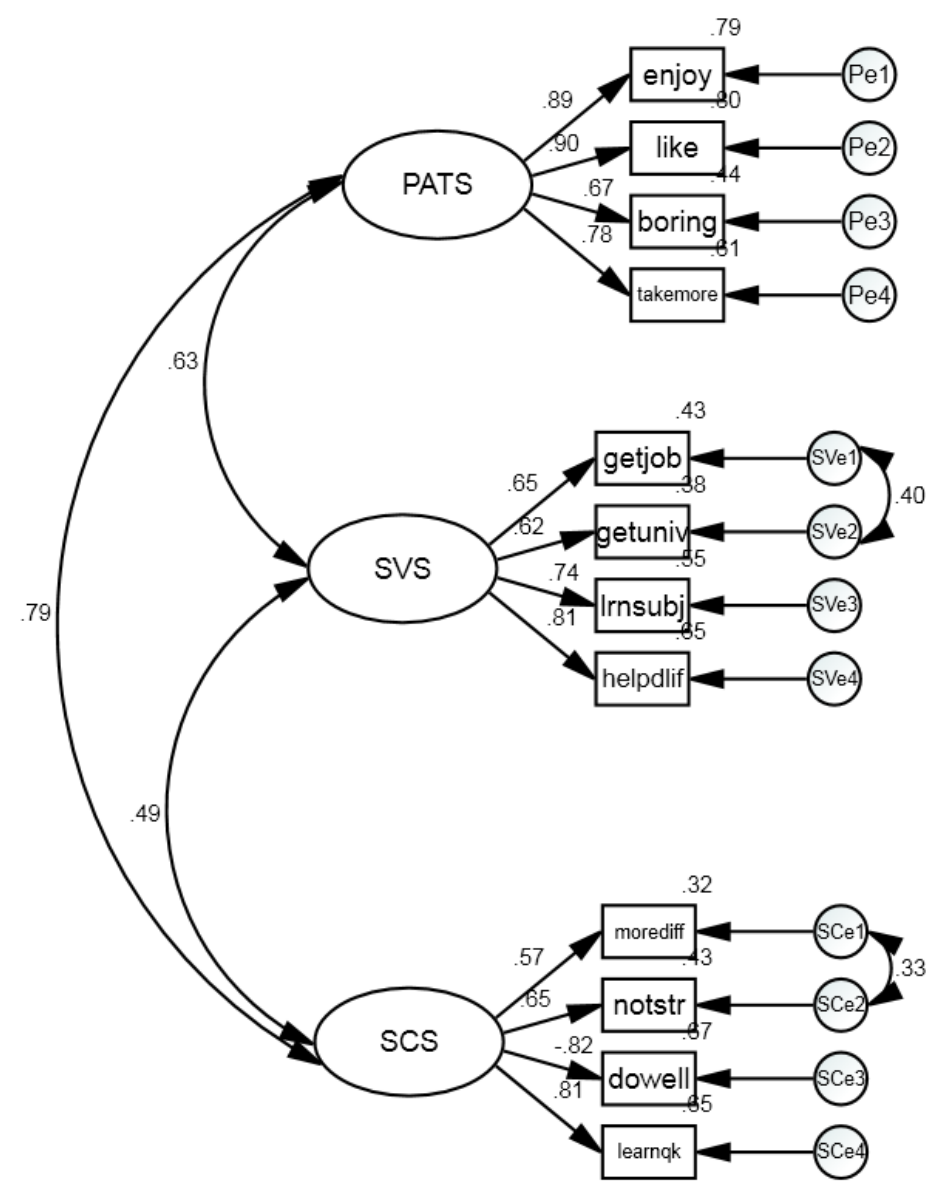

Figure 9. Finalized measurement model with standardized estimates 


\section{Reliability}

The reliability coefficients for the three factors above were $\alpha=0.88,0.82$, and 0.82 for PATS, SVS, and SCS, respectively.

The analytical software used to create the structural equation model in this study was IBM AMOS version 20. This software is also able to perform a CFA. This is beneficial particularly when the model being tested is a hybrid model that contains a measurement portion that must be identified prior to analysis. Thus, the affective variables were further clarified by placing them in a measurement model in AMOS. The results of this analysis along with the standardized regression weights are seen in Figure 9. As one can see, all of the indicators loaded highly on each of the factors with standardized regression weights ranging from .57 to .89 . The latent factors explained a high percentage of the variability in each of the indicators as well (see Table 11).

Table 11

$\underline{\text { Squared Multiple Correlations of Affective Variable Factors }}$

\begin{tabular}{llc}
\hline Latent Factor & Indicator & Multiple $R^{2}$ \\
\hline \multirow{2}{*}{ PATS } & ENJOY & .786 \\
& LIKE & .804 \\
& BORING & .445 \\
& TAKEMORE & .607 \\
\hline \multirow{2}{*}{ SVS } & GETJOB & .557 \\
& GETUNIV & .510 \\
& LRNSUBJ & .508 \\
& HELPDLIF & .561 \\
\hline \multirow{2}{*}{ SCS } & MORDIFF & .381 \\
& NOTSTRG & .479 \\
\hline
\end{tabular}


An advantage of using AMOS to perform a CFA is that it takes into account the measurement error of each indicator (Kline, 2011). This is significant because each measurement error represents the unique variance of the indicator which is the variance not explained by the latent factor. Thus, the arrows leading from the factor to an indicator represent only the variance the factor explains in the indicator. In addition, AMOS can empirically modify the model by adding parameters in order to improve model fit (Kline, 2011). These are called Modification Indices (MI) and are actually univariate Lagrange multipliers expressed as chi-square statistics with a single degree of freedom (Kline, 2011). The higher the MI value, the greater the theoretical improvement in model fit. Thus, a perusal of the MI table in the AMOS analysis summary can guide one to constrain parameters that could improve the model fit.

An initial analysis of the model found that the model fit the data poorly or adequately, at best (see Table 12). Generally, two indicators are used to evaluate the goodness-of-fit of a model to the data. The first is a chi-square test whose nonsignificance is used as an indicator that the model is a good fit to the data. Typically, researchers are looking for a non-significant chi-square value that would indicate that their model is not significantly different from a model that "matches" the covariance matrix perfectly (Kline, 2011). However, in models where the sample size is large, as in this case, even small discrepancies between the model and the data can result in significance. Thus, the researcher needs to include other measures of model-fit. Kline (2011) recommends using the chi-squared statistic with $d f$, RMSEA (with CI and $p$ close), CFI and SRMR. 
Table 12

Values of Fit Indices for the Measurement Model

\begin{tabular}{lcc}
\hline \multirow{2}{*}{ Index } & \multicolumn{2}{c}{ Model } \\
\cline { 2 - 3 } & Initial & Final \\
\hline$\chi^{2}$ & 1447.007 & 721.318 \\
$d f$ & 51 & 49 \\
$p$ & $<.001$ & $<.001$ \\
RMSEA $(90 \% \mathrm{CI})$ & $.087(.083-.091)$ & $.062(.058-.066)$ \\
$p$ CLOSE & $<.001$ & $<.001$ \\
CFI & .939 & .971 \\
SRMR & .0496 & .0373 \\
\hline
\end{tabular}

An analysis of the initial model yielded a model that is over-identified with 78 sample moments and 27 estimated parameters for a $d f$ of 51 . Analysis showed that the chi-square test failed to demonstrate a good model fit $\left(\chi^{2}=1447.007, d f=51, p<.001\right)$, had a marginal RMSEA(CI) (.087(.083-.091)), a marginal CFI (.939) and a good SRMR (.0496). Overall, given the sample size $(\mathrm{N}=3601)$ and the relatively high correlations between the latent factors, this model fit the data only adequately. Therefore, an attempt was made to better fit the model. However, because this is a CFA model, very few modifications should be made and those should be justified (Kline, 2011). The modification indices (MI) were scanned for additional parameters that could be added to improve model fit. Generally, MI's greater than 20 would indicate a parameter that needs to be added. But the nature of this model showed MI's much higher than this (with correspondingly low parameter changes). Thus, very high values were chosen between components that could be correlated. Two MI's were chosen in which to add parameters: 
SCe1 to SCe2 $(\mathrm{MI}=300.188$, Par Change $=.188)$ and SVe1 to SVe2 $(\mathrm{MI}=267.684$, Par Change $=.152$ ). These were chosen because they were error variances within the same latent factor and the likelihood of their being correlated was logical. Other MI's were high as well but were not correlated due to restrictions from SEM rules. For example, Pe4 and SVS have an MI of 146.783, but, in this case, one should not correlate an indicator's error with a latent factor.

Another analysis with the added correlations yielded much better results (see Table 12): $\chi^{2}=721.318, d f=49, p<.001 ;$ CFI $=.971 ; \operatorname{RMSEA}(90 \mathrm{CI})=.062(.058-.066)$, $p$ close $<.001 ;$ SRMR $=.0373$. The chi-square statistic remained significant indicating an ill-fitting model. But, with the high sample size, this was expected. The CFI was good, the RMSEA was OK, with numbers below 0.05 being considered good, and the SRMR was acceptable. The confidence interval for the RMSEA was narrow indicating that this is a rather precise indication of the fit of the model for the general population. In both tested models, the $p$ CLOSE statistic was significant meaning that the model was not much different than the null hypothesis model. However, the $90 \%$ CI values of the RMSEA indicate that the true value of the RMSEA has a $90 \%$ probablilty of remaining in the OK range for RMSEA point values. Most likely the high sample size and correlations of the indicators has made this statistic significant in the same manner as the chi-squared test.

\section{Structural Model}

The structural model was constructed according to the parameters outlined in the literature review. The exploratory data set was used first to test the goodness of fit. The model fit statistics showed a good fitting model with the following statistics: $\chi^{2}=1024.03$, 
$d f=101, \mathrm{p}<.001, \mathrm{CFI}=.963, \mathrm{RMSEA}(90 \mathrm{CI})=.049(.047-.052), p$ close $=.633$, and $\mathrm{SRMR}=.0345$. The chi-square test was significant, but the large sample size likely contributed to this value. The CFI indicates a good fit, the RMSEA indicates a "good" fit as indicated by values $<.5$. The $90 \%$ confidence interval of the RMSEA is narrow indicating relatively good precision. The $p$ close statistic is $>.05$ indicating that the model is not similar to the null hypothesis model.

Having used the exploratory data set to fine-tune the model, the validation data set was then analyzed. The model fit statistics showed a good fitting model with the following statistics: $\chi^{2}=881.301, d f=101, \mathrm{p}<.001, \mathrm{CFI}=.962, \operatorname{RMSEA}(90 \mathrm{CI})$ $=.050(.047-.053), p c l o s e=.574$, and SRMR $=.0332$. All of the fit indices are in the "good" range with RMSEA registering on the "good"/"OK" border. The CI is narrow indicating good precision and the $p$ close statistic is not significant meaning that this model is not similar to the null model. The following figure shows the simplified model with the unstandardized direct effects and their significance. 


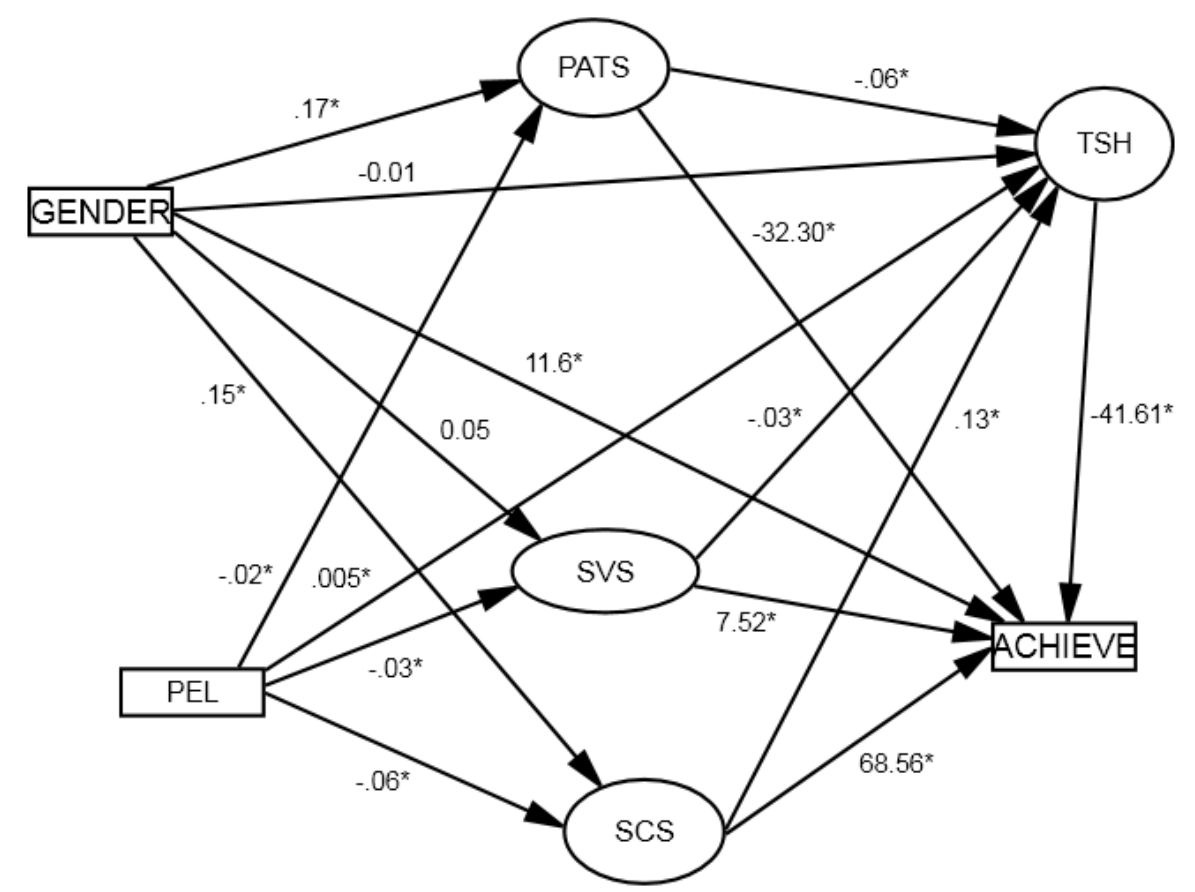

Figure 10: Simplified Model with direct effects and significance. Those designated with a “*” are significant at $p<.05$.

The research questions dealt with mediating effects of the affective variables, PATS, SVS, and SCS from Gender and PEL to TSH and ACHIEVE. Therefore, one needed to determine the significance of the direct and indirect pathways in the model. Table 13 shows the direct, indirect, and total effects ( all unstandardized) of the relationships between the variables along with their significance at the $p=.05$ level (using two-tailed $t$ tests). The bootstrap analysis showed that all of the direct pathways were significant except for the Gender to SVS path. All of the indirect paths were significant and all of the Total effect paths were significant except three (Gender to SVS, Gender to TSH, and PEL to TSH). This model is complicated in that there are two antecedent causal variables in Gender and PEL that both work through the same mediating affective variables, PATS, SVS, and SCS. Thus, it is possible for one causal variable such as Gender to have an insignificant effect on a mediator (SVS), but that 
mediator to have a significant effect on the outcome variable (TSH). In mediation terms, " $a$ " could be insignificant while " $b$ " could be significant because " $b$ " is being influenced by the other causal variable.

Table 13

Unstandardized Parameter Bootstrap Estimates with Significance Indicated

\begin{tabular}{|c|c|c|c|c|}
\hline Hypothe & sized Path & Direct Effect (c') & Indirect Effect $(a b)$ & Total Effect (c) \\
\hline Gender & $\longrightarrow$ PATS & $.166^{*}$ & 000 & $.166^{*}$ \\
\hline Gender & $\longrightarrow \mathrm{SVS}$ & .049 & .000 & .049 \\
\hline Gender & $\longrightarrow \mathrm{SCS}$ & $.149 *$ & .000 & $.149 *$ \\
\hline Gender & $\longrightarrow \mathrm{TSH}$ & -.010 & $.008 *$ & -.002 \\
\hline Gender & $\longrightarrow$ ACHIEVE & 11.60 & 5.281 & $16.885^{*}$ \\
\hline PEL & $\longrightarrow$ PATS & $-.022 *$ & .000 & $-.022 *$ \\
\hline PEL & $\longrightarrow \mathrm{SVS}$ & $-.029 *$ & .000 & $-.029 *$ \\
\hline PEL & $\longrightarrow \mathrm{SCS}$ & $-.063 *$ & .000 & $-.063 *$ \\
\hline PEL & $\longrightarrow \mathrm{TSH}$ & .005 & $-.006^{*}$ & -.001 \\
\hline PATS & $\longrightarrow \mathrm{TSH}$ & $-.059 *$ & .000 & $-.059 *$ \\
\hline SVS & $\longrightarrow \mathrm{TSH}$ & $-.027 *$ & .000 & $-.027 *$ \\
\hline SCS & $\longrightarrow \mathrm{TSH}$ & $.130^{*}$ & .000 & $.130^{*}$ \\
\hline PATS & $\longrightarrow$ ACHIEVE & $-32.30 *$ & $2.448 *$ & $-29.85^{*}$ \\
\hline SVS & $\longrightarrow$ ACHIEVE & $7.521 *$ & $1.115^{*}$ & $8.637^{*}$ \\
\hline SCS & $\longrightarrow$ ACHIEVE & $68.56^{*}$ & $-5.415 *$ & $63.14 *$ \\
\hline TSH & $\longrightarrow$ ACHIEVE & $-41.61 *$ & .000 & $-41.61 *$ \\
\hline
\end{tabular}




\section{Research Question 1}

"Does gender have an indirect effect on time spent on homework through the affective variables associated with self-regulatory learning (Positive Affect Towards Science, Student Valuing Science, and Self-Confidence in Science)? Gender had a nonsignificant direct effect on Time Spent on Homework $\left(c^{\prime}=-.010, p>.05\right)$ but had a significant positive, indirect effect on Time Spent on Homework $(\mathrm{ab}=.008, p<.05)$. According to the results where girls were coded with a 1 and boys with a 2, boys had a .008 units higher Time Spent on Homework value than girls. However, the indirect effect of Gender on Time Spent on Homework goes through Positive Affect Towards Science, Student Valuing Science, and Self-Confidence in Science simultaneously. Unfortunately, AMOS does not differentiate between the paths. Therefore, one has to utilize a method of determining specific effects within the model called phantom modeling (Macho, 2011). Here, latent variable paths were added to the exogenous variable of choice. These paths mimic the paths from the exogenous variable to the endogenous variable specified. In this case, Gender had three paths that led to Time Spent on Homework. So, three paths were added to Gender to mimic the three paths through Positive Affect Towards Science, Student Valuing Science, and Self-Confidence in Science (paths through the latent variables G1...G6 of figure 11). However, the variables in these phantom paths are latent variables given random names. Then, the paths between them are given the same variance (designated, in figure 11, with lower case letters) as the paths in the model. When the analysis was computed, the separate unstandardized path effects 
that each affective variable has on TSH from Gender were displayed in the phantom arm of the analysis. Figure 11 shows this set-up.

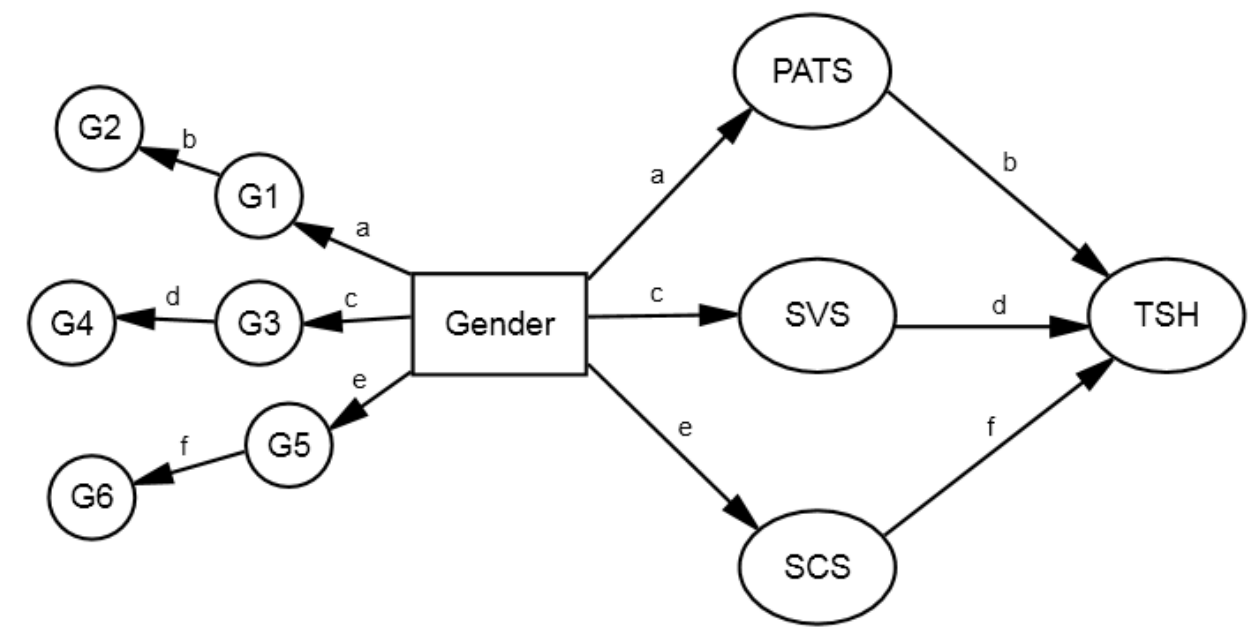

Figure 11: Phantom model construction for effects of Gender on Time Spent on

Homework(TSH). The same method was used for analysis of Parent Educational Level on Time Spent on Homework.

The original "non-phantom" model reported the unstandardized indirect effect, ab, between Gender and Time Spent on Homework $\mathrm{as} a b=.008, p<.05$. Phantom variable analysis found the partial indirect effects of Gender to Time Spent on Homework to be -.010, -.001, and .019 for Positive Affect Towards Science, Student Valuing Science, and Self-Confidence in Science, respectively. All were significant at the $p<.05$ level. These values indicate that girls tend to have a small but significantly higher level of positive affect towards and valuation of science compared to boys. However, boys have a much greater and significant self-confidence in science. Table 14 has the complete list of disaggregated indirect effects. 
Table 14

$\underline{\text { Phantom Model Disaggregated Indirect Effects (Unstandardized) }}$

\begin{tabular}{lccc}
\hline Variables & $\begin{array}{c}\text { Total } \\
\text { Indirect Effect }\end{array}$ & $\begin{array}{c}\text { Mediating } \\
\text { Affective Variable }\end{array}$ & $\begin{array}{c}\text { Partial } \\
\text { Indirect Effect }\end{array}$ \\
\hline Gender on TSH & $.008^{*}$ & PATS & $-.010^{*}$ \\
& & SVS & $-.001^{*}$ \\
\hline PEL on TSH & SCS & $.019^{*}$ \\
& $-.006^{*}$ & PATS & $.001^{*}$ \\
& & SVS & $.001^{*}$ \\
& & SCS & $-.008^{*}$ \\
\hline
\end{tabular}

Note: ${ }^{*}$ Correlation is significant at the $p<.05$ level.

\section{Research Question 2}

"Does Parent Education Level have an indirect effect on Time Spent on Homework through the affective variables associated with self-regulatory learning (Positive Affect Towards Science, Student Valuing Science, and Self-Confidence in Science)?" Parent Education Level had a significant direct effect, c', on Time Spent on Homework $\left(c^{\prime}=.005, p<.05\right)$ and a significant negative, indirect effect on Time Spent on Homework $(a b=-.006, p<.05)$. This indicates that in the direct effect, for every one-unit increase in Parent Education Level, there was a corresponding increase in Time Spent on Homework by .005 units. For the indirect effect, every one-unit increase in Parent education Level there is a corresponding decrease in Time Spent on Homework by .006 units through the affective variables of self-directed learning. Phantom variable analysis was utilized to differentiate the three separate indirect effects caused by the three affective variables. The observed partial indirect effects of Parent Education Level to Time Spent on Homework to be .001, .001, and -.008 for Positive Affect Towards Science, 
Student Valuing Science, and Self-Confidence in Science, respectively. All were significant at the $p<.05$ level (See Table 14).

Evident in the Parent Education Level data is competitive mediation (Zhao, Lynch, \& Chen, 2010). In this situation the overall direct and indirect effects have opposite signs. This occurs only in the Self-Confidence in Science component of Parent Education Level's indirect effect on Time Spent on Homework. Both Positive Affect Towards Science and Student Valuing Science display complementary mediation (Zhao, et al., 2010) where the signs are both positive. Thus, Parent Education Level has an overall positive, significant effect on Time Spent on Homework when Positive Affect Towards Science and Student Valuing Science are considered, while Parent Education Level has a significant negative effect on Time Spent on Homework when Self-Confidence in Science is considered.

Research Question 3

"Does Time Spent On Homework have a significant mediating effect between Self-Confidence in Science and science Achievement?" Time Spent on Homework had a significant, negative mediating effect between Self-Confidence in Science and Achievement $(\mathrm{ab}=-5.415, p<.05)$. For every one unit increase in Self-Confidence in Science, Achievement dropped 5.415 units when considering Time Spent on Homework. However, the direct effect on Achievement of Self-Confidence in Science was significant and positive $\left(c^{\prime}=68.56, p<.05\right)$ indicating that for every one unit increase in SelfConfidence in Science, student achievement increased 68.56 units. This also demonstrates a suppression effect where the direct, $c^{\prime}$, and indirect, $a b$, effects have opposite signs. 


\section{Research Question 4}

"Does time spent on homework have a significant mediating effect between positive affect toward science and science achievement?" Time Spent on Homework had a significant, positive, mediating effect between Positive Affect Towards Science and Achievement $(\mathrm{ab}=2.448, p<.05)$ indicating that for every 1 unit increase in Positive Affect Towards Science, Achievement increased 2.448 units through the mediating effects

of Time Spent on Homework. Again, suppression effects were observed in this instance as the direct effect of PATS on achievement was negative ( $\left.c^{\prime}=-32.30, p<.05\right)$.

Research question 5

"Does Time Spent on Homework have a significant mediating effect between Students Valuing Science and science Achievement?” Time Spent on Homework had a significant, positive, mediating effect between Students Valuing Science and Achievement $(\mathrm{ab}=1.115, p<.05)$. For every 1unit increase in Students Valuing Science, there was a corresponding increase in Achievement by 1.115 units when Time Spent on Homework is a mediator. Unlike the previous two examples, inconsistent mediation was not present in this example.

\section{Research Question 6}

"Is there gender invariance (equivalence) in the model?" To answer this question, the data set was split into two groups by gender. A covariance matrix was created for each group in SPSS to be used as the data source for the SEM analysis in AMOS. First, the measurement model was tested for gender invariance by careful orchestration of constraints added to the model systematically in order to ascertain significance of chisquare tests. To begin, the finalized measurement model (see Figure 9) was used to run 
the initial groups analysis. This was called the configuration model and had no parameters constrained other than those already set to 1 for purposes of model identification. Then, certain parameters were constrained in subsequent versions of the model in order to determine what portions of the model showed invariance or noninvariance between the groups females and males. After each analysis was performed, a chi-square difference test was calculated to determine whether the newest model iteration differed significantly from the configuration model. No significant difference indicated that the model parameters that were constrained measured both groups equivalently (showed invariance). Table 15 summarizes the findings for the measurement model.

The constraining of elements within the model was accomplished by labeling the regression weight of the element with a random value so that the element was held equal across both groups. The model description section of Table 15 describes what elements of the model were constrained. That element was allowed to be freely estimated during the next round of chi-square testing if the constraints produced a significant chi-square test. If it was not significant, its constraints were held through the next testing round. This cumulative process allows the researcher to identify those elements that are not equal (noninvariant) across the groups.

Models A through J represent constrained elements in the measurement model. It was found that all of the factor loadings for Positive Affect Towards Science and Students Valuing Science along with the "not strength" item loading on the factor Self-Confidence in Science were invariant between males and females. Noninvariance was found to exist in the error covariances between $\mathrm{SVe} 1$ and $\mathrm{SVe} 2$ and $\mathrm{SCe} 1$ and $\mathrm{SCe} 2$, as well as the 
other item loadings of Self-Confidence in Science; "do well" and "learn quick". It should be noted that model E showed significant noninvariance when all of the factor loadings were constrained. Subsequent tests of all of the loadings for Positive Affect Towards Science and Students Valuing Science showed invariance in models F and G.

\section{Table 15}

Goodness-Of-Fit Statistics for Tests of Gender Invariance on Measurement Model: A Summary

\begin{tabular}{|c|c|c|c|c|c|c|}
\hline Model Description & $\begin{array}{l}\text { Comparative } \\
\text { Model }\end{array}$ & $\chi^{2}$ & df & $\Delta \chi^{2}$ & $\Delta \mathrm{df}$ & Significance \\
\hline $\begin{array}{l}\text { (1) Configuration Model: No } \\
\text { equality constraints imposed }\end{array}$ & $\mathrm{N} / \mathrm{A}$ & 812.975 & 98 & $\mathrm{~N} / \mathrm{A}$ & $\mathrm{N} / \mathrm{A}$ & $\mathrm{N} / \mathrm{A}$ \\
\hline $\begin{array}{l}\text { Model A: All factor loadings and } \\
\text { error covariances are constrained }\end{array}$ & A vs. (1) & 880.961 & 109 & 67.99 & 11 & $p<.001$ \\
\hline $\begin{array}{l}\text { Model B: Only the two error } \\
\text { variances are constrained }\end{array}$ & B vs. (1) & 851.579 & 100 & 38.595 & 2 & $p<.001$ \\
\hline $\begin{array}{l}\text { Model C: Error covariance between } \\
\text { SVe1 and SVe2 constrained }\end{array}$ & C vs. (1) & 818.559 & 99 & 5.584 & 1 & $p<.05$ \\
\hline $\begin{array}{l}\text { Model D: Error covariance between } \\
\text { SCe1 and } \mathrm{SCe} 2 \text { constrained }\end{array}$ & D vs. (1) & 846.027 & 99 & 33.052 & 1 & $p<.001$ \\
\hline $\begin{array}{l}\text { Model E: All factor loadings are } \\
\text { constrained }\end{array}$ & E vs. (1) & 851.371 & 107 & 38.396 & 9 & $p<.001$ \\
\hline $\begin{array}{l}\text { Model F: Factor loadings for PATS } \\
\text { constrained }\end{array}$ & F vs. (1) & 816.840 & 101 & 3.865 & 3 & NS \\
\hline $\begin{array}{l}\text { Model G: Factor loadings for PATS } \\
\text { and SVS constrained }\end{array}$ & G vs. (1) & 820.466 & 104 & 7.491 & 6 & NS \\
\hline $\begin{array}{l}\text { Model H: Factor loadings for } \\
\text { PATS, SVS and "notstr" } \\
\text { constrained }\end{array}$ & H vs. (1) & 822.437 & 105 & 9.462 & 7 & NS \\
\hline $\begin{array}{l}\text { Model I: Factor loadings for PATS, } \\
\text { SVS, "notstr" and "dowell" } \\
\text { constrained }\end{array}$ & I vs. (1) & 839.469 & 106 & 26.494 & 8 & $p<.001$ \\
\hline $\begin{array}{l}\text { Model J: Factor loadings for PATS, } \\
\text { SVS, "notstr" and "learnqk" } \\
\text { constrained }\end{array}$ & J vs. (1) & 850.282 & 106 & 37.307 & 8 & $p<.001$ \\
\hline $\begin{array}{l}\text { Model AA: Latent variable } \\
\text { covariances are constrained }\end{array}$ & AA vs. (1) & 846.558 & 108 & 33.583 & 10 & $p<.001$ \\
\hline Model BB: "cov1" is constrained & BB vs. (1) & 831.059 & 106 & 18.084 & 8 & $p<.05$ \\
\hline Model CC: "cov2" is constrained & CC vs. (1) & 824.042 & 106 & 11.067 & 8 & NS \\
\hline $\begin{array}{l}\text { Model DD: "cov2" and "cov3" are } \\
\text { constrained }\end{array}$ & DD vs. (1) & 824.062 & 106 & 11.087 & 8 & NS \\
\hline
\end{tabular}


Therefore, the noninvariance demonstrated in model E must lay in the latent variable Self-Confidence in Science. Thus, when transitioning between models G and H, factor loadings for Self-Confidence in Science were tested individually in order to find the noninvariance.

Models AA through DD represent constrained elements in the structural portion of the model. Noninvariance was found in the covariance between PATS and SCS.

Finally, gender invariance in the final hybrid model was conducted using the automated multi-group analysis function in AMOS. Prior to analysis, the hybrid model was modified by the removal of the Gender causal variable. This was done because the separate groups being tested were gender based and the inclusion of this variable in the model itself was redundant. This automated analysis function was particularly useful as this model is complex and would have taken a lot of time to complete. Tests of invariance were done on the measurement weights, structural weights and structural covariances within the model. The results of the analysis are in Table 16.

Table 16

$\underline{\text { Summary of Full SEM Model of Gender Invariance }}$

\begin{tabular}{lccccc}
\hline Model Description & $\chi^{2}$ & df & $\Delta \chi^{2}$ & $\Delta$ df & Significance \\
\hline $\begin{array}{l}\text { Configuration model: No equality } \\
\text { constraints imposed }\end{array}$ & 1142.061 & 180 & N/A & N/A & N/A \\
$\begin{array}{l}\text { Measurement weights constrained } \\
\begin{array}{l}\text { Structural weights and measurement } \\
\text { weights constrained }\end{array}\end{array}$ & 1456.011 & 194 & 13.95 & 14 & NS \\
$\begin{array}{l}\text { Structural covariances, structural } \\
\text { weights, and measurement weights } \\
\text { constrained }\end{array}$ & 1463.057 & 202 & 20.996 & 22 & NS \\
\hline
\end{tabular}

$\mathrm{N} / \mathrm{A}=$ not applicable; $\mathrm{NS}=$ not significant 
The nonsignificance of the cumulative tests for invariance showed that the hybrid model measured males and females equally across the factors within the model.

This gender invariance analysis result notwithstanding, AMOS calculated the critical ratios between parameters in the model and displayed them in a matrix. This was done for the chosen paths for both boys and girls. Critical ratios are z-scores and are considered significant if their value exceeds $|1.96|$. The parameters of interest were examined and reported in Table 17. The results of this analysis showed that the only significant difference between genders occurred in the PEL to SCS path, z-score $=2.01$. All other paths were not significantly different from one another.

Table 17

Critical Ratios Between Parameters

\begin{tabular}{|c|c|c|c|c|c|c|c|}
\hline & \multirow{2}{*}{ Path } & & \multicolumn{2}{|c|}{ Males } & \multicolumn{2}{|c|}{ Females } & \multirow{2}{*}{ z-score } \\
\hline & & & Estimate & $\mathrm{P}$ & Estimate & $\mathrm{P}$ & \\
\hline PATS & $\longleftarrow$ & PEL & -0.018 & 0.473 & 0.035 & 0.151 & 1.522 \\
\hline SCS & $\longleftarrow$ & PEL & 0.005 & 0.832 & 0.070 & 0.002 & $2.01 *$ \\
\hline SVS & $\longleftarrow$ & PEL & -0.039 & 0.078 & 0.004 & 0.866 & 1.393 \\
\hline $\mathrm{TSH}$ & $\leftarrow$ & PATS & 0.236 & 0.000 & 0.229 & 0.001 & -0.069 \\
\hline TSH & $\leftarrow$ & SCS & -0.528 & 0.000 & -0.552 & 0.000 & -0.146 \\
\hline TSH & 4 & PEL & -0.042 & 0.038 & -0.027 & 0.226 & 0.502 \\
\hline $\mathrm{TSH}$ & 4 & SVS & -0.038 & 0.322 & -0.079 & 0.087 & -0.677 \\
\hline ACHIEVE & $\leftarrow$ & $\mathrm{TSH}$ & -0.095 & 0.197 & -0.122 & 0.007 & -0.317 \\
\hline ACHIEVE & $\leftarrow$ & SCS & -0.551 & 0.000 & -0.559 & 0.000 & -0.065 \\
\hline ACHIEVE & 4 & SVS & 0.119 & 0.018 & 0.126 & 0.007 & 0.096 \\
\hline ACHIEVE & $\leftarrow$ & PATS & 0.222 & 0.003 & 0.266 & 0.000 & 0.450 \\
\hline
\end{tabular}

Note: $* p<0.05$ 


\section{CHAPTER V \\ DISCUSSION}

This chapter presents a summary of the study and important conclusions drawn from the findings presented in Chapter IV. It provides a discussion of the findings and the implications for action and recommendations for further research.

\section{Summary of the study}

Homework has been shown to have a significant, positive effect on student achievement and grades, particularly at the secondary level (Cooper, et al., 2006). However, homework completion and its effect on grades is controlled within the realm of the student and its success as a learning strategy depends on many things including the student's interest in the subject, their confidence, the time they have to complete it, gender and other factors within the home such as parent education level and parent involvement (Trautwein \& Ludtke, 2007; J. Xu, 2007; J. Xu, Corno, Lyn, 2006). Given the importance of homework as a learning strategy and its positive effect on achievement, it is important to clarify those aspects that contribute the most to successful homework experiences.

Through the work of Eccles (2002) and Trautwein (2006), homework research has focused heavily on students' affective beliefs and their relevance. Expectancy-Value theory (Eccles, 2002) and self-efficacy theory (Bandura, 1997) identify student self- 
confidence and valuation of the subject as integral components of academic motivation and Trautwein (2006) places them as antecedents to homework factors in his model of homework. Trautwein also includes student and parent factors in his model and places them as precursors to the affective variables. One can interpret from his model that student factors influence affective variables that, in turn, affect homework behavior. But, because his research is founded in hierarchical linear modeling, causality among the variables cannot be assigned. Thus, a method of analysis needed to be used that could confirm the placement of these variables in a causal sequence while at the same time demonstrate their importance to homework's relevance.

It was the intent of this research to explore the causal relationship among the homework model factors of Student Positive Affect Towards Science, Student Valuation of Science, Self-Confidence in Science, Gender, Parent Education Level, and SelfConfidence in Science.

Methodologically, the whole TIMMS sample was split into two groups, exploratory and validation sets in order to obtain a 2 -fold cross validation sample. This process lends credibility to the study by allowing the researcher to run the model with two separate sample groups. The exploratory sample was used to check the goodness-offit of the model. Once goodness of fit was achieved, the validation set was used to generate the data for the research questions. Covariance matrices were created and these were used as the data source for the structural equation models.

Structural equation modeling (SEM) with mediational analysis was used to test the causal relationships among the variables of the study. Mediational analysis is a causal test because it assumes that if a mediational variable is present, then that variable must be 
caused by an antecedent variable that, in turn, affects a variable coming after it. This sequence of events is considered a causal sequence and is identified as a causal relationship. If no mediation is found, then one cannot assume a causal relationship. Additionally, phantom variables were utilized to isolate the individual indirect effects of both Gender and Parent Education Level.

\section{Affective Variables/Self-Regulatory Learning As Mediators}

Answers to six research questions were sought in order to better understand the relationship of homework to science achievement and the affective variables that reflect the qualities of self-regulated learning. The first two research questions asked about the affective variables' roles as mediators in the effect of Gender and Parent Education Level on Time Spent on Homework.

Research question 1. Does gender have an indirect effect on time spent on homework through the affective variables associated with self-regulatory learning (selfconfidence in science, positive affect towards science, and students valuing science)? The results demonstrate that girls tend to have a slight but significantly higher Positive Affect Towards Science than boys. Girls also showed a higher Student Valuation of Science than boys, and while this was not significant, it was very close, $p=.054$. Boys, on the other hand, showed a significant and higher Self-Confidence in Science than girls.

Interestingly, while the indirect effect, $a b$, of Gender on Time Spent on Homework was significant, its direct effect, $c^{\prime}$, was not $\left(c^{\prime}=-.010, p>.05\right)$. This nonsignificance direct effect, therefore, will only allow the paths through the affective variables to be either full mediation or none depending on the significance of the individual paths. Phantom analysis allowed for this separate path analyses and showed 
that all paths displayed significant indirect effects. Therefore, Positive Affect Towards Science, Students Valuing Science, and Self-Confidence in Science demonstrated full mediation meaning that all of the influence of Gender on Time Spent on Homework occurred through mediators and not directly. Does this mean that these are the only three mediators that act between Gender and Time Spent on Homework? No. There may be other variables that were not tested in this model. For example, Trautwein (2006) identified other factors such as student conscientiousness and cognitive abilities that could have their roots in gender differences that could contribute to the homework effect. This complete mediation also indicates that Positive Affect Towards Science, Students Valuing Science, and Self-Confidence in Science, as mediators between gender and TSH, are consistent with the hypothesized theoretical framework as it was created for this model.

Research question 2. Does parent education level have an indirect effect on time spent on homework through the affective variables associated with self-regulatory learning (self-confidence in science, positive affect towards science, and students valuing science)? The paths leading from Parent Education Level to Time Spent on Homework are more complicated. First, the direct effect of Parent Education Level on Time Spent on Homework was significant and positive. Unlike the gender paths where the direct effect of Gender on Time Spent on Homework was not significant, complete mediation cannot be happening in this part of the path diagram due to this significant direct effect. Overall, the sum of the indirect effects was significant. Looking at each path individually, the indirect path through Self Confidence in Science was significant and had a negative sign that is opposite the sign of the direct effect. Since they are opposites, this classifies this 
mediation as competitive (Zhao, et al., 2010). The interpretation of this mediation is that the model is consistent with the hypothesized framework but there may be a missing mediator in the direct path that is the same sign as the direct effect (see figure 12) (Zhao, et al., 2010). Thus, the data indicates that there may be another unidentified variable that is competing against Self-Confidence in Science in the sense that it has the opposite sign.

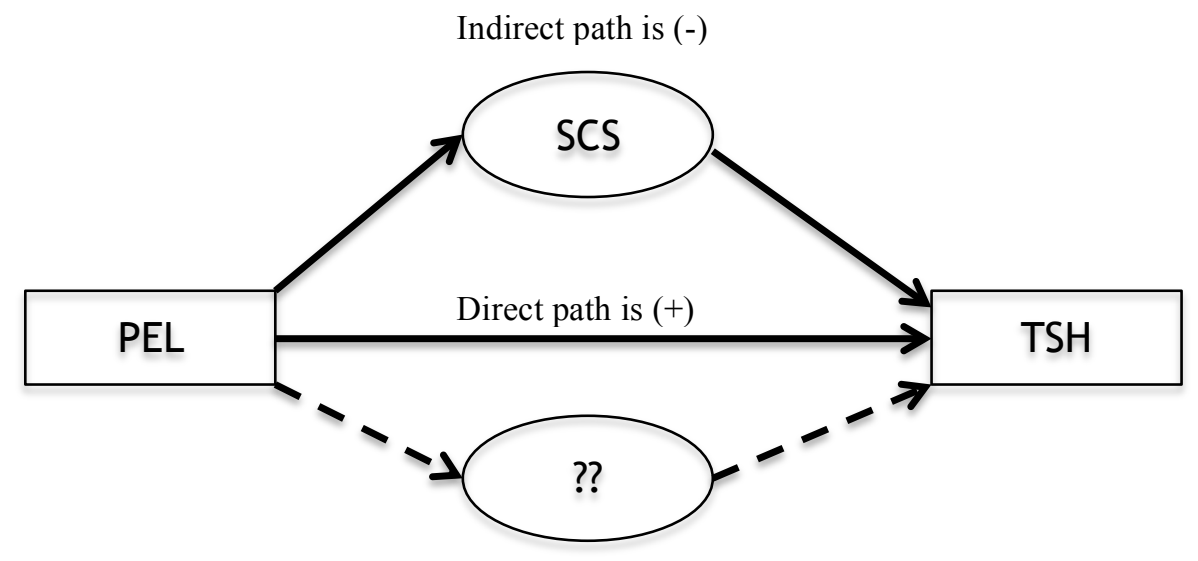

Unknown mediation path is $(+)$

Figure 12: Competitive mediation. Variable "??" is unknown but would be a competing mediator to SCS and would have an indirect effect with an opposite sign.

The path through PATS demonstrates complementary mediation (Zhao, et al., 2010). Here, the signs of both the direct path and indirect path are positive (they could also both be negative) and thus, act together in the same manner as Kenny's (2013) partial mediation where the variable present is mediating, but there is another mediator somewhere with the same sign that is yet unknown.

The indirect path running from PEL through SVS was significant. This, like Positive Affect Towards Science is a complementary mediation as the indirect path has a positive sign, the same as the direct effect. 
It is interesting to note that these competitive and complementary mediations all assume that there are unknown variables, yet to be identified, that are either competing with or supporting the mediation between the causal and outcome variables. But in discussing the possible unknowns, Zhao (2010) states that “...more and more complex models could theoretically be developed with multiple mediators. However, parsimony dictates simpler models are preferred."

Research questions 3, 4, and 5 (respectively). Does time spent on homework have a significant mediating effect between self-confidence in science and science achievement? Does time spent on homework have a significant mediating effect between positive affect toward science and science achievement? Does time spent on homework have a significant mediating effect between students valuing science and science achievement? Time Spent on Homework acted as a significant mediator for all of the paths between the affective variables and achievement. The direct paths between the affective variables and Achievement were all significant as well. Complementary mediation existed in the Students Valuing Science relationship and competitive mediation occurred through Time Spent on Homework from Self-Confidence in Science and Positive Affect Towards Science to Achievement. The presence of Time Spent on Homework as a mediator between the affective variables that characterize self-regulated learning and Achievement is consistent with the hypothesized theoretical framework. However, as before, there must be other, omitted mediator variables present with the same sign as the direct effects (Zhao, et al., 2010). 
Research Question 6: Is there gender invariance in the model? There were two individual pockets of noninvariance in the measurement model. Two item loadings of the factor Self-Confidence in Science were measured differently between boys and girls: "I usually do well in science" and "I learn things quickly in science". The noninvariance means that these two factors do not have the same meaning for each group. One wonders what "doing well" means to girls and boys and how is this different between them. Is the grade of an "A" doing well for boys and a "B" for girls or visa versa? The same types of questions arise for learning things quickly. Obviously, both doing well and learning quickly are highly subjective terms that have a wide range of interpretations. Perhaps this is the root of the discrepancy. However, the measurement model noninvariance did not affect the gender invariance of the hybrid model overall as gender invariance was found to exist within the hybrid model because there were no significant chi-square differences between the constrained models.

\section{Study Conclusions}

One can conclude from these findings that gender affects Time Spent on Homework through all the affective variables associated with self-regulated learning; Positive Affect Towards Science, Students Valuing Science, and Self-Confidence in Science. More specifically, however, phantom analysis showed that time spent on homework for girls' acts through the Positive Affect Towards Science, and Student Valuation paths while boys' acts through the Self-Confidence in Science path. This result is not new. Trautwein (2009) saw similar results when he found that males tend to have a higher self-confidence in all subjects while at the same time, may not like or value those subjects. 
The findings in this study support the models proposed by Eccles (2002) and Trautwein (2006). Granted, this study used homework as a main focus and Eccles' model did not look at homework, but the relationships of the variables in the model correspond to the positions of similar variables in Eccles' model. This model shows that there are significant differences between boys and girls when it comes to their affective beliefs concerning science. Many studies, including those cited earlier, have shown that boys and girls differ in their affect towards different subjects (Harris \& Nixon, 1993; Trautwein, et al., 2009) that can be traced to gender role perceptions in Eccles' model. These gender role differences contribute to the building of students' self-schema that can eventually influence their affectual perception of different subjects. Traditionally, girls favor the humanities such as English and the arts while boys prefer the sciences and math (Trautwein, et al., 2009). This may explain the higher self-confidence demonstrated by boys in this study.

Trautwein's model was supported as well. Both models demonstrated that affective variables have a significant mediational effect between the student characteristics of gender and parent education level and time spent on homework. In addition, this and Trautwein's model both place homework between the affective variables and achievement - a mediational role. This structure is supported by the significant indirect effect obtained from the current study.

Conversely, there were some differences as well. Trautwein's model has gender linked directly to homework variables whereas the present model found no significant direct effect of gender on homework. Trautwein's model also contains a lot of other 
factors not analyzed in the current model. But, further research can use this model to study other factors that have the same relationship within the model.

\section{Study Limitations}

There are several limitations to this study that if addressed would make this study more informative and relevant. First, the homework factors of time spent on homework and frequency of homework neglect to take into account several other factors that others have found to be much more relevant (Trautwein, 2006). These include homework compliance, percentage of homework completed and concentration on homework. Simply measuring the time and frequency does not necessarily predispose a student to better grades. This can be seen in lower achieving students who may spend much more time on homework but fail to achieve as highly as those students who invest less time. On the other hand, percent of homework completed equals the playing field because no matter how long it may take a student to do $100 \%$ of the homework, it is still complete and could be used to inform a homework latent variable.

A second limitation is the lack of studies that deal with the effects of Parent

Education Level on homework. Findings from this study contribute to the literature by showing that Parent Education Level has both significant direct and indirect effects on homework through the variables describing self-regulatory learning. These results would suggest that parents with higher education levels tend to have students who spend more time on homework. But, the competitive and complimentary indirect effects suggest that other variables are present that contribute to the relationship. Further research will have to be conducted in order to uncover these other factors. 
The third limitation is the preponderance of unidentified variables. All but a few of the indirect effects in this study were either competitive or complementary effects. In the past, researchers termed complementary indirect effects as partial effects and competitive indirect effects as inconsistent (D. Kenny, 2013). These previous researchers wrote these effects off as failures of the mediational analysis (Zhao, et al., 2010). But Zhao (2010) argues that these are not failures, but indicators of the presence of other mediators that are contributing to the indirect effects. The present research indicates a number of unknown variables that must be affecting the indirect effect, and our inability to identify these is a limitation of this study.

Finally, much of the previous homework research uses hierarchical linear modeling to perform data analyses because homework's is a multi-level effect; the student and the class. This research is student level only. This research should be extended to the class level to understand the differences that may appear. This can be done as the TIMSS data can be organized by class.

\section{Implications}

The evidence from this study suggests that homework is a teaching tool that can affect achievement, but only through other mediating variables that are tied to characteristics of self-regulated learning. Thus, students who display the characteristics of positive affect, valuation, and self-confidence in the subject will make better use of the homework given than those who do not. Thus, it is logical to conclude that teachers should include lessons or parts of lessons that help foster characteristics of self-regulated learning in order to make their homework assignments more effective. 
At the school level, these results can be used in different ways depending upon whether the school is primary or secondary. Given the importance of the affective variables, primary schools would need to focus on building these qualities in students from an early age. They should encourage students to find the fun and meaning in all of the subjects; math, science, art, music, language arts, and social studies so that the children could have positive feelings towards schools and gain a sense of value for the things they are learning. This is important at the primary level because secondary students have typically solidified their opinions on school subjects.

At the secondary level, school administration should attempt to deter homework policies that place too much academic emphasis on the practice. This research demonstrates, to a degree, that homework's relevance and effectiveness depends heavily, and in some cases exclusively, on factors uncontrollable in the classroom. The affective characteristics of self-directed learning, having been quite formalized in their youth, are difficult for teachers to influence at the secondary level. Therefore, it might be prudent to have homework become a non-graded, although important, participatory aspect of a students academic grade. In other words, teachers should not grade a homework assignment on its completion, but rather use it as a tool for students to gain additional practice outside of class.

By taking that thought even further, one could argue that homework in the traditional sense, should be eliminated all together. A couple of reasons for this are (1) homework, at the elementary level, has not been shown to positively effect achievement, and (2) homework's relationship to science achievement in this study seems small, albeit significant. In fact, the direct effects of the affective variables on science achievement are 
much greater in magnitude than the indirect effects through homework, which is telling as this indicates that there are other omitted variables that may have much greater impacts on science achievement than homework. This begs the question, "Is the benefit of doing homework worth the cost of the time it takes to complete it, in regards to science achievement?" The answer to this may be a strong "no". In this study, homework's benefit, in an academic sense, is significant yet seemingly negligible. If homework's academic benefit is small, then why continue to do it? Perhaps homework's value lies in behavior modification. It was mentioned that elementary teachers give homework so their students learn time management. This can be said of secondary students as well. High school teachers can make the claim that they are preparing their students for college where much of the student's learning will occur outside the classroom during their studying. Moreover, if this is a simple question of learning time management skills, could the students not learn that by doing other activities such as having a job, participating in extra-curricular activities, or volunteering?

\section{Recommendations}

Students, teachers, building and district level administrators as well as policymakers could be well served by following the recommendations given here.

First, in the classroom, teachers need to provide concrete examples of real-life applications of their subjects. This needs to include the use of real-world examples or other methods that tie what the students are learning to real-life. Geometry teachers could utilize blueprint schematics to demonstrate angles, elevations, and rudimentary trigonometric expressions. Science teachers could do any number of things including real-time experimental analyses of phenomena within the school, such as the 
effectiveness of antibacterial soaps in the restrooms. Tying the lessons to what we do every day will increase the relevance of the subject to the student thereby increasing the students affect towards the subject and their sense of the subjects value to their goals. Teachers should also allow students small successes in the beginning of the term that build over time to increase student self-confidence. As students experience these successes, their confidence increases.

Students who understand the relationship between the characteristics of selfregulated learning, homework and achievement are well armed with the knowledge to change their habits and perceptions. It is recommended that teachers inform students of the results in this study so that the students can begin to actively seek meaning and realworld applications of the subjects they are taking.

As mentioned in the implications, school and district level administration are encouraged to re-evaluate homework policies that were, most likely, created many years ago. Homework involves too many factors outside the control of the schools to make its inclusion as an academic grade, particularly at the secondary level. Homework, itself, is a behavioral phenomenon that has a process to it and thus needs to be taught as such.

It is recommended that the TIMSS questionnaire be re-evaluated in light of its questions related to homework. A big limitation to the effectiveness of this research is the narrow scope of the homework variable to time and frequency. The TIMSS team could rephrase the questions in such a manner as to make this variable more reliable. Additionally, the gender non-invariance found in two of the SCS factors could be rephrased in order to make the phrase more equitable to both sexes. 
Furthermore, the use of these results could go a long way in dealing with achievement gap issues. Of the many issues surrounding the gap in achievement is the often futile attempt by teachers to have at-risk students complete homework (Callahan, Rademacher, \& Hildreth, 1998). These students have not been taught the behaviors of self-regulated learning that are crucial to homework completion (Callahan, et al., 1998; Ramdass \& Zimmerman, 2011). The evidence in this study demonstrates that all students, at-risk or not, will benefit from learning and internalizing the affective variables so that they can benefit from the motivation needed to successfully complete homework whether it be completion of a few math problems to studying many hours for a major exam.

It should be noted as well, that these results should not be constrained only to science achievement. These recommendations can be easily applied to all subjects.

Finally, it is recommended that further homework studies be done with the model developed in this research. Homework researchers have developed many ways to measure the affective variables in this model (J. S. Eccles, Adler, T. F., Futterman, R., Goff, S. B., Kaczala, C. M., Meece, J. L., \& Midgley, C., 1983; Singh, et al., 2002; Trautwein, Ludtke, Schnyder, et al., 2006; Wigfield \& Eccles, 2000; Zimmerman, 2002). These could be sampled and used in the model along with measures of parent education level and a typical standardized test such as the ACT, SAT, or PSAT. Furthermore, accurate measurements of homework completion and effort, such as those developed by Trautwein (2006) could be used instead of homework time and frequency. 


\section{REFERENCES}

Atkinson, J. W. (1957). Motivational determinants of risk-taking behavior. Psychological Review, 64, 359-372.

Atkinson, J. W. (1964). An introduction to motivation.

Atkinson, J. W., \& Feather, N. T. (1966). A theory of achievement motivation (Vol. 66): Wiley New York.

Balli, S. J., Demo, D. H., \& Wedman, J. F. (1998). Family Involvement with Children's Homework: An Intervention in the Middle Grades. Family Relations, 47(2), 149157.

Bandura, A. (1997). Self Efficacy: The Exercise of Control. New York: W. H. Freeman and Co.

Becker, H. J., \& Epstein, J. L. (1982). Parent Involvement: A Survey of Teacher Practices. Elementary School Journal, 83(2), 85-102.

Byrne, B. M. (2009). Structural equation modeling with AMOS: Basic concepts, applications, and programming: CRC Press.

Callahan, K., Rademacher, J. A., \& Hildreth, B. L. (1998). The Effect of Parent Participation in Strategies To Improve the Homework Performance of Students Who Are At Risk. Remedial and Special Education, 19(3), 131-141.

Caprara, G. V., Fida, R., Vecchione, M., Del Bove, G., Vecchio, G. M., Barbaranelli, C., $\&$ Bandura, A. (2008). Longitudinal analysis of the role of perceived self-efficacy for self-regulated learning in academic continuance and achievement. Journal of Educational Psychology, 100(3), 525.

Choi, N. (2005). Self-Efficacy and Self-Concept as Predictors of College Students' Academic Performance. Psychology in the Schools, 42(2), 197-205.

Choi, N., Bush, S., English-Hunter, A., and Truitt, T. (2011). Factorial Validity of the Scores from the TIMSS 2007 Mathematics Attitude Scale. Paper presented at the American Educational Research Association Annual Conference, New Orleans, LA. 
Cooper, H. (1989). Synthesis of Research on Homework. Educational Leadership, 47(3), $85-91$.

Cooper, H., Robinson, J. C., \& Patall, E. A. (2006). Does Homework Improve Academic Achievement? A Synthesis of Research, 1987-2003. Review of Educational Research, 76(1), 1-62.

Corno, L. (1996). Homework Is a Complicated Thing. Educational Researcher, 25(8), 27-30.

Cross-validation (statistics). (2013, January 6). Wikipedia, The Free Encyclopedia Retrieved January 14, 2013, from http://en.wikipedia.org/w/index.php?title=Crossvalidation_(statistics)\&oldid $=531654145$

Davis-Kean, P. E. (2005). The influence of parent education and family income on child achievement: the indirect role of parental expectations and the home environment. Journal of Family Psychology, 19(2), 294.

Dettmers, S., Trautwein, U., \& Ludtke, O. (2009). The relationship between homework time and achievement is not universal: evidence from multilevel analyses in 40 countries. School Effectiveness \& School Improvement, 20(4), 375-405.

Dettmers, S., Trautwein, U., Ludtke, O., Goetz, T., Frenzel, A. C., \& Pekrun, R. (2011). Students' Emotions during Homework in Mathematics: Testing a Theoretical Model of Antecedents and Achievement Outcomes. Contemporary Educational Psychology, 36(1), 25-35.

Dettmers, S., Trautwein, U., Ludtke, O., Kunter, M., \& Baumert, J. (2010). Homework Works If Homework Quality Is High: Using Multilevel Modeling to Predict the Development of Achievement in Mathematics. Journal of Educational Psychology, 102(2), 467-482.

Duckworth, A. L., \& Seligman, M. E. P. (2006). Self-Discipline Gives Girls the Edge: Gender in Self-Discipline, Grades and Achievement Test Scores. [Article]. Journal of Educational Psychology, 98(1), 198-208. doi: 10.1037/00220663.98.1.198

Eccles, J., \& et al. (1993). Age and Gender Differences in Children's Self- and Task Perceptions during Elementary School. Child Development, 64(3), 830-847.

Eccles, J. S., Adler, T. F., Futterman, R., Goff, S. B., Kaczala, C. M., Meece, J. L., \& Midgley, C. (1983). Expectancies, values, and academic behaviors. In J. T. Spence (Ed.), Achievement and acheivement motivation (pp. 75-146). San Francisco, CA: W. H. Freeman. 
Eccles, J. S., \& Wigfield, A. (2002). Motivational beliefs, values, and goals. Annual review of psychology, 53(1), 109-132.

Eccles, J. S., Wigfield, A. (1995). In the mind of the actor: The structure of adolescents' achievement task values and expectancy-related beliefs. Personlity and Social Psychology Bulletin, 21(3), 215-255.

Epstein, J. L., \& Van Voorhis, F. L. (2001). More Than Minutes: Teachers' Roles in Designing Homework. Educational Psychologist, 36(3), 181-193.

Fan, X., \& Chen, M. (2001). Parental Involvement and Students' Academic Achievement: A Meta-Analysis. Educational Psychology Review, 13(1), 1-22. doi: 10.1023/a:1009048817385

Feather, N. T. (1982). Human values and the prediction of action: An expectancy-valence analysis. Expectations and actions: Expectancy-value models in psychology, 263289.

Field, A. (2009). Discovering Statistics Using SPSS (3rd ed.). London: Sage.

Foy, P., Galia, Joseph, and Li, Isaac. (2008). Scaling the Data from the TIMSS 2007 Mathematics and Science Assessment. In J. F. Olson, Martin, Micael O., Mullis, Ina V.S. (Ed.), TIMSS 2007 Technical Report. Chestnut Hill, MA: International Association for the Evaluation of Educational Achievement (IEA).

Gill, B. P., \& Schlossman, S. L. (2003a). A Nation at Rest: The American Way of Homework. Educational Evaluation and Policy Analysis, 25(3), 319-337.

Gill, B. P., \& Schlossman, S. L. (2004). Villain or Savior? The American Discourse on Homework, 1850-2003. Theory Into Practice, 43(3), 174-181.

Goldberg, K. (2007). The homework trap. Encounter, 20(4), 70-89.

Hancock, G. R., and Mueller, R.O. (Ed.). (2010). The Reviewer's Guide to Quantitative Methods in the Social Sciences. New York: Routledge.

Hanson, S. L. (1994). Lost Talent: Unrealized Educational Aspirations and Expectations among U.S. Youths. Sociology of Education, 67(3), 159-183.

Harris, S., \& Nixon, J. (1993). School work, homework and gender. [Article]. Gender \& Education, 5(1), 3.

Hartlep, N. D., \& Ellis, A. Are Household Income, Gender, and Race Important in Shaping Parental Involvement in Children's Education? : Online Submission. 
Harvey, J. J. (1983, October 7, 1999). A Nation at Risk: The Imperative For Educational Reform Retrieved January 17, 2011, from http://www2.ed.gov/pubs/NatAtRisk/risk.html

Hill, C. (1994). Testing and assessment: An applied linguistic perspective. Educational Assessment, 2(3), 179-212.

Hong, E., \& Milgram, R. M. (1999). Preferred and Actual Homework Style: A CrossCultural Examination. Educational Research, 41(3), 251-265.

House, J. D. (2009). Classroom Instructional Strategies and Science Career Interest for Adolescent Students in Korea: Results from the TIMSS 2003 Assessment. Journal of Instructional Psychology, 36(1), 13-19.

Hoy, W. K., \& Woolfolk, A. E. (1993). Teachers' sense of efficacy and the organizational health of schools. The Elementary School Journal, 355-372.

Joncas, M. (2008). TIMSS 2007 Sample Design. In J. F. Olson, Martin, Michael O., Mullis, Ina V.S. (Ed.), TIMSS 2007 Technical Report. Chestnut Hill, MA: International Association for the Evaluation of Educational Achievement (IEA).

Kaestle, C. F. (1978). Social Change, Discipline, and the Common School in Early Nineteenth-Century America. Journal of Interdisciplinary History, 9(1 (Summer 1978)), 1-17.

Keith, T. Z., Diamond-Hallam, C., \& Fine, J. G. (2004). Longitudinal Effects of InSchool and Out-of-School Homework on High School Grades. School Psychology Quarterly, 19(3), 187.

Kenny, D. (2013, May 1, 2013). Mediation. SEM Retrieved July 2, 2013

Kenny, D. A. (2011, September 6, 2011). SEM: Terminology and Basics. Structural Equation Modeling Retrieved January 16, 2013

Kitsantas, A., Cheema, J., \& Ware, H. W. (2011). Mathematics Achievement: The Role of Homework and Self-Efficacy Beliefs. Journal of Advanced Academics, 22(2), 310-339.

Kline, R. B. (2011). Principles and Practice of Structural Equation Modeling (3rd ed.). New York: The Guilford Press. 
Lau, S., Roeser, R. W., Kupermintz, H., Center for Research on Evaluation, S., Student Testing, L. A. C. A., \& California Univ, L. A. C. f. t. S. o. E. (2002). On Cognitive Abilities and Motivational Processes in Students' Science Engagement and Achievement: A Multidimensional Approach to Achievement Validation. CSE Technical Report.

Lee, J. F., Jr., \& Pruitt, K. W. (1979). Homework Assignments: Classroom Games or Teaching Tools? Clearing House, 53(1), 31-35.

Macho, S., and Ledermann, T. (2011). Estimating, testing, and comparing specific effects in structural equation models: the phantom model approach. Psychological Methods, 16(1), 34-43.

Margolis, H., \& McCabe, P. P. (2004). Self-Efficacy: A Key to Improving the Motivation of Struggling Learners. Clearing House, 77(6), 241.

Martin, M. O., \& Preuschoff, C. (2008). TIMSS 2007 Technical Report. In J. F. Olson, Martin, Michael O., Mullis, Ina V.S. (Ed.). Chestnut Hill, MA: International Association for the Evaluation of Educational Achievement (IEA).

McNeil, R. B. (1999). Parental involvement as social capital: differential effectiveness on science achievement, truancy, and dropping out. Social Forces, 78(1), 117-144.

Mikk, J. (2006). Students' Homework and TIMSS 2003 Mathematics Results: Online Submission.

Mikk, J. (2007). Economic, Educational and Cultural Predictors of Science Learning in Lithuania and Estonia: Online Submission.

Mo, Y., \& Singh, K. (2008). Parents' Relationships and Involvement: Effects on Students' School Engagement and Performance. RMLE Online: Research in Middle Level Education, 31(10), 1-11.

Muhlenbruck, L., Cooper, H., Nye, B., \& Lindsay, J. J. (1999). Homework and achievement: Explaining the different strengths of relation at the elementary and secondary school levels. Social Psychology of Education, 3(4), 295-317. doi: 10.1023/a:1009680513901

Mullis, I. V. S., Martin, M. O., Ruddock, G. J., O'Sullivan, C. Y., Arora, A., Erberber, E. (2005). TIMSS 2007 Assessment Frameworks. Boston: Boston College.

Nunnaly, J. (1978). Psuchometric thoery. New York: McGraw-Hill. 
Olson, J. F., Martin, Micael O., Mullis, Ina V.S., Foy, Pierre, Erberber, Ebru, Preuschoff, Corinna. (2008). Scaling the Data from the TIMSS 2007 Mathematics and Science Assessment. In J. F. Olson, Martin, Micael O., Mullis, Ina V.S. (Ed.), TIMSS 2007 Technical Report. Chestnut Hill, MA: International Association for the Evaluation of Educational Achievement (IEA).

Parsons, J. E., \& Goff, S. B. . (1980). Achievement motivation and values: An alternative perspective. In L. J. Fryans (Ed.), Achievement Motivation (pp. 322-339). New York: Plenum.

Patall, E. A., Cooper, H., \& Robinson, J. C. (2008). Parent Involvement in Homework: A Research Synthesis. Review of Educational Research, 78(4), 1039-1101.

Pekrun, R., Goetz Thomas, Titz Wolfram, Perry Raymond P. (2002). Academic Emotions in Students' Self-Regulated Learning and Achievement: A Program of Qualitative and Quantitative Research. [Article]. Educational Psychologist, 37(2), 91-105.

Ramdass, D., \& Zimmerman, B. J. (2011). Developing Self-Regulation Skills: The Important Role of Homework. Journal of Advanced Academics, 22(2), 194-218.

Sabah, S., \& Hammouri, H. (2010). Does Subject Matter Matter? Estimating the Impact of Instructional Practices and Resources on Student Achievement in Science and Mathematics: Findings from TIMSS 2007. Evaluation \& Research in Education, 23(4), 287-299.

Schibeci, R. A., Riley, J.P. (1986). Influence of students' background and perceptions on science attitudes and achievement. Journal of research in sceince teaching, 23(3), 177-187.

Schreiber, J. B. (2002). Institutional and Student Factors and Their Influence on Advanced Mathematics Achievement. Journal of Educational Research, 95(5), 247.

Schumaker, R. E., \& Lomax, Richard G. (2010). A Beginner's Guide to Structural Equation Modeling (Third ed.). New York: Routledge.

Self-Schema. (2012, May 19, 2012) Retrieved June 24, 2012, from http://en.wikipedia.org/wiki/Self-schema

Singh, K., Granville, M., \& Dika, S. (2002). Mathematics and Science Achievement: Effects of Motivation, Interest, and Academic Engagement. Journal of Educational Research, 95(6), 323-332.

Sirin, S. R. (2005). Socioeconomic status and academic achievement: A meta-analytic review of research. Review of Educational Research, 75(3), 417-453. 
Snyder, J., Bolin,E, \& Zumwalt,K. (1992). Curriculum implementation Handbook of research on curriculum (pp. 402-435). New York: Macmillan.

Stemler, S. (2004, 03/01/2004). A comparison of consensus, consistency, and measurement approaches to estimating interrater reliability. Practical Assessment, Research \& Evaluation Retrieved January 13, 2013, from http://PAREonline.net/getvn.asp?v=9\&n=4

Trautwein, U. (2007). The homework achievement relation reconsidered: Differentiating homework time, homework frequency, and homework effort. Learning \& Instruction, 17(3), 372-388.

Trautwein, U., \& Koller, O. (2003). The Relationship Between Homework and Achievement--Still Much of a Mystery. Educational Psychology Review, 15(2), 115.

Trautwein, U., Koller, O., Schmitz, B., \& Baumert, J. (2002). Do Homework Assignments Enhance Achievement? A Multilevel Analysis in 7th-Grade Mathematics. Contemporary Educational Psychology, 27(1), 26.

Trautwein, U., \& Ludtke, O. (2007). Students' Self-Reported Effort and Time on Homework in Six School Subjects: Between-Students Differences and WithinStudent Variation. Journal of Educational Psychology, 99(2), 432-444.

Trautwein, U., \& Ludtke, O. (2009). Predicting homework motivation and homework effort in six school subjects: The role of person and family characteristics, classroom factors, and school track. Learning \& Instruction, 19(3), 243-258.

Trautwein, U., Ludtke, O., Kastens, C., \& Koller, O. (2006). Effort on Homework in Grades 5-9: Development, Motivational Antecedents, and the Association With Effort on Classwork. Child Development, 77(4), 1094-1111.

Trautwein, U., Ludtke, O., Schnyder, I., \& Niggli, A. (2006). Predicting Homework Effort: Support for a Domain-Specific, Multilevel Homework Model. Journal of Educational Psychology, 98(2), 438-456.

Trautwein, U., Niggli, A., Schnyder, I., \& Ludtke, O. (2009). Between-Teacher Differences in Homework Assignments and the Development of Students' Homework Effort, Homework Emotions, and Achievement. Journal of Educational Psychology, 101(1), 176-189.

Trusty, J. (1998). Family Influences on Educational Expectations of Late Adolescents. Journal of Educational Research, 91(5), 260-270.

Wagner, P., Schober, B., \& Spiel, C. (2008). Time Students Spend Working at Home for School. Learning and Instruction, 18(4), 309-320. 
Walberg, H. J., Paschal, R. A., \& Weinstein, T. (1985). Homework's Powerful Effects on Learning. Educational Leadership, 42(7), 76.

Weiner, B. (2010). The Development of an Attributio-Based Theory of Motivation: A History of Ideas. Educational Psychologist, 45(1), 28-36.

Weiner, B., Frieze, I., Kukla, A., Reed, L., Rest, S., Rosenbaum, R. M. (1971). Perceiving the causes of success and failure. Morristown, NJ: General Learning.

Wigfield, A. (1994). Expectancy-Value Theory of Achievement Motivation: A Developmental Perspective. Educational Psychology Review, 6(1), 49-78.

Wigfield, A., \& Eccles, J. S. (1992). The development of achievement task values: A theoretical analysis. Developmental review, 12(3), 265-310.

Wigfield, A., \& Eccles, J. S. (2000). Expectancy-value theory of achievement motivation. Contemporary Educational Psychology, 25(1), 68-81.

Xu, J. (1994). Doing homework: A study of possibilities. Unpublished doctoral dissertation. Teachers College. Columbia University. New York.

$\mathrm{Xu}, \mathrm{J}$. (2006). Gender and homework management reported by high school students. Educational Psychology, 26(1), 73-91.

Xu, J. (2007). Middle-School Homework Management: More than Just Gender and Family Involvement. Educational Psychology, 27(2), 173-189.

$\mathrm{Xu}$, J. (2010). Predicting homework time management at the secondary school level: A multilevel analysis. Learning and Individual Differences, 20(1), 34-39.

$\mathrm{Xu}$, J. (2011). Homework Completion at the Secondary School Level: A Multilevel Analysis. The Journal of Educational Research, 104, 171-182.

Xu, J., Corno, L. (1998). Case Studies of Families Doing Third-Grade Homework. Teachers College Record, 100(2), 402-436.

Xu, J., Corno, Lyn. (2006). Gender, Family Help, and Homework Management Reported by Rural Middle School Students. Journal of Research in Rural Education, 21(2), $1-13$.

Xu, M., Kushner Benson, Susan N., Mudrey-Camino, Renee, Steiner, Richard P. (2010). The Relationship between Parental Involvement, Self-Regulated Learning, and Reading Achievement of Fifth Graders: A Path Analysis Using the ECLS-K Database. Social Psychology of Education: An International Journal, 13(2), 237269. 
Zhao, X., Lynch, J. G., \& Chen, Q. (2010). Reconsidering Baron and Kenny: Myths and truths about mediation analysis. Journal of Consumer Research, 37(2), 197-206.

Zimmerman, B. J. (2002). Becoming a Self-Regulated Learner: An Overview. Theory Into Practice, 41(2), 64-72.

Zimmerman, B. J., \& Kitsantas, A. (2005). Homework Practices and Academic Achievement: The Mediating Role of Self-Efficacy and Perceived Responsibility Beliefs. Contemporary Educational Psychology, 30(4), 397-417. 


\title{
APPENDIX
}

\section{U N I V R I T Y O F LOUISVILLE \\ Human Subjects Protection Program Office \\ MedCenter One - Suite 200 \\ 501 E. Broadway \\ Louisville, KY 40202-1798 \\ Office: 502.852.5188 Fax: 502.852.2164}

\author{
DATE: \\ November 01, 2013 \\ TO: \\ Namok Choi \\ FROM: \\ The University of Louisville Institutional Review Board \\ IRB\#: \\ 13.0741 \\ STUDY TITLE: \\ THE MEDIATING EFFECT OF HOMEWORK BETWEEN SELF-REGULATED \\ LEARNING AND SCIENCE ACHIEVEMENT \\ REFERENCE \#: \\ 328625 \\ DATE OF REVIEW: \\ $11 / 1 / 2013$ \\ IRB STAFF CONTACT: Name: Jackie Powell, CIP \\ Phone: 852-4101 \\ Email: jspowe01@Louisville.edu
}

This study was reviewed on 11/1/13 and determined by a designated member of the Institutional Review Board that the study is exempt according to 45 CFR 46.101(b) under category (4) Research involving the collection or study of existing data, documents, records, pathological specimens, or diagnostic specimens, if these sources are publicly available or if the information is recorded by the investigator in such a manner that subjects cannot be identified, directly or through identifiers linked to the subjects.

This study was also approved through 45 CFR 46.116 (D), which means that it has been granted a waiver of informed consent because it meets the following criteria:

- The research involves no more than minimal risk to the subjects.

- The waiver or alteration will not adversely affect the rights and welfare of the subjects.

- The research could not practicably be carried out without the waiver or alteration.

-Whenever appropriate, the subjects will be provided with the additional pertinent information after participation.

- That the research presents no more than minimal risk of harm to subjects and involves no procedures for which written consent is normally required outside of the research context.

Documents/Attachments reviewed and approved:

\begin{tabular}{|l|l|}
\hline Initial Review Submission Packet & Exempt \\
\hline Form Name & Outcome \\
\hline IRB Study Application & Exempt \\
\hline
\end{tabular}

Full Accreditation since June 2005 by the Association for the Accreditation of Human Research Protection Programs, Inc.

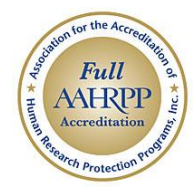




\begin{tabular}{|l|l|l|l|}
\hline Study Document & Oersion Number & Version Date & Outcome \\
\hline Title & $10 / 30 / 2013$ & \\
\hline $\begin{array}{l}\text { Kingsley Dissertation } \\
\text { Chapter 3 Methodology }\end{array}$ & Version 1.1 & & \\
\hline
\end{tabular}

Since this study has been approved under the exempt category indicated above, no additional reporting, such as submission of Progress Reports for continuation reviews, is needed. If your research focus or activities change, please submit an Amendment to the IRB for review to ensure that the indicated exempt category still applies. Best wishes for a successful study. Please send all inquiries to our office email address at hsppofc@louisville.edu

Thank you for your submission.

Sincerely,

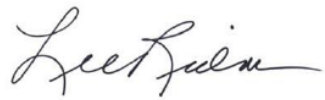

S. Lee Ridner, PhD

Social/Behavioral/Education Institutional Review Board Member

$\mathrm{SLR} / \mathrm{jsp}$ 


\section{CURRICULUM VITAE}

NAME: $\quad$ Matthew D. Kingsley

ADDRESS: 6313 Matten Court

Prospect, KY 40059

DOB: $\quad$ Pottstown, Pennsylvania - January 07, 1968

EDUCATION: $\quad$ Ph.D., University of Louisville. College of Education and Human Development, Leadership, Foundations \& Human Resource Education. December 2013.

M.S., Indiana University Southeast. Secondary Education, 2001.

B.S., Indiana University Southeast. Secondary Education, 1996.

B.A., DePauw University. Biology, 1990

\section{EXPERIENCE:}

Assistant Principal, duPont Manual High School, Louisville, KY July 2010-present

Assistant Principal, Academy @ Shawnee, Louisville, KY

September 2005-June 2010

Chemistry, Biology Teacher, Moore High School, Louisville, KY July 2003-September 2005

Chemistry, Biology Teacher, Floyd Central High School, Floyds Knobs, IN August 1996-June 2003 


\section{PRESENTATIONS:}

PLC Facilitators Meeting

Professional Learning Communities - a

refresher course

New Teacher Induction - Manual High

School

Alternative Assessment and Classroom

Management

PLC's: duPont Manual Summer Growth Series

Assessment and Grading That Work:

Utilizing Standards-Based Grading in the

Classroom

Improving Formative Practices through

Effective Assessments
August 13, 2013

August 14, 2013

August 15, 2013

August 15, 2013

July 27-28, 2012

June 5-7, 2012

October-

December

2011

\section{AFFILIATIONS/MEMBERSHIPS:}

President, Jefferson County Assistant

Principals Association

Jefferson County Assistant Principals

2005-present

Association

National Board Professional Teaching

2001-2011

Standards, Adolescent and Young Adult

Science

\section{INTERESTS:}

Homework and its effect on student achievement outcomes

Standards-based grading

Teacher Stress and its effect on teaching and learning 
AWARDS:

AEGON Grant Recipient (2003). A \$3000 grant to purchase and utilize probe-ware in chemistry and biology classes at Moore Traditional High School.

National Board Certification (2001) in Adolescent and Young Adult Science

Herman Miller Outstanding Student Teacher (1996) 